\title{
Formation of Aerosol Nanoparticles by Gas-Phase Hydrolysis Reaction of Uranium Hexafluoride
}

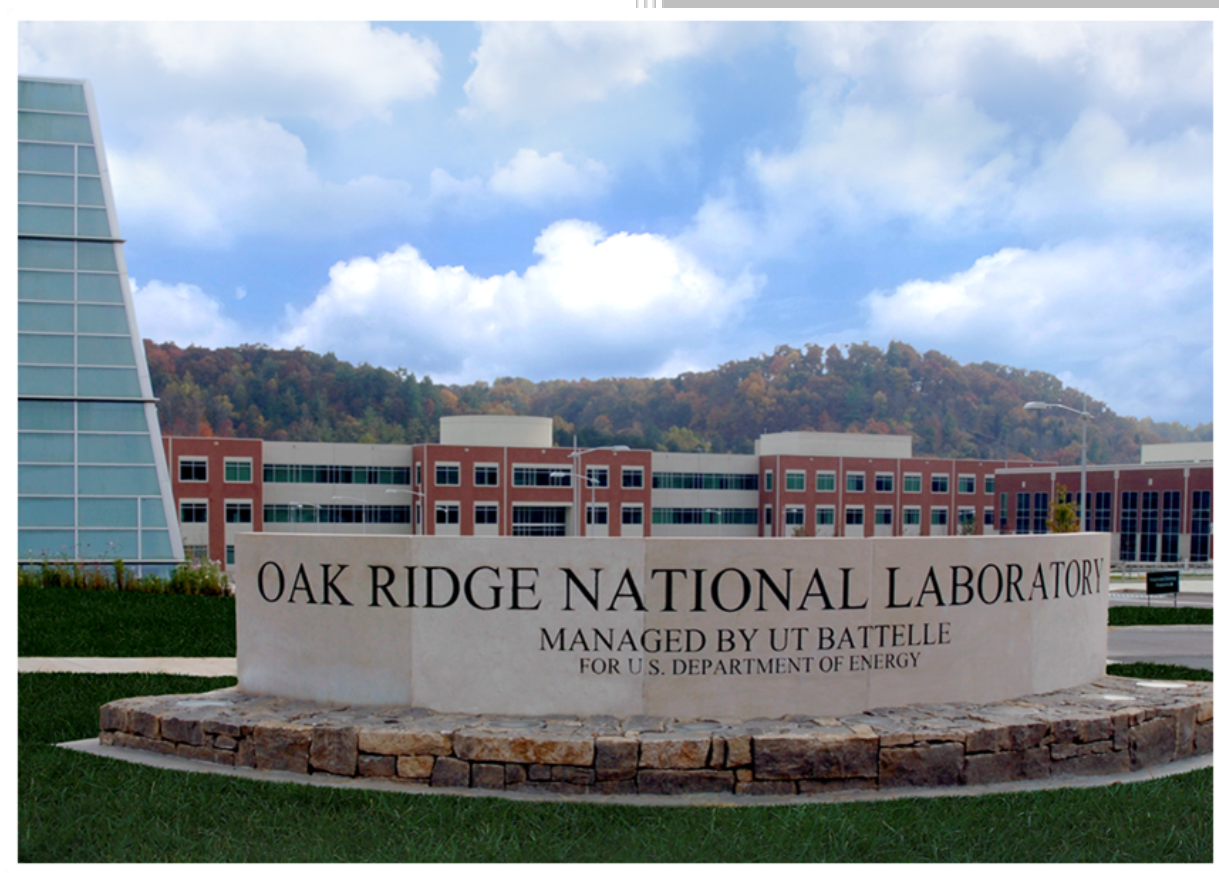

Approved for public release. Distribution is unlimited.

Meng-Dawn Cheng Joshua A. Hubbard Jason M. Richards Glenn A. Fugate

February 19, 2021 


\title{
DOCUMENT AVAILABILITY
}

Reports produced after January 1, 1996, are generally available free via US Department of Energy (DOE) SciTech Connect.

Website www.osti.gov

Reports produced before January 1, 1996, may be purchased by members of the public from the following source:

\author{
National Technical Information Service \\ 5285 Port Royal Road \\ Springfield, VA 22161 \\ Telephone 703-605-6000 (1-800-553-6847) \\ TDD 703-487-4639 \\ Fax 703-605-6900 \\ E-mail info@ntis.gov \\ Website http://classic.ntis.gov/
}

Reports are available to DOE employees, DOE contractors, Energy Technology Data Exchange representatives, and International Nuclear Information System representatives from the following source:

Office of Scientific and Technical Information

PO Box 62

Oak Ridge, TN 37831

Telephone 865-576-8401

Fax 865-576-5728

E-mail reports@osti.gov

Website http://www.osti.gov/contact.html

This report was prepared as an account of work sponsored by an agency of the United States Government. Neither the United States Government nor any agency thereof, nor any of their employees, makes any warranty, express or implied, or assumes any legal liability or responsibility for the accuracy, completeness, or usefulness of any information, apparatus, product, or process disclosed, or represents that its use would not infringe privately owned rights. Reference herein to any specific commercial product, process, or service by trade name, trademark, manufacturer, or otherwise, does not necessarily constitute or imply its endorsement, recommendation, or favoring by the United States Government or any agency thereof. The views and opinions of authors expressed herein do not necessarily state or reflect those of the United States Government or any agency thereof. 
Environmental Sciences Division

\title{
FORMATION OF AEROSOL NANOPARTICLES BY HYDROLYSIS REACTION OF URANIUM HEXAFLUORIDE
}

\author{
Meng-Dawn Cheng* \\ Joshua A. Hubbard ${ }^{\dagger}$ \\ Jason M. Richards* \\ Glenn A. Fugate*
}

* Oak Ridge National Laboratory

${ }^{\dagger}$ Sandia National Laboratory

Date Published: February 19, 2021

Prepared by

OAK RIDGE NATIONAL LABORATORY

Oak Ridge, TN 37831-6036

managed by

UT-BATTELLE, LLC

for the

US DEPARTMENT OF ENERGY

under contract DE-AC05-00OR22725 



\section{CONTENTS}

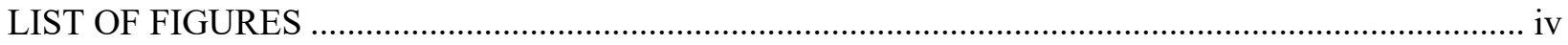

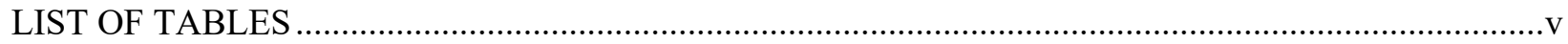

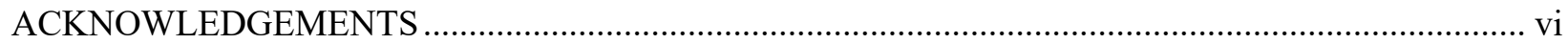

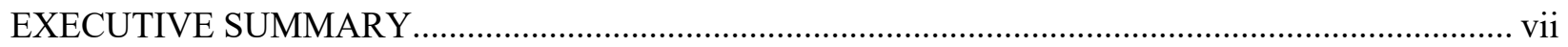

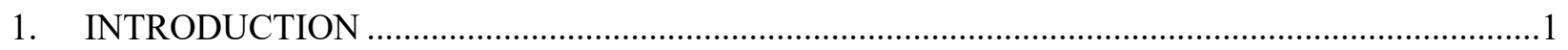

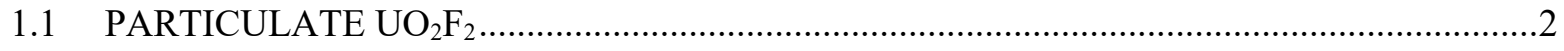

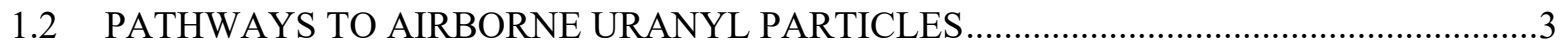

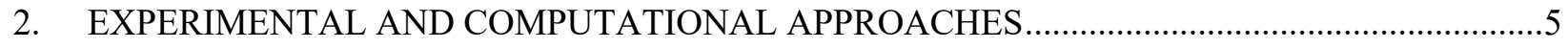

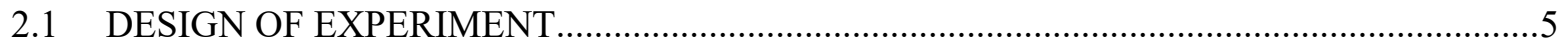

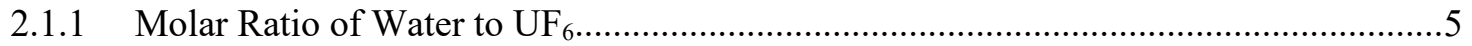

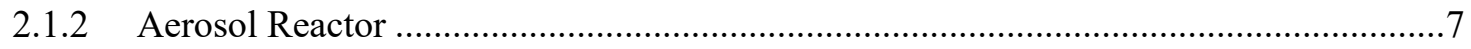

2.1.3 Evaluation of Particle Transport in an Aerosol Reactor ...............................................

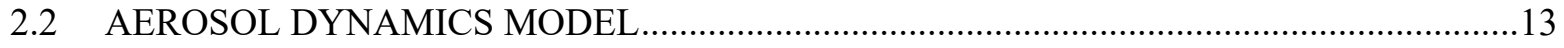

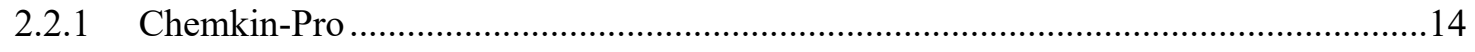

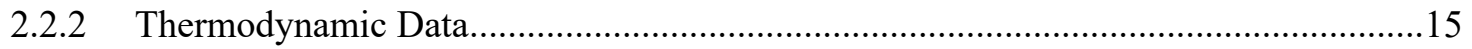

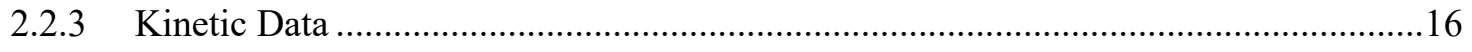

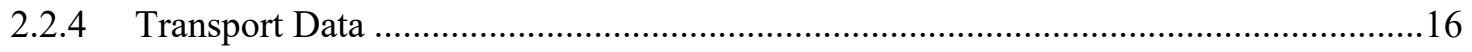

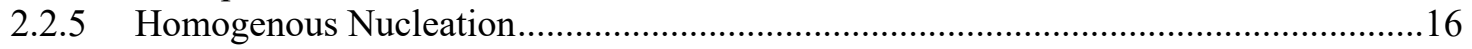

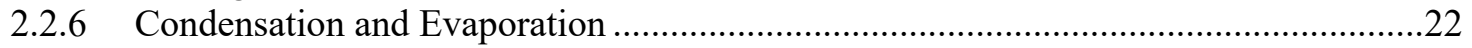

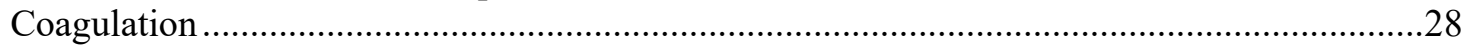

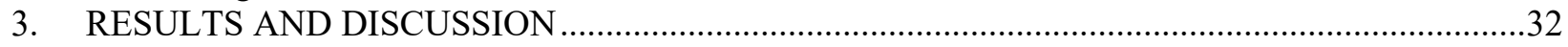

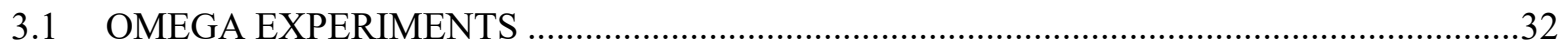

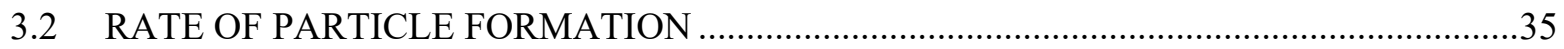

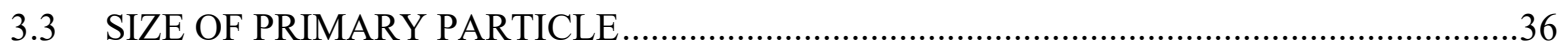

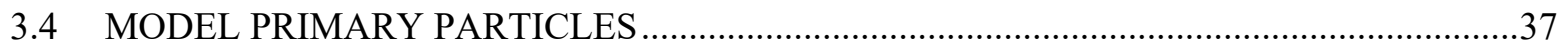

3.5 VERIFICATION OF AEROSOL DYNAMICS MODEL SIMULATION ...............................44

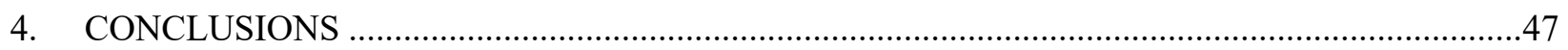

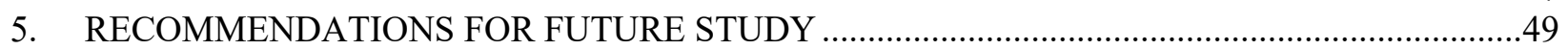

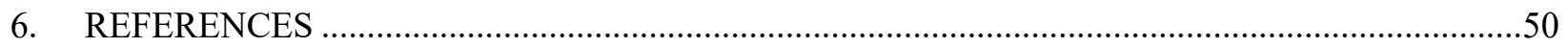

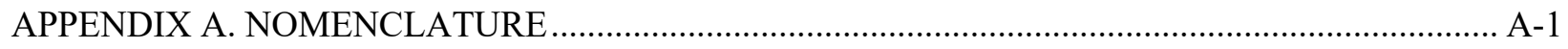

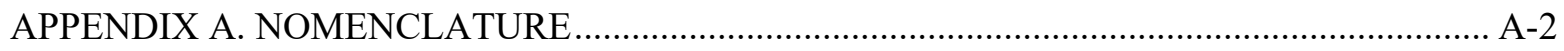




\section{LIST OF FIGURES}

Figure 1. Idealized atmospheric aerosol particle size distributions (adapted from Seinfeld and Pandis 1998)

Figure 2. Uranyl aerosol particles (the white smoke) visible immediately after $\mathrm{UF}_{6}$ was released

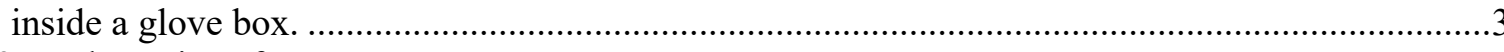

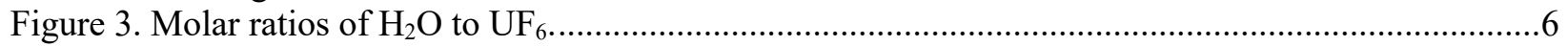

Figure 4. Schematic drawing of the aerosol reactor used in this study .....................................................

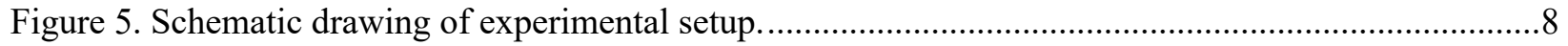

Figure 6. Calculated transport efficiencies by various forces at 10 LPM sheath flow. ..............................9

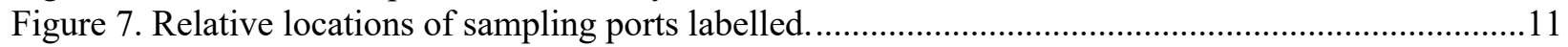

Figure 8. Experimental setup for testing the particle transport efficiency in the reactor..........................11

Figure 9. Test particle concentration outputs over time. Two colored curves were sampled $4 \mathrm{~h}$ apart showing the stability of the aerosol generation throughout the experiment. ........................12

Figure 10. $\mathrm{NaCl}$ particle transport efficiency calculated at the four sampling ports. ...............................13

Figure 11. A schematic of aerosol dynamics processes. Homogeneous nucleation occurs when a supersaturated vapor transforms into a more energetically favorable aerosol. Small nanoparticles can also form in a purely coagulational process in which growth starts at the monomer size. Small particles then aggregate through diffusion processes to form fractal particles such as soot. These small particles may also coalesce if their properties favor self-diffusion. Finally, vapor of a separate species may condense onto an existing site or particle, which is called "heterogeneous nucleation."

Figure 12. Homogeneous nucleation rate data for water at various gas temperatures and saturation ratios (SRs).

Figure 13. Homogeneous nucleation rate data for water at various gas temperatures and saturation ratios (SRs).

Figure 14. The Fuchs correction factor is applied to vapor mass transfer, to and from the droplet surface, to account for non-continuum effects in Eq. (20).

Figure 15. The difference between droplet and free-stream temperature at various free-stream temperatures (legend) and saturation ratios (SRs).

Figure 16. The number concentration, $n$, as a function of particle diameter, $d_{p}$, at $2 \mathrm{E}-3 \mathrm{~s}$ for water

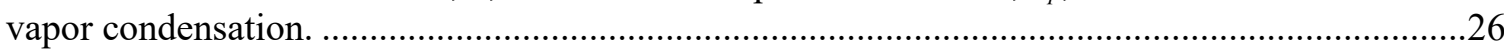

Figure 17. The average particle diameters for Eq. (25) and Chemkin-Pro as a function of time for

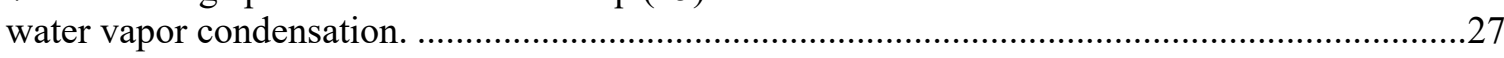

Figure 18. The errors in average particle size, $E_{d p, a v g}$, as a function simulation time for different levels of particle size distribution discretization (number of particle size bins).............................27

Figure 19. Computer processing times, $t_{\text {compute }}$, for different levels of particle size discretization ranging from 128 to 4,096 bins.

Figure 20. During coagulation and coalescence, two particles of different sizes merge to form a single particle of equivalent volume.

Figure 21. Brownian coagulation coefficients between particles 1 and 2, $\beta_{12}$, were calculated in MATLAB and plotted alongside tabulated data (symbols) from Seinfeld and Pandis (1998).

Figure 22. An analytical solution to the coagulation equation was used to verify that the MATLAB implementation of the semi-implicit method of Jacobson (2005) was correct. 


\section{LIST OF TABLES}

Table 1. Linear regression results of the curves shown in Figure 25...................................................36

Table 2. Gas and particle properties used to simulate the evolution of particle size and particle temperature of coagulating and coalescing $\mathrm{UO}_{2} \mathrm{~F}_{2}$ particles. 


\section{ACKNOWLEDGEMENTS}

The research project was funded by the National Nuclear Security Administration Nuclear Nonproliferation (NA-22) Defense Nuclear Nonproliferation program. The authors acknowledged operational assistance by Hal Jennings and Chris Boring. Discussions with Paula Cable-Dunlap, Roger Kapsimalis, Jennifer Ladd-Lively, Shannon Mahurin, Dave Messinger, Andrew Miskowiec, Ken Rhodes, and Lee Trowbridge were greatly appreciated. 


\section{EXECUTIVE SUMMARY}

The aerosol physics of uranyl particle formation has been addressed in this research using advanced aerosol instrumentation and an aerosol dynamics model. Based on the research works, we conclude that the formation and growth of aerosol particles by gas-phase $\mathrm{UF}_{6}$ hydrolysis strongly depends on the availability of water molecules in our reactor conditions. The total number concentration of the $\mathrm{UO}_{2} \mathrm{~F}_{2}$ particulate material that could be produced in the hydrolysis reaction is also regulated primarily by the availability of water molecule concentration. The higher the water molecule concentration, the higher the number and the larger the size of $\mathrm{UO}_{2} \mathrm{~F}_{2}$ aerosol particles that could be produced in a reactor custom-built at ORNL. Although the aerosol reactor was enabling the study of particle formation kinetics, the instrumentation was still insufficient in characterizing the chemical composition of the produced particles as well as the time-dependent evolution of the particulate species. The temporal evolution could impact the eventual fate of the particles upon release to the environment (i.e., the physio-chemical transformation, transport, and removal).

On uranyl particle formation kinetics, we found that the growth rates of aerosol particles appeared to approach a single number in the range of $0.05 \pm 0.03-0.08 \pm 0.04 \mathrm{~nm} / \mathrm{s}$, statistically, as the $\omega$ value becomes smaller than 1 . The size of primary particles from the $\mathrm{UF}_{6}$ hydrolysis at water-deprived condition was estimated to be $3.6 \pm 0.4 \mathrm{~nm}$; the higher the availability of water molecules, the larger the primary particles. The ability to precisely control the availability of water molecules in the reaction could lead to the production of nearly monodispersed aerosol particles. In other words, the result suggests that one can precisely manipulate the size of $\mathrm{UO}_{2} \mathrm{~F}_{2}$ aerosol particles by controlling the water vapor availability and interaction of water molecules with $\mathrm{UF}_{6}$ in the reaction. This finding has significant implications in the engineering manufacturing of fuel powder materials and possibly to future development and deployment of an environmental sampling apparatus.

Computational methods based on ANSYS/Chemkin-Pro and MATLAB platforms were developed to simulate aerosol dynamics, which can be applied broadly to industrial processes such as particulate material production and improve current reactive flow dynamics modeling tools. The methods were developed for simulating homogeneous nucleation, condensation and evaporation, and coagulation and coalescence. Homogeneous nucleation from super-saturated vapor was implemented in the surfacekinetics user routine using the modified theory of Dillmann and Meier that showed good agreement with published data. Size-dependent surface reaction rates were also implemented and demonstrated the newly implemented surface-kinetic rate dependence on particle size. Aerosol coagulation in Chemkin-Pro was verified against a semi-implicit coagulation formulation used in atmospheric aerosol modeling. Results from Chemkin-Pro were then compared with the semi-implicit method for the transition coagulation regime with complete coalescence in which the initial distribution was composed entirely of monomers. In the current state, Chemkin-Pro can model externally mixed aerosols.

Using a reasonable value for the activation energy of self-diffusion, we computationally verified the primary particle size and predicted a size range for the $\mathrm{UO}_{2} \mathrm{~F}_{2}$ primary particles comparable to that estimated from experiments. The results strongly suggest that the volume-driven coalescence process assumption used in the derivation of the primary particle model was reasonable. Questions remain as to the chemical pathways and energetics of the nucleation process leading to the formation of the primary particles. 


\section{INTRODUCTION}

Similar to oxygen and nitrogen gases, airborne particles or aerosol are ubiquitous in the air. Unlike oxygen and nitrogen that are essential to human survival, aerosol may have adverse effects to human health. The size of aerosol ranges from a nanometer to tens of micrometer. Aerosol particles are tiny solid and or liquid particles suspended in the air. The nature of aerosol particles is strongly dependent on their source, production route, the environment they encountered, and the duration they remain in the environment.

By this definition, any small solid, liquid, and/or mixture of solid and liquid objects capable of being suspended and floating in the air are called "aerosol." The ability to remain airborne represents one of the unique abilities of aerosol particles in transporting molecules to a farther distance. The consumption of fossil fuels (e.g., gasoline, diesel, or kerosene) by internal combustion engines to generate energy to power automobiles, aircraft, and modern power plants would produce aerosol such as soot particles in the size range of a few tens to a few hundreds of nanometers. These soot particles have significant impacts to atmospheric radiation balance because they can effectively absorb solar energy and rerelease long-wave energy to cause surface heating. Soot particles are also toxic to human health. In another example relevant to this report, if aerosol particles are produced by a chemical reaction such as hydrolysis of uranium hexafluoride in the air, the reaction products can be expected to be $\mathrm{UO}_{2} \mathrm{~F}_{2}$, uranyl hydrates, and or a mixture of both in the aerosol phase, and hydrogen fluoride (HF) in the gas phase. Thus, one can expect that the size of aerosol particles spans from $1 \mathrm{~nm}$ to tens of a micrometer (or tens of thousands of nanometers), about 5 to 6 orders of magnitude, and the composition of aerosol is highly complicated in space and time depending on the sources and the environment.

Figure 1 shows an idealized particle size distribution of atmospheric aerosol particles. The distribution is multimodal, showing that atmospheric aerosol consists of several populations of particles. The particle size ranges from $1 \mathrm{~nm}$ to $100 \mu \mathrm{m}$; particles in each mode originated from various sources contributing particulate materials making up the respective population. The removal processes or sinks of particles in each population are also displayed. For example, particles in the population (of sizes from 0.1 to $1 \mu \mathrm{m}$ ) could come from chemical conversion of gases to low-volatility vapors, nucleation, and condensation growth to nuclei or nanoparticles then growing to droplets and or aggregates before they are removed by rain or washout by precipitation. Particles in this mode could also originate from primary nanoparticles in the range of 1 to $<100 \mathrm{~nm}$ that were produced from the vapor phase. The fundamentals of the complex mass transfer processes of atmospheric aerosol can be applied and adapted to model $\mathrm{UO}_{2} \mathrm{~F}_{2}$ formation and transformation. 


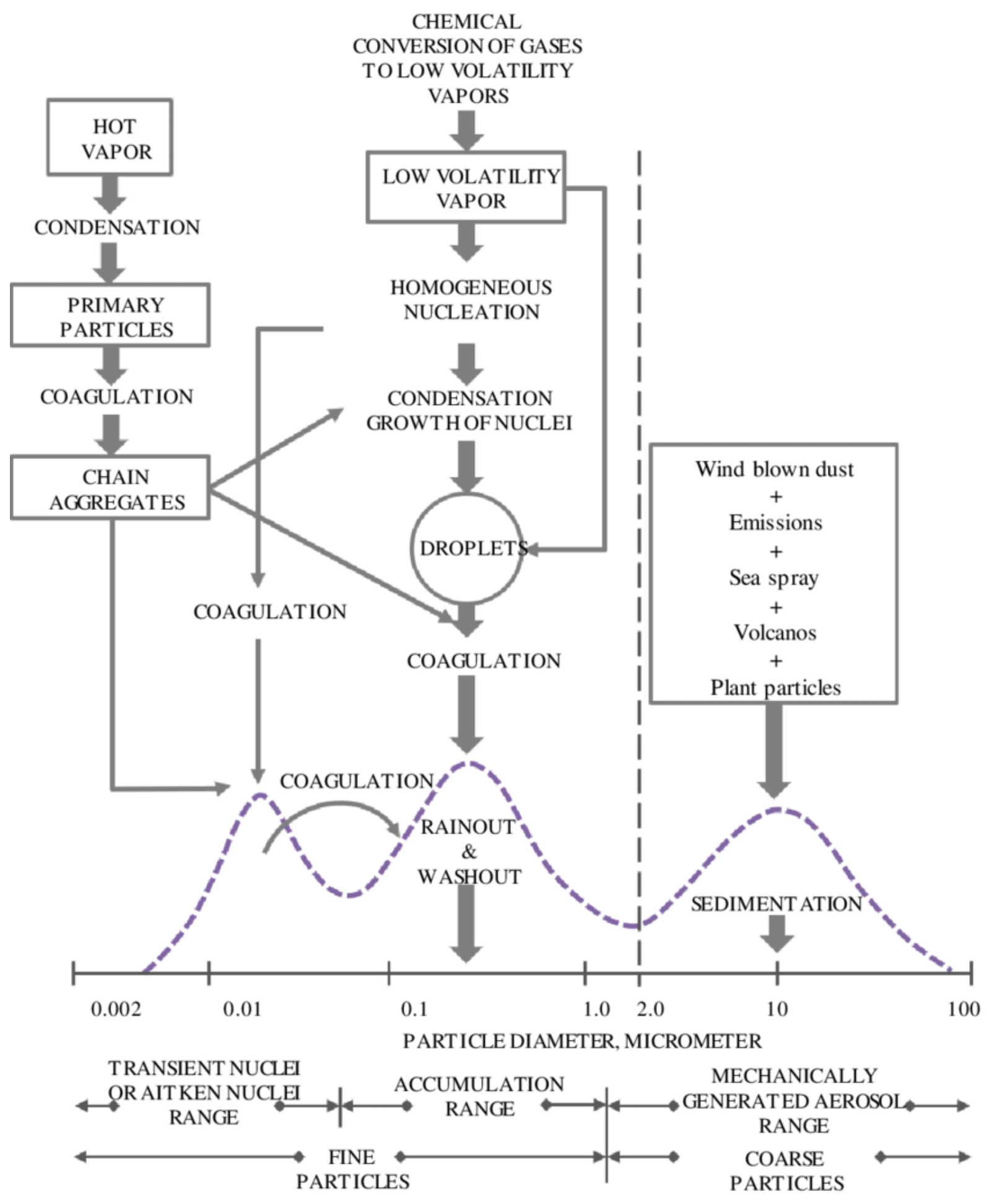

Figure 1. Idealized atmospheric aerosol particle size distributions (adapted from Seinfeld and Pandis 1998).

\subsection{PARTICULATE $\mathrm{UO}_{2} \mathrm{~F}_{2}$}

The uranyl ion forms solid salt species (e.g., $\mathrm{UO}_{2} \mathrm{~F}_{2}$ ) (called "particles" or "particulate matter" hereafter) that are generally not a commodity to the nuclear industry but play a key intermediate role in $\mathrm{UF}_{6}$ 
applications, such as in the production of $\mathrm{UO}_{2}$ powder for nuclear fuel production (Hou et al. 2007, Lind et al. 2010) or in the verification of weapons declarations as a unique tracer for nuclear sites (Kemp 2008, 2016). Therefore, it is of great importance to improve our understanding of the formation mechanism and the evolution of properties of this particulate species in nuclear manufacturing processes and its fate as they are produced in relevant environmental conditions.

\subsection{PATHWAYS TO AIRBORNE URANYL PARTICLES}

Fog formation occurs at the instance of $\mathrm{UF}_{6}$ release to the air (Figure 2), which is a phenomenon known since the beginning of the nuclear age. The white fog is an aerosol consisting of particulate matter or particles of complicated chemical composition. After extensive characterization efforts for the particulate materials in the past few decades, we now know that the aerosol population consists of $\mathrm{UO}_{2} \mathrm{~F}_{2}$ as a main reaction product when $\mathrm{UF}_{6}$ is in contact with $\mathrm{H}_{2} \mathrm{O}$ vapor (Kessie 1967, Bostick et al. 1983, 1984, Kips et al. 2007, Kips and Kristo 2009, Pickrell 1982, 1984, 1985). UF 6 hydrolysis produces solid $\mathrm{UO}_{2} \mathrm{~F}_{2}$ particles and also $\mathrm{HF}$, a hazardous toxic gas, as written in Eq. (1):

$$
\mathrm{UF}_{6}(\mathrm{~g})+2 \mathrm{H}_{2} \mathrm{O}(\mathrm{g})->\mathrm{UO}_{2} \mathrm{~F}_{2}(\mathrm{~s})+4 \mathrm{HF}(\mathrm{g})
$$

Equation (1) generally serves as the basis in predicting the reaction-generated HF concentration for consequence analysis in environmental management and safety of $\mathrm{UF}_{6}$ storage and operation, particularly in industries in which environmental safety and health concerns were caused by the hazardous gas HF. (Schotte 1987, Hanna et al. 1991, Witlox 1994a, 1994b, West and Axler 1995, Giannissi et al. 2013, Cheng 2018). The intermediate by-product $\mathrm{UO}_{2} \mathrm{~F}_{2}$ is typically of less interest but has been suggested for use as a tracer for identifying sources involved in nuclear fuel processing and nuclear forensics (Kemp 2008, 2016).

Recently, Hu et al. (2008, 2009, 2014) used the relativistic density function theory to computationally show that intermediate species containing a U-O-U bond were found

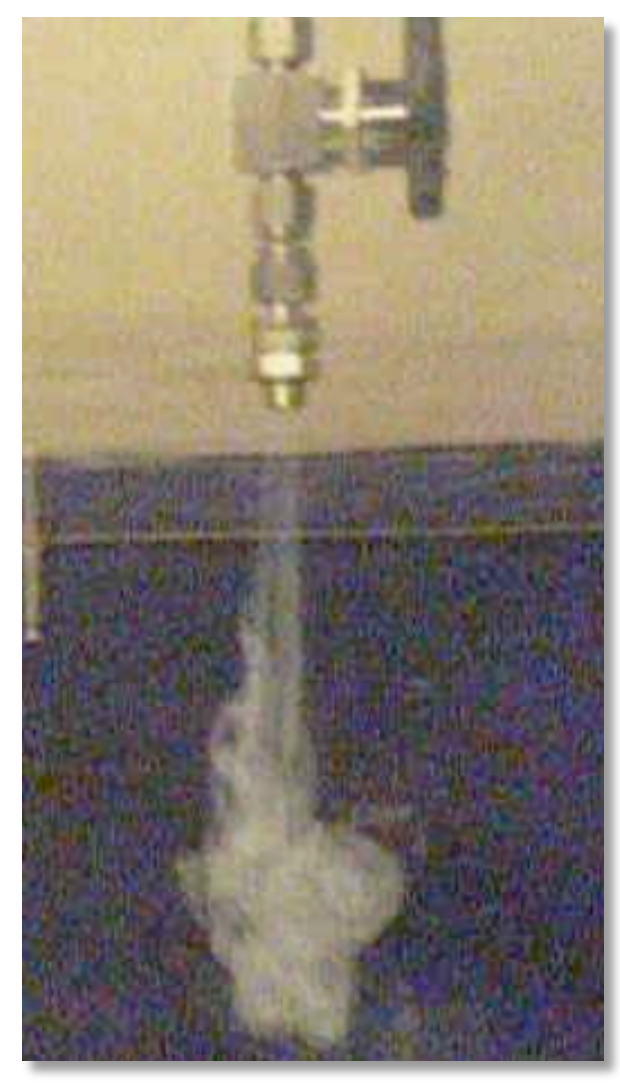

Figure 2. Uranyl aerosol particles (the white fog) visible immediately after $\mathrm{UF}_{6}$ was released inside a glove box. because of several probable reactions involving $\mathrm{UF}_{5} \mathrm{OH}$ and $\mathrm{UF}_{6}$ or $\mathrm{UF}_{5} \mathrm{OH}$ and $\mathrm{UF}_{5} \mathrm{OH}$ under the condition of enriched $\mathrm{UF}_{6}$ and small amounts of $\mathrm{H}_{2} \mathrm{O}$ (i.e., small $\omega$ condition) where $\omega$ is the molar ratio of $\mathrm{H}_{2} \mathrm{O}$ to $\mathrm{UF}_{6}$. In large $\omega$ conditions, the coordination energy between $\mathrm{UF}_{6}$ and $\left(\mathrm{H}_{2} \mathrm{O}\right)_{\mathrm{n}}$ in $\mathrm{UF}_{6}-\mathrm{nH}_{2} \mathrm{O}$ (e.g., where $\left.\mathrm{n}=1-3\right)$ increases as water changes from single molecules to the associated dimer and trimer. These computational studies suggest that the initial step of $\mathrm{UF}_{6}$ hydrolysis led first to one $\mathrm{H}_{2} \mathrm{O}$ molecule to coordinate with uranium as a ligand of $\mathrm{UF}_{6}$. An additional one or two $\mathrm{H}_{2} \mathrm{O}$ molecules then enhanced the coordination through hydrogen bonding with ligand $\mathrm{H}_{2} \mathrm{O}$ and $\mathrm{F}$. Second, the additional $\mathrm{H}_{2} \mathrm{O}$ molecules catalyzed $\mathrm{UF}_{6}$ hydrolysis by bridging the hydrogen that transfers from ligand $\mathrm{H}_{2} \mathrm{O}$ to $\mathrm{F}$ and stabilizes the transition state through hydrogen bonding. The additional $\mathrm{H}_{2} \mathrm{O}$ molecules associate the products of the hydrolysis, $\mathrm{UF}_{5} \mathrm{OH}$ and $\mathrm{HF}$, through hydrogen bonding. The eliminated HF was then removed depending on the water content and bonding types of the reaction products. 
When $\omega \geq 3$, the first step of hydrolysis becomes exothermic, and the HF tends to associate with $\mathrm{UF}_{5} \mathrm{OH}$ and $\mathrm{H}_{2} \mathrm{O}$ tightly. Lind et al. (2010) showed that hydrolysis of one $\mathrm{UF}_{6}$ and two $\mathrm{H}_{2} \mathrm{O}$ molecules is the favorable pathway as a tri-molecular reaction. One water molecule provides the hydrogen to the nascent $\mathrm{HF}$ in the transition state that accepts one hydrogen from the other water molecule that is reacting with $\mathrm{UF}_{6}$ to form $\mathrm{UF}_{5} \mathrm{OH}$. No mechanistic information, computationally or experimentally, was given that could lead to a concrete conclusion about the production of $\mathrm{UO}_{2} \mathrm{~F}_{2}$.

So far, these molecular dynamics modeling works (Hu et al. 2008, 2009, 2014) suggested only the pathway of the $\mathrm{UF}_{6}$ hydrolysis in the gas phase, but none did for the condensed phase in which the formation of $\mathrm{UO}_{2} \mathrm{~F}_{2}$ aerosol particles exist. The aerosol formation process and kinetics remain unknown. In this technical memorandum, we report the results from a study of $\mathrm{UO}_{2} \mathrm{~F}_{2}$ particle formation in a controlled gas-phase hydrolysis reaction in an aerosol reactor designed and fabricated by the US Department of Energy's Oak Ridge National Laboratory. We derived the size of the primary $\mathrm{UO}_{2} \mathrm{~F}_{2}$ particle diameter, the particle formation rate, and the subsequent growth of the produced particles. We used the experimental techniques and computational tools amenable to use at the time of writing of this report, realizing aerosol technology is a rapidly evolution area of research and many cutting-edge instrumentation and measurement techniques will become available in the next few years. 


\section{EXPERIMENTAL AND COMPUTATIONAL APPROACHES}

A large volume of research data has been taken to characterize the property of uranyl aerosol materials in the past three decades, but very little progress has been made to improve our understanding of the formation process of the aerosol materials in the hydrolysis reaction in the gas phase. Aerosol science and technology has advanced greatly in the past couple of decades. Cutting-edge aerosol instruments can detect airborne particles as small as $1 \mathrm{~nm}$ (Kangasluoma et al. 2015, Vanhanen et al. 2011) and probe the chemical composition of a single particle of the size of tens of nanometers in near real time (Smith and Miller 1989, Laskin et al. 2018). Such capabilities did not exist in the 1980s.

\subsection{DESIGN OF EXPERIMENT}

In our investigation, the main control variable of the uranyl aerosol formation in the gas-phase hydrolysis reaction was the molar ratio of $\mathrm{H}_{2} \mathrm{O}$ to $\mathrm{UF}_{6}$ (i.e., the $\omega$ value). Using only the molar ratio as a single dial in our experiment significantly reduced the complexity and effort in trying to explore the entire parametric space of $\mathrm{UF}_{6}$ and $\mathrm{H}_{2} \mathrm{O}$ and to mimic a condition of what might have occurred in the real world.

\subsubsection{Molar Ratio of Water to $\mathbf{U F}_{6}$}

\begin{tabular}{|c|c|c|c|c|c|c|c|}
\hline \multicolumn{2}{|c|}{$\begin{array}{c}\omega= \\
{\left[\mathrm{H}_{2} \mathrm{O}\right] /\left[\mathrm{UF}_{6}\right]}\end{array}$} & \multirow[t]{2}{*}{$\begin{array}{c}\mathrm{H}_{2} \mathrm{O} \text { in } \\
\mathrm{ppb}\end{array}$} & \multicolumn{5}{|c|}{$\mathrm{UF}_{6}(\mathrm{ppmv})$} \\
\hline RH & & & 1.00 & 50.00 & 100.00 & 500.00 & $1,000.00$ \\
\hline 0.0003 & $\%$ & 100 & 0.010 & 0.0020 & 0.0010 & 0.00020 & 0.00010 \\
\hline 0.0016 & $\%$ & 500 & 0.050 & 0.010 & 0.0050 & 0.0010 & 0.00050 \\
\hline 0.0032 & $\%$ & 1,000 & 0.10 & 0.020 & 0.010 & 0.0020 & 0.0010 \\
\hline 0.016 & $\%$ & 5,000 & 0.50 & 0.10 & 0.050 & 0.010 & 0.0050 \\
\hline 0.032 & $\%$ & 10,000 & 1 & 0.20 & 0.10 & 0.020 & 0.010 \\
\hline 0.161 & $\%$ & 50,000 & 5 & 1 & 0.50 & 0.10 & 0.050 \\
\hline 0.323 & $\%$ & 100,000 & 10 & 2 & 1 & 0.20 & 0.10 \\
\hline 1.61 & $\%$ & 500,000 & 50 & 10 & 5 & 1 & 0.50 \\
\hline 3.23 & $\%$ & $1,000,000$ & 100 & 20 & 10 & 2 & 1 \\
\hline 16.1 & $\%$ & $5,000,000$ & 500 & 100 & 50 & 10 & 5 \\
\hline 32.3 & $\%$ & $10,000,000$ & 1,000 & 200 & 100 & 20 & 10 \\
\hline 50 & $\%$ & $15,488,210$ & 1,549 & 310 & 155 & 31 & 15 \\
\hline 75 & $\%$ & $23,232,310$ & 2,323 & 465 & 232 & 46 & 23 \\
\hline
\end{tabular}




\begin{tabular}{|r|r|r|r|r|r|r|r|}
\hline 90 & $\%$ & $28,277,914$ & 2,828 & 566 & 283 & 57 & 28 \\
\hline 95 & $\%$ & $29,427,600$ & 2,943 & 589 & 294 & 59 & 29 \\
\hline
\end{tabular}

Figure 3. Molar ratios of $\mathrm{H}_{2} \mathrm{O}$ to $\mathrm{UF}_{6}$.

The molar ratio of $\mathrm{H}_{2} \mathrm{O}$ to $\mathrm{UF}_{6}$ is called " $\omega$." The numerical value of $\omega$ determines how the reaction should proceed according to the literature. The value controls the availability of water molecules in the hydrolysis reaction; therefore, it enables us to precisely manipulate the reaction to hopefully proceed at a given pathway. For our experimental design, the calculated $\omega$ values are shown in Figure 3. For example, the $\omega$ value of 1 is equivalent to the condition in which the absolute water molecule concentration is 100 ppmv and the $\mathrm{UF}_{6}$ concentration is also $100 \mathrm{ppmv}$. The aerosol reactor operating on a large $\omega$ value would provide a wet condition in which water molecules are abundant and $\mathrm{UF}_{6}$ is the limiting factor in the reaction. On the other hand, a small $\omega$ value would direct the hydrolysis reaction to a water-lean or dry condition. The ability to manipulate the $\omega$ value opened the door to precision experiment for a systematic study of the $\mathrm{UF}_{6}$ hydrolysis reaction.

To manipulate the $\omega$ value, one can simultaneously vary the molar ratios of $\mathrm{UF}_{6}$ and $\mathrm{H}_{2} \mathrm{O}$ or fix one and vary the other. The latter option was more cost-effective in terms of labor and expenses than the former; additionally, the range of $\mathrm{UF}_{6}$ and $\mathrm{H}_{2} \mathrm{O}$ quantity that could be handled safely and precisely in a laboratory environment is finite. Therefore, the $\mathrm{UF}_{6}$ concentration would be held at a constant value of $100 \mathrm{ppmv}$ in all reactions. This met the laboratory environment, safety, and health controls and simplified the efforts required to map the parameter space displayed in Figure 3. The experimental conditions to be performed were represented in the column of $100 \mathrm{ppmv}$ of $\mathrm{UF}_{6}$, which left us a six orders of magnitude-wide range of the $\omega$ value to operate (i.e., from 0.001 to 294). This wide range can be translated into a relative humidity (RH) condition of $0.0003 \%$ to $95 \% \mathrm{RH}$ in $298 \mathrm{~K}$ and $1,013 \mathrm{mbar}$. We thus believe any release of $\mathrm{UF}_{6}$ in the real-world scenario was captured in the range at which we could operate; thus, the aerosol reactor experimental technique offers a tunable platform for studying the reaction. 


\subsubsection{Aerosol Reactor}

The aerosol reactor was designed and constructed in-house for the study. Figure 4 illustrates the columnar aerosol reactor used to perform controlled $\mathrm{UF}_{6}$ hydrolysis experiments in the gas phase. The reactants, $\mathrm{UF}_{6}$ and $\mathrm{H}_{2} \mathrm{O}$, were introduced in a carrier gas at 1 liter per minute (LPM) flow rate, each through a $0.32 \mathrm{~cm}$ ID tube at the opposing direction at the upper section of the reactor. The separation distance of the two tube tips was $\sim 4 \mathrm{~cm}$. This arrangement promotes the mixing of the reactants. The exhaust from the reactor is at the bottom in the lower section of the reactor and was vacuum pumped directly to a mitigation system shown in Figure 5. The mitigation system consisted of an alumina packed tube and a highefficiency particulate air (HEPA) filter. The pressure inside the reactor was continuously monitored with a Dwyer Magnehelic gauge and maintained at zero $\mathrm{cm}-\mathrm{H}_{2} \mathrm{O}$ or a slightly negative pressure.

The reactor was a cylinder fabricated from stainless steel and was $103 \mathrm{~cm}$ in length and $15.24 \mathrm{~cm}$ in inner diameter. The reactor consisted of two body sections that were Viton O-ring-sealed in the middle with six flanges to clamp both sections together. The two sections could be separated to allow reactor maintenance and future modification

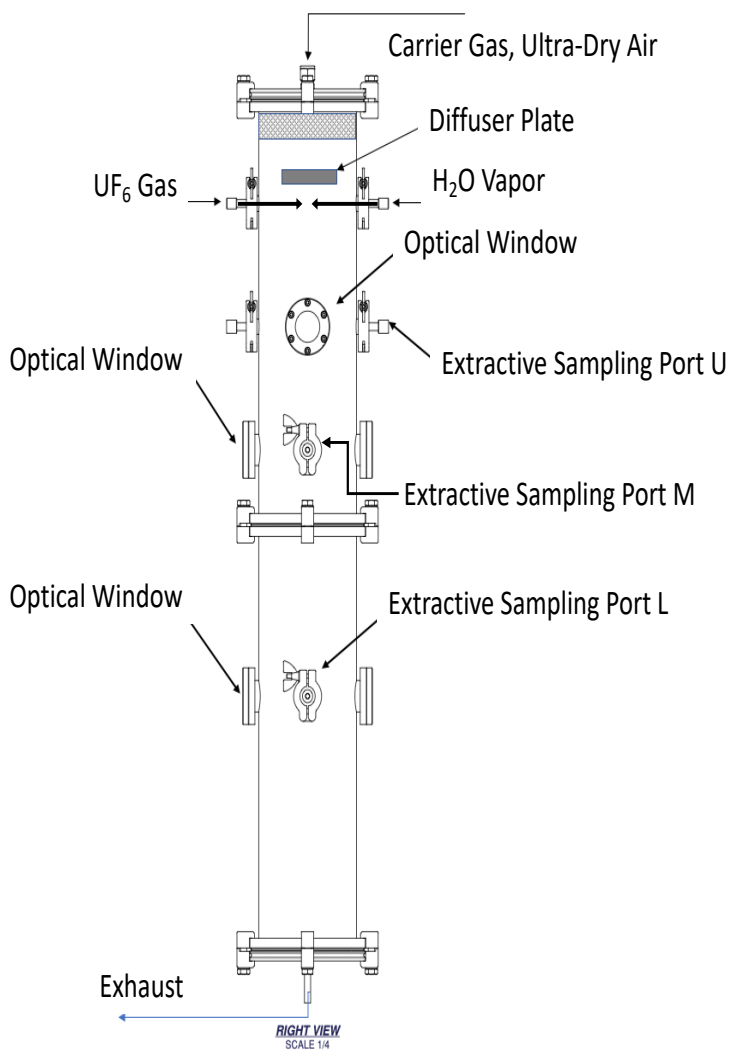

Figure 4. Schematic drawing of the aerosol reactor used in this study. if desired. A $2.54 \mathrm{~cm}$ thick honeycomb mesh with $0.079 \mathrm{~cm}$ size cells was inserted at the top of the reactor above a diffuser plate to generate laminar flow of carrier gas that was introduced from the top. The diffuser plate was used to block about $25 \%$ of the crosssectional area in the center of the reactor directly behind the honeycomb. This created a lower-pressure cavity region for facilitating reactant mixing. There were three pairs of optical $\mathrm{CaF}_{2}$ window ports for optical and spectroscopic observations, and three pairs of extractive sampling ports (labelled as $\mathrm{U}, \mathrm{M}$, and L in Figure 1) were positioned along the column length of the aerosol reactor.

The hydrolysis reaction occurs when $\mathrm{UF}_{6}$ and $\mathrm{H}_{2} \mathrm{O}$ are mixed. The residual reactants and reaction products, $\mathrm{UO}_{2} \mathrm{~F}_{2}$ and $\mathrm{HF}$, were transported by the carrier gas, an ultradry air, down the reactor column toward the exhaust. The ultradry air was generated by a Parker ultradry air generator (Model UDA-300). The flow rate of the ultradry carrier gas varied between 20 and 50 LPM depending on the experiment.

Figure 5 is the schematic drawing of the entire experimental setup and the aerosol reactor, consisting of four components: the $\mathrm{UF}_{6}$ release module, the aerosol reactor, the water vapor source, and the exhaust mitigation module. Not included in the setup drawing is the array of instruments installed on the reactor for observations. In this report, we will present data from a commercial instrument called the "scanning mobility particle sizer" (SMPS; Quant et al. 1993, Chen et al. 1999) available from TSI, Inc. The UF 6 release and mitigation modules are the only two required by the US Department of Energy environment, safety, and health regulations to be in a fume hood based on the material quantity used in this study. The aerosol reactor was operated as a non-radioactive component outside of the hood. The alumina column 
was used to remove $\mathrm{HF}$ and residual $\mathrm{UF}_{6}$, and a HEPA filter capsule was used to remove residual particles before the exhaust went into the hood and was ventilated. The exhaust of each instrument (e.g., SMPS) that extracted the sample from the aerosol reactor was routed through a mitigation module that comprised a HEPA filter and an alumina-packed tube before the exhaust was vented back to the hood. This mitigation module is for instrument exhaust only, separate from the treatment module for the reactor described earlier. The diligent mitigation precaution was taken to reduce the potential environment, safety, and health risks faced when working with radiological and hazardous materials.

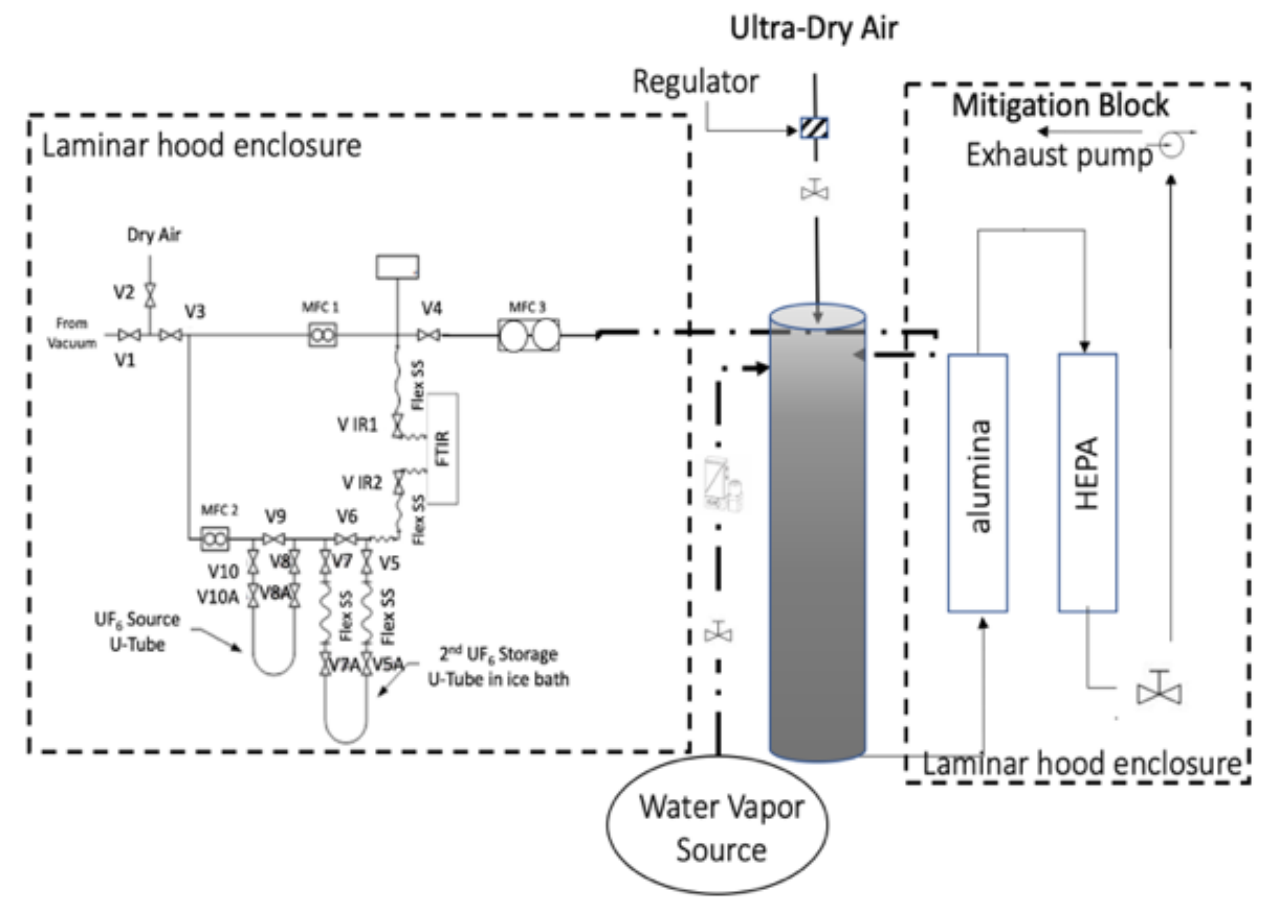

Figure 5. Schematic drawing of experimental setup.

A manifold was designed to allow delivery of controlled flows of $\mathrm{UF}_{6}$ over a wide range of concentrations. The system can be purged with inert air and evacuated to allow for the system to be thoroughly dried to remove all water. The gas stream was split using two MKS mass flow controller units allowing the $\mathrm{UF}_{6}$ gas stream to be diluted up to several orders of magnitude as needed. The initial $\mathrm{UF}_{6}$ stream was generated from sublimation of solid in the first U-tube, which was held at ambient temperatures. The solid-gas equilibrium at $25^{\circ} \mathrm{C}$ generated a partial pressure approaching saturation of $\sim 112$ Torr (Anderson et al. 1994). This $\mathrm{UF}_{6}$-laden gas stream then passed through the second U-tube that was chilled to condense material. This effectively reduced the gas concentration to a steady, adjustable concentration that was dependent on the temperature of the U-tube. The UF 6 gas composition was monitored with a Bruker Fourier-transformed infrared spectrometer (Bruker Model ALPHA) using one or more of the spectral bands. The measurement was performed before dilution of the gas to its final desired composition because some of the target concentrations may be below the detection ability of the Fouriertransformed infrared spectrometer. The $\mathrm{UF}_{6}$ concentration was maintained at $100 \mathrm{ppm}$ for all the data presented in this report.

A low level of water vapor was generated using an instrument manufactured by Kin-Tek (Model: Span $\mathrm{Pac}_{2} \mathrm{O}$ ) based on the trace source permeation technique. The technique can generate moisture trace standards from $100 \mathrm{ppb}$ to $100 \mathrm{ppm}$. The Span $\mathrm{Pac}_{2} \mathrm{O}$ generator holds the trace sources permeation tube at a constant temperature and introduces a controlled flow of dilution gas over the tube. A small, accurate, constant flow of $\mathrm{H}_{2} \mathrm{O}$ vapor permeated from the tube was mixed with the dry dilution gas to form the 
parts per million ( $\mathrm{ppm}$ ) or parts per billion ( $\mathrm{ppb}$ ) moisture standard. The moisture standard then flowed through the generator output to a monitor probe. The flow of the water vapor to the reactor was set at 1 LPM, same as that of the $\mathrm{UF}_{6}$ flow rate into the aerosol reactor.

For higher concentrations of water, the relative humidity $(\mathrm{RH})$ was maintained using a split flow system. A valve was used to divert a fraction of the flow through a sparger submerged in distilled water. The wetted gas was recombined with the dry gas, passed through a droplet collection vessel, and then flowed past an RH probe. The valve was adjusted to select the desired RH. The RH was monitored online by a Vaisala hygrometer (Model MI70). The concentration of the water vapor was then adjusted for temperature to provide a true concentration being fed to the system.

\subsubsection{Evaluation of Particle Transport in an Aerosol Reactor}

Prior to hydrolysis experiments, the aerosol reactor was evaluated first for its particle transport efficiency to understand the potential loss of particles. Loss of aerosol particles inside the reactor during transport by the sheath flow can be attributed to several mechanisms, including transport line bending, inertial, diffusional, electrostatic, and thermophoretic forces as most common forces. Line bending, such as a $90^{\circ}$ turn, has a significant impact on the transport of particles, particularly for supermicron-sized ones. Because the aerosol reactor is a linear columnar configuration, the loss due to line bending was ignored. Diffusional loss to the reactor wall

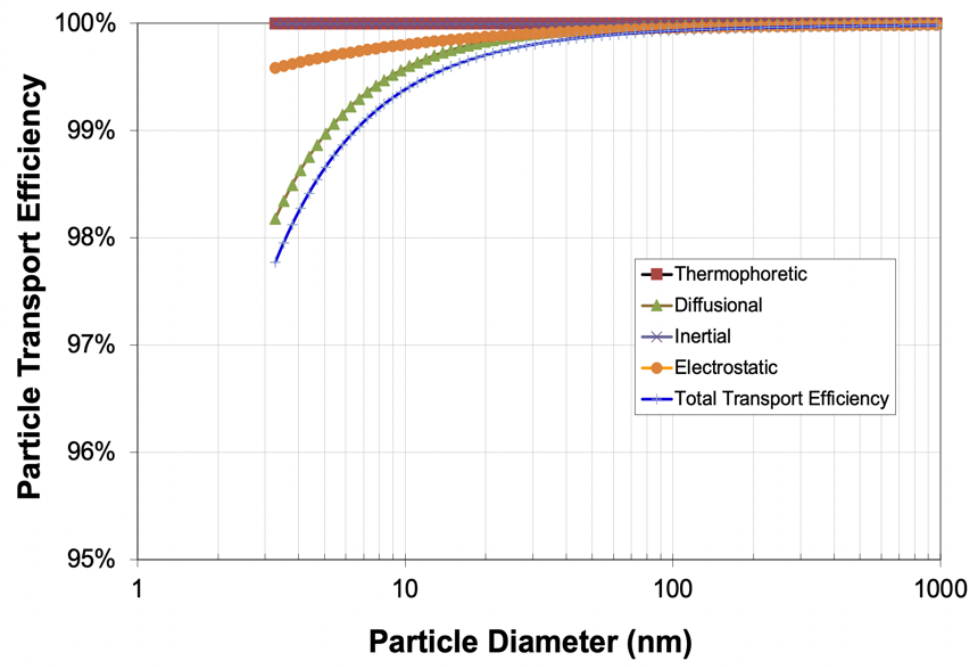

Figure 6. Calculated transport efficiencies by various forces at 10 LPM sheath flow. was significant when a particle was within the critical trajectory, while the thermophoretic force exists when there was temperature difference between the reactor wall and the sheath air. Electrostatic force exists when particles carry surface charges and are mostly important for small particles travelling in or close by an electrical field. The four forces were evaluated using Eqs. (2)-(5). Transport efficiency under the influence of the four forces was displayed individually in the figure as a function of particle size. Figure 6 shows the estimated transmission loss of particles in the reactor operated at a $10 \mathrm{LPM}$ flow rate at $1 \mathrm{~atm}$ and $20^{\circ} \mathrm{C}(293 \mathrm{~K})$. Similar efficiency curves were obtained for the sheath flow up to 100 LPM and not repeated here.

The following equations were used in the particle transport efficiency calculation:

$$
\begin{gathered}
\text { Thermophoretic }-\eta_{p, t h}=\left\{\frac{T_{w}+\left(T-T_{w}\right) \cdot \exp \left[-\frac{\pi D_{t} h L}{\rho Q C_{p}}\right]}{T}\right\}^{P_{r} \cdot K_{t h}} \\
\text { Diffusion- } \eta_{p, \text { diff }}=\exp \left(-\frac{\pi D_{t} L V_{d, \text { diff }}}{Q}\right) \\
\text { Inertial- } \eta_{p, \text { inertia }}=\exp \left(-\frac{\pi D_{t} L V_{d, \text { inertia }}}{Q}\right)
\end{gathered}
$$




$$
\text { Electrostatic }-\eta_{p, e s}=1-\left(\frac{q^{2} L C_{c}}{\pi \epsilon_{o} \mu d_{p} D_{t} Q}\right)^{1 / 3}
$$

where $\eta$ is the efficiency of particle transmission under the influence of the corresponding force, $T$ is the gas temperature at the inlet, $T_{w}$ is the wall temperature, $\rho$ is the gas density, $Q$ is the sheath flow rate, $C_{p}$ is the specific heat at constant pressure, $D_{t}$ is the reactor diameter, $h$ is a dimensionless factor $\left(=\frac{N_{u} * k_{g}}{D_{t}}\right)$, and $L$ is the length of the reactor. $N_{u}$ is a complex function of Prandtl constant, reactor geometry, the gas and wall temperatures (Yook and Pui 2005). $\operatorname{Pr}$ is the Prandtl constant $\left(=\frac{C_{p^{*} \mu}}{k_{g}}\right), \mu$ is the dynamic viscosity, $k_{g}$ is the thermal conductivity of dry air, $V_{d, \text { diff }}$ is the particle velocity due to diffusion, $V_{d \text {, inertia }}$ is the particle velocity due to the inertia effect, $C_{c}$ is the Cunningham correction factor (Hinds 1999), and $\epsilon_{o}$ is the permittivity in vacuum. $K_{\text {th }}$ is calculated as

$$
K_{t h}=\left(\frac{2 C_{s} C_{c}}{1+3 C_{m} K_{n}}\right)\left[\frac{\frac{K_{g}}{K_{p}} C_{t} K_{n}}{1+2 \frac{K_{g}}{K_{p}}+2 C_{t} K_{n}}\right]
$$

The total transport efficiency was calculated as the product of the four efficiencies discussed above. The total transport efficiency was predicted to be greater than $99 \%$ for spherical particles of diameter as small as $7 \mathrm{~nm}$ and $97.8 \%$ for particles $3-7 \mathrm{~nm}$. Similar results (not shown in this paper) were found for 100 LPM flow rate condition. In other words, we found the aerosol reactor has a high particle transport efficiency and a minute number of particles; particularly small ones (e.g., $<10 \mathrm{~nm}$ ) on the order of $1 \%-$ $3 \%$ could be lost.

The predicted particle transport efficiency was experimentally validated using four test materials: $\mathrm{NaCl}$, $\mathrm{NiCl}_{2}, \mathrm{AgCl}_{2}$, and $\mathrm{Fe}_{3} \mathrm{O}_{4}$. The test materials were prepared in $0.01 \% \mathrm{w} / \mathrm{w}$ solution $\left(\mathrm{NaCl}, \mathrm{NiCl}_{2}\right.$, and $\mathrm{AgCl}_{2}$ ) while $\mathrm{Fe}_{3} \mathrm{O}_{4}$ was in a colloidal suspension. The particles were produced by using an atomization apparatus (TSI Model 3076) and their size distributions were measured at the inlet and various sampling locations (labelled as $\mathrm{C}_{1}, \mathrm{C}_{2}, \mathrm{C}_{3}$, and $\mathrm{C}_{4}$ ) on the aerosol reactor. Figure 7 shows the labelled sampling ports on the reactor. 
The generated particles were dried using a

diffusion drier before they were introduced into the reactor from the inlet at the center on the top cover plate of the reactor. The experimental setup for the evaluation was drawn as shown in Figure 8. The particle size for a material was chosen by selecting a voltage that corresponds to an electrical mobility and particle diameter desired on the power supply for the differential mobility analyzer (DMA) 1 (TSI Model 3085). The DMA1-selected particles were monitored using a TSI Model 3788 nanowater condensation particle counter (CPC). A SMPS (i.e., electrical classifier [TSI Model 3082] equipped with a DMA2 [TSI Model 3085]) was used to monitor the size distribution from the generator online. The dash line in Figure 8 indicates the alternative use of the instrument during experiment. The electrical classifier (Model 3085) segregates particles by using the electrophoretic migration velocity while the CPC counts the size-selected particles. The TSI AIM software combines the size data from the DMA and particle count data from the CPC and reduced the data to produce a size distribution as shown in Figure 9 as an example.

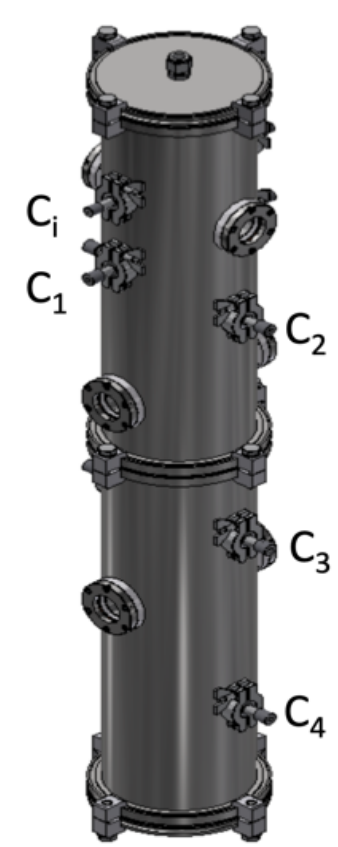

Figure 7. Relative locations of sampling ports labelled.

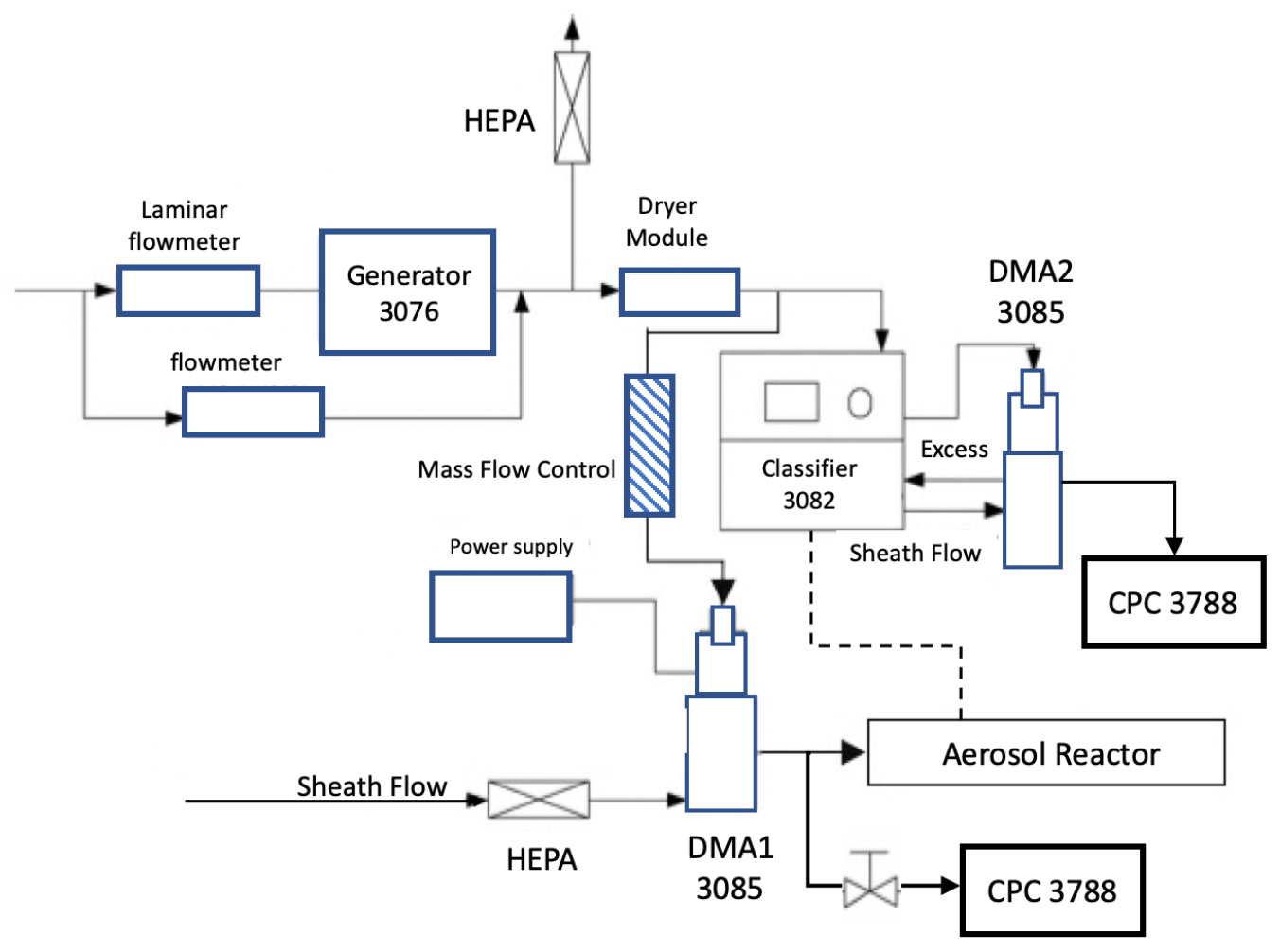

Figure 8. Experimental setup for testing the particle transport efficiency in the reactor. 


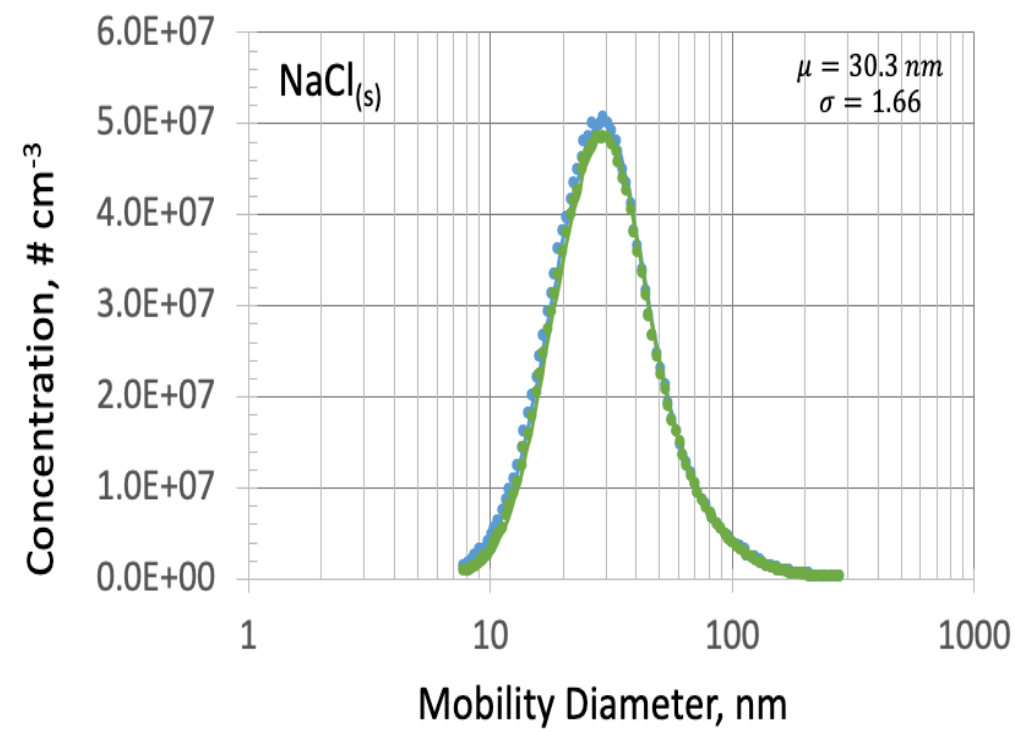

Figure 9. Test particle concentration outputs over time. Two colored curves were sampled $4 \mathrm{~h}$ apart showing the stability of the aerosol generation throughout the experiment.
Figure 9 shows an example of the size distribution for $\mathrm{NaCl}$, one of the test particles. The geometric mean diameter (GMD) of the $\mathrm{NaCl}$ aerosol population was $29 \mathrm{~nm}$ with a geometric standard deviation of 1.66 , indicating the population is polydisperse. The particle number concentration at the GMD was approximately $5.0 \mathrm{E}+7$ $\# \mathrm{~cm}^{-3}$. The size distributions of the other test particles exhibited a similar shape of particle size distribution, but the peak size and dispersion varied depending on the materials used. The stability of the aerosol generation over time during an experiment was remarkable with variation less than $\pm 1 \%$.

We calculated the transport efficiency in reference to the inlet concentration. For example, the ratio $C_{1} / C_{i}$ represents the particle number concentration sampled at the port $\mathrm{C}_{1}$ to the concentration sampled at the inlet, $C_{i}$. Similarly, we calculated the ratios for the ports $C_{2}, C_{3}$, and $C_{4}$ as shown in Figure 7. The efficiency decreased slightly by less than $0.1 \%$ as the flow traversed down the reactor column. Nevertheless, the efficiency at the four sampling ports was greater than $99 \%$ for particles greater than $8 \mathrm{~nm}$. The results were consistent with the calculated efficiency shown in Figure 6. No significant changes were observed in the pattern and magnitude of the transport efficiency curves as shown in Figure 10 from $\mathrm{NaCl}$ particle material at the four different sampling ports. Again, particles consisting of the other three materials (i.e., $\mathrm{NiCl}_{2}, \mathrm{AgCl}_{2}$, and $\mathrm{Fe}_{3} \mathrm{O}_{4}$ ) showed similar transport efficiency; thus, their curves will not be repeated here. 


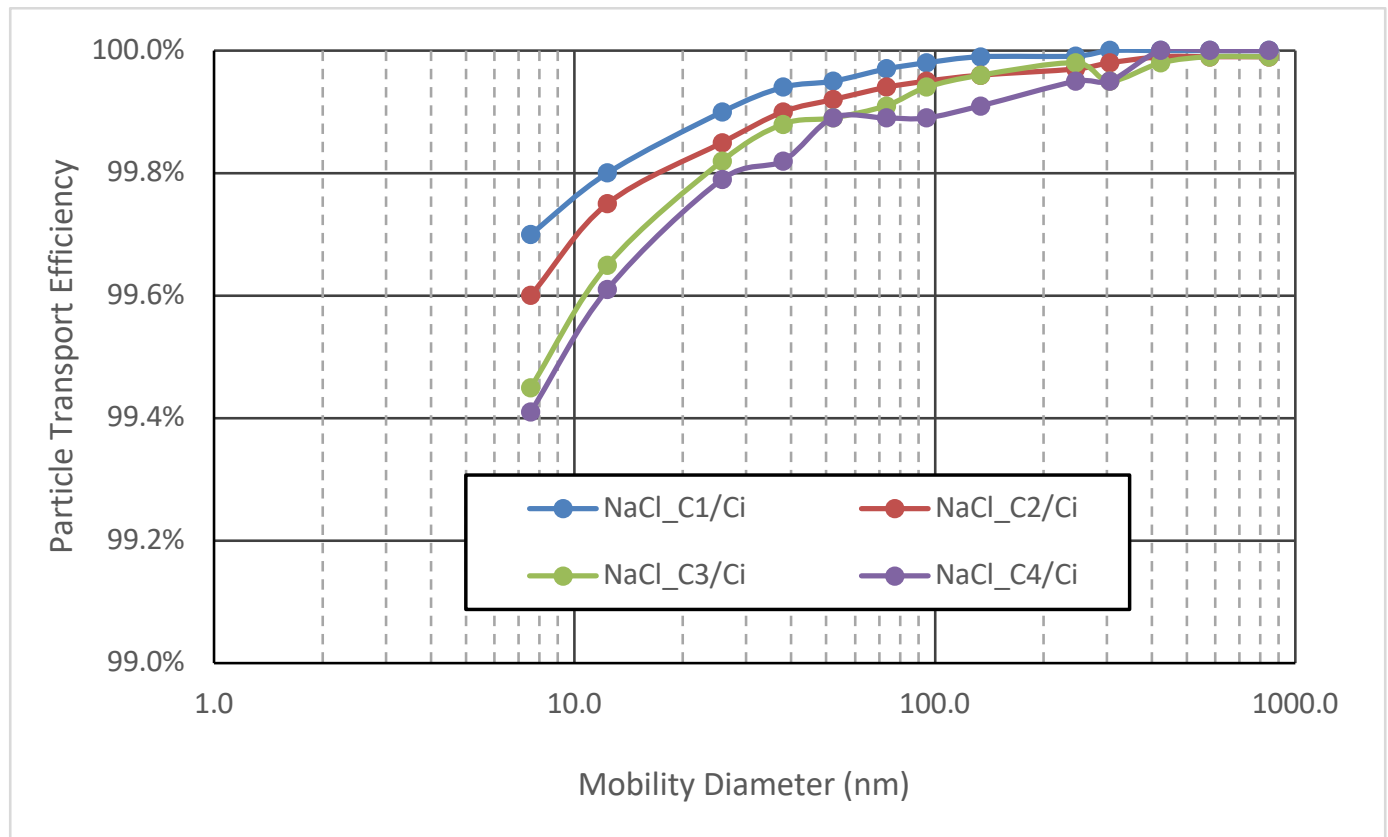

Figure 10. $\mathrm{NaCl}$ particle transport efficiency calculated at the four sampling ports.

\subsection{AEROSOL DYNAMICS MODEL}

To understand the dynamics of an aerosol in any material production system, its time dependent size distribution and chemical composition must be known along with the composition of the surrounding vapor phase. We described the aerosol dynamics model developed by Hubbard et al. (2019) for this project. Gas phase production of TiO2 from TiCl4 has been studied extensively (Ulrich 1971, Pratsinis et al. 1990, Ahktar et al. 1991, 1994, Xiong and Pratsinis 1991, Pratsinis and Spicer 1998, Rigo et al. 1998, Spicer et al. 2002, Zeatoun and Feke 2005, Cheng et al. 2007, West et al. 2009, Wang et al. 2010) along with other gas phase production processes such as $\mathrm{SiO}_{2}$ from silane (Woo et al. 2009). In these processes, chemical reactions between gaseous species result in particle nuclei, which then grow through various mechanisms. The final size and shape of these particles can be controlled, to some degree, by controlling the concentrations of the gas phase species, temperatures, pressures, and so on. Spray pyrolysis (Messing et al. 1993) and flame reactors (Pratsinis 1998) are other examples of processes in which particles of desired properties are produced in a chemically reacting environment. It is desirable to model these reactions and the accompanying aerosol dynamics to engineer production processes and control resultant outputs.

Aerosol dynamics encompass physical processes that alter the properties of an aerosol and its environment: coagulation and agglomeration, condensation, evaporation, nucleation, deposition, gas adsorption and absorption, and scavenging (Brock and Oates 1987, Cheng et al. 2007, Chou et al 2007, Coltrin et al 1991, 1998, Creighton et al. 2008). Chemistry also plays an important role, but chemical rate equations are not explicitly written into the aerosol dynamics equation. Key aerosol dynamics processes are illustrated in Figure 11. 


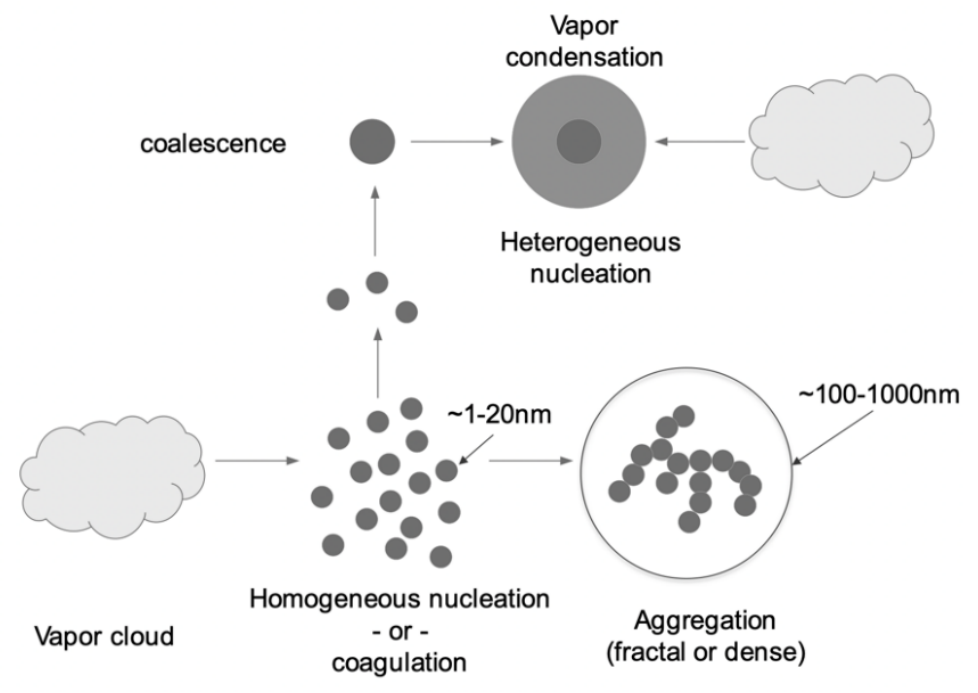

Figure 11. A schematic of aerosol dynamics processes.
The general aerosol dynamics equation describes the aerosol number concentration $(n)$ as a function of time $(t)$ for a given particle volume $(v)$. The source term $(\Psi)$ accounts for the generation of particles through homogeneous and heterogeneous nucleation, as well as other processes. The second term on the right side of Eq. (6) represents particle growth or particle shrinkage due to condensation and evaporation. $\mathfrak{R}$ is a removal term that can be used to represent processes such as gravitational sedimentation or thermophoretic losses to surface. The integral terms on the right side of Eq. (6) represent coagulation, which is a dominant process for

particles smaller than a few hundred nanometers. In the simulation of coagulation, interactions occur among all particle sizes denoted $v$ and $u$ governed by the coagulation kernel $\beta$.

$$
\begin{aligned}
\frac{\partial n(v, t)}{\partial t} & =\Psi(v, t)-\frac{\partial}{\partial v}[I(v, t) n(v, t)]-\mathfrak{R}(v, t) n(v, t) \\
& +\frac{1}{2} \int_{0}^{v} \beta(u, v-u) \cdot n(u, t) \cdot n(v-u, t) \cdot d u-n(v, t) \int_{0}^{\infty} \beta(u, v) \cdot n(u, t) \cdot d u
\end{aligned}
$$

Homogeneous nucleation occurs when a supersaturated vapor transforms into a more energetically favorable aerosol. Small nanoparticles can also form in a purely coagulational process in which growth starts at the monomer size. Small particles then aggregate through diffusion processes to form fractal particles such as soot. These small particles may also coalesce if their properties favor self-diffusion. Finally, vapor of a separate species may condense onto an existing site or particle, which is called "heterogeneous nucleation. Two methods are commonly employed to solve the aerosol dynamics equation: sectional methods in which the size and chemical distributions are distributed amongst discrete size bins, and modal methods in which the distribution is continuous and mathematical operations are performed over the entire size distribution. Moment methods can be computationally faster but are generally used to represent less complicated systems. Sectional methods are not limited in the number of size bins, or chemical constituents, that can be simulated thereby providing a good representation of complex systems in which specific particle attributes (e.g., liquid/solid/chemical composition) are desired with high particle size resolution. Sectional methods have been used for many years to model the evolution of aerosols (Frenklach and Harris 1987, Gelbard and Seinfeld 1979, 1980, Gelbard et al. 1980, Jacobson et al. 1994, Jacobson and Turco 1995, McGraw et al. 1003, McGraw and Wright 1993, Zhang et al. 1999, Jacobson 2005, Upadhyay and Ezekoye 2006) and were used in this study.

\subsubsection{Chemkin-Pro}

Chemkin-Pro is a modeling platform that can be used to simulate chemical kinetics and aerosol dynamics for a variety of processes. Chemkin-Pro was originally developed at Sandia National Laboratories but has 
since been commercialized and upgraded to include additional features. Chemkin-Pro models chemical reactions in gas and on surfaces. Surfaces can be aerosol particles or reactor walls; therefore, ChemkinPro has been widely applied to chemical vapor deposition (Coltrin et al. 1991, 1998, Creighton et al. 2008). One of the key inputs to Chemkin-Pro is thermodynamic data for all species used in the simulation. Specific heat, enthalpy, and entropy must be known for all species. In addition to solving thermodynamics, Chemkin-Pro also solves chemical rate equations. Thus, kinetic data for all reactions are also required as inputs. Frequently, kinetic data are lesser known than thermodynamic data. Transport data (e.g., diffusion coefficients, viscosities, thermal conductivities, and thermal diffusion coefficients) are also needed if the solution is to be obtained within a spatially nonhomogeneous reactor.

Chemkin-Pro comes equipped with many reactor models. The reactors can be open so that species flow in and out across the control volume boundaries in a numerical simulation. Reactors can also be closed such as in a batch reaction so that no additional species could enter or exit the reactor. The reaction can be homogeneous or partially stirred. Other models such as the plug flow reactor are one-dimensional. One of the most significant attributes of Chemkin-Pro, from the perspective of material production and industrial processes, is the inclusion of aerosol dynamics. Nucleation (conversion of gaseous species to solid dispersed species), coalescence (the merging of two particles into a single spherical particle), and aggregation (the addition of two particles to form one larger particle where coalescence does not occur) are all treated numerically with either the sectional method or moment method. Fluent (ANSYS Inc), a computational fluid dynamics code, uses Chemkin-Pro libraries to incorporate chemistry and aerosol dynamics into reactive flow simulations.

Chemkin-Pro also has a well-developed application programming interface (API). When the base Chemkin-Pro functionality cannot address specific processes, users can write custom functions in Fortran or $\mathrm{C}++$, which are then compiled into static and dynamically linked libraries that are called at runtime.

The API enables Chemkin-Pro to be applied to unique processes in which user-specified relationships are needed to represent the system behavior.

\subsubsection{Thermodynamic Data}

The first input to Chemkin-Pro is thermodynamic data for all species present in the simulation. The specific heat capacity $C_{p k}^{o}$, specific enthalpy $H_{k}^{o}$, and specific entropy $S_{k}^{o}$ are calculated within the program using constants that must be obtained from Chemkin-Pro's native thermodynamic property database or other sources, such as JANAF tables. The subscript $k$ represents different species, $T$ is temperature, and $R$ is the ideal gas constant. The functional fits used in Chemkin-Pro are shown in Eqs. (7)-(9).

$$
\begin{gathered}
\frac{C_{p k}^{o}}{R}=a_{1 k}+a_{2 k} T_{k}+a_{3 k} T_{k}^{2}+a_{4 k} T_{k}^{3}+a_{5 k} T_{k}^{4} \\
\frac{H_{k}^{o}}{R T_{k}}=a_{1 k}+\frac{a_{2 k}}{2} T_{k}+\frac{a_{3 k}}{3} T_{k}^{2}+\frac{a_{4 k}}{4} T_{k}^{3}+\frac{a_{5 k}}{5} T_{k}^{4}+\frac{a_{6 k}}{T_{k}} \\
\frac{S_{k}^{o}}{R}=a_{1 k} \ln \left(T_{k}\right)+a_{2 k} T_{k}+\frac{a_{3 k}}{2} T_{k}^{2}+\frac{a_{4 k}}{3} T_{k}^{3}+\frac{a_{5 k}}{4} T_{k}^{4}+a_{7 k}
\end{gathered}
$$

Other data, such as Gibbs free energy, are derived from the fundamental properties of specific heat capacity, enthalpy, and entropy. 


\subsubsection{Kinetic Data}

The second input needed for Chemkin-Pro is kinetic data for all gas phase and surface reactions. The most common kinetic rate specification technique is a simple Arrhenius form in which rates of reaction depend on the reaction rate constant $K$ :

$$
K=A T^{\xi} \exp \left(\frac{-E}{R T}\right)
$$

In the Arrhenius form, Eq. (10), the prefactor $A$, temperature exponent, $\xi$, and activation energy $E$ must be specified for each reaction. For aerosol processes such as nucleation and condensation, Arrhenius forms are inadequate to represent processes that depend on properties such as the free-stream vapor concentration and particle size. Physicochemical specification of rates of reaction were needed and implemented using the surface-kinetics user routine of the Chemkin-Pro API.

\subsubsection{Transport Data}

The scope of this work was limited to homogeneously mixed reactors (spatially). Partially stirred reactors and other nonhomogeneous reactor types require specification of transport data.

\subsubsection{Homogenous Nucleation}

Nucleation is the process of gas phase clustering and liquid drop formation. Homogeneous nucleation occurs when clustering and formation initiates without a surface for the reaction to commence, in a supersaturated environment. Heterogenous nucleation occurs when there is a preexisting surface or site (e.g., ion) where nucleation preferentially occurs. The presence of nucleation sites modifies the thermodynamics of cluster formation. A common example of homogenous nucleation is the formation of clouds. A warm, water-saturated parcel of air rises buoyantly through the atmosphere. As it cools adiabatically, the air becomes supersaturated and it lies in a state of non-equilibrium. The water vapor molecules will cluster through diffusive processes, forming water droplets. Thermodynamic arguments have been used to predict the size of resultant clusters and the rate of cluster formation.

\subsubsection{Classical Nucleation Theory}

Classical nucleation theory (CNT) is one established theory. CNT hinges on the capillarity assumption which relates the change in Gibbs free energy $(\Delta G)$ to the bulk properties of the liquid.

$$
\Delta G=4 \pi r_{p}^{2} \sigma_{p}-\frac{4}{3} \pi r_{p}^{3} \rho_{p} \frac{R T}{M} \ln (S R)
$$

In Eq. (11), $r_{p}$ is cluster radius, $\sigma_{p}$ is the surface tension of the bulk material, $\rho_{p}$ is the bulk density of the liquid phase (i.e., particle), $T$ is the free-stream temperature, $M$ is the molecular mass of the nucleating species $\left(\mathrm{g} \mathrm{mol}^{-1}\right)$, and $S R$ is the saturation ratio of the nucleating species (unitless), defined as the ratio of free-stream vapor pressure $\left(P_{v, \infty}\right)$ to the saturation vapor pressure at the free-stream temperature $\left(P_{v, \text { sat }}(T)\right)$. The saturation ratio is also referred to as the RH for sub-saturated conditions.

Under super-saturated conditions, $S R>1$, nucleation can occur. The homogeneous nucleation rate, $J$, is given by

$$
J=4 \pi r_{c}^{2} \mathrm{~B}_{x} Z_{n} N_{x} \exp \left(\frac{-\Delta G_{c}}{k T}\right)
$$


In Eq. (12), $r_{c}$ is the critical cluster radius determined by

$$
r_{c}=\frac{2 \sigma_{p} M}{\rho_{p} R T \cdot \ln (S R)}
$$

According to CNT, below the critical cluster size, it is thermodynamically favorable for the cluster to disassociate back into the vapor phase. Above the critical cluster size, it is thermodynamically favorable for the cluster to grow. The molecular concentration of nucleating species in the gas phase is denoted $N_{x}$. The number of molecules striking the droplet surface per unit area per unit time is specified by $B_{x}$ :

$$
B_{x}=N_{x} \sqrt{\frac{k_{B} T}{2 \pi m_{1}}}
$$

Here, $k_{B}$ is the Boltzmann constant $\left(1.38 \cdot 10^{-23} \mathrm{~J} \mathrm{~K}^{-1}\right)$, and $m_{1}$ is the mass of a single molecule of the nucleating species. A non-equilibrium correction factor, $Z_{n}$, is included:

$$
Z_{n}=\frac{m_{1}}{2 \pi r_{c}^{2} \rho_{p}} \sqrt{\frac{\sigma_{p}}{k T}}
$$

For water, the liquid surface tension, $\sigma_{p}$, from $-40^{\circ} \mathrm{C} \leq T<0^{\circ} \mathrm{C}$ is given by

$$
\sigma_{p}=\sum_{n=0}^{6} a_{n} T_{\circ}{ }^{n}
$$

and for $0^{\circ} \mathrm{C}<T \leq 40^{\circ} \mathrm{C}$,

$$
\sigma_{p}=75.7-0.151 \cdot T^{\circ} \mathrm{C}
$$

(Jacobson 2005). In Eqs. (14) and (15), the temperature must be in degrees Celsius, denoted $T^{\circ}{ }^{\circ}$. The coefficients, $a_{n}$, are given by $75.93,0.115,0.06818,6.511 \mathrm{E}-3,2.933 \mathrm{E}-4,6.283 \mathrm{E}-6$, and $5.285 \mathrm{E}-8$.

The Gibbs free energy change at the critical cluster radius, $\Delta G_{c}$, is given by

$$
\Delta G_{C}=\frac{4}{3} \pi r_{c}^{2} \sigma_{p}
$$

Thus, with CNT, the critical cluster size and nucleation rate can be calculated with the bulk surface tension of the nucleating species and gas-phase super-saturation.

\subsubsection{Dillmann and Meier Theory}

Adaptations and modifications to CNT have been formulated to make nucleation theory a better representation of experimental data. The Dillmann and Meier theory (DMT) was implemented here because of its published agreement with experimental data for water nucleation (Dillmann and Meier 1991). In principle, the major difference between theories is how $\Delta G$ is calculated. McClurg and Flagan (1998) pointed out that $\Delta G$ in CNT is simply a truncation of a longer series of terms. Including terms beyond those included in CNT appears to provide better agreement between theory and experiment. Dillmann and Meier formulated a model which allowed for the inclusion of translational, rotational, vibrational, and configurational degrees of freedom as well as the variation of surface tension with cluster size (Dillmann and Meier 1991). The Dillmann-Meier homogeneous nucleation rate, $J_{D M}$, is given by 


$$
\begin{aligned}
J_{D M} & =\frac{1}{3} \sqrt{\frac{\theta}{\pi}\left(1+\alpha_{1} i_{c}{ }^{-1 / 3}+\frac{9 \tau}{2 \theta} i_{c}^{-2 / 3}\right)} \\
& \times\left(\frac{s_{1} P_{v, \infty}}{2 \pi m_{1} k T}\right) \\
& \times\left[q_{0} \cdot \exp \left(-\kappa_{i_{c}} \theta i_{c}{ }^{2 / 3}-\tau \ln \left(i_{c}\right)+i_{c} \ln (S R)\right)\right]
\end{aligned}
$$

Equation (19) is considerably more complex than the nucleation flux predicted by CNT, hence the utility of CNT. The dimensionless surface tension, $\theta$, is given by

$$
\theta=\frac{\sigma_{p} s_{1}}{k T}
$$

where $s_{1}$ is the surface area of an individual molecule of the nucleating species. The number of molecules in the critical cluster is $i_{c}$. Other parameters in Eq. (19) result from the derivation of DMT, which includes non-ideal gas behavior. For water, $\tau=2.166$, and $q_{0}=0.151 \rho_{c}$, where the critical point properties of water are given by $T_{c}=647.13 \mathrm{~K}, P_{c}=220.60 \mathrm{bar}$, and $\rho_{c}=0.323 \mathrm{~g} \mathrm{~cm}^{-3}$. The critical cluster size is calculated with the following polynomial expression

$$
\tau x^{3}+\frac{1}{3} \alpha_{1} \theta x^{2}+\frac{2}{3} \theta x-\ln (S R)=0
$$

where

$$
x=i_{c}{ }^{-1 / 3}
$$

The alpha and kappa constants are calculated with the following formulae.

$$
\begin{gathered}
\alpha_{1}=\frac{\left(\kappa_{2}-1\right)-\left(\kappa_{1}-1\right) \cdot 2^{-2 / 3}}{2^{-1 / 3}-2^{-2 / 3}} \alpha_{2}=-\frac{\left(\kappa_{2}-1\right)-\left(\kappa_{1}-1\right) \cdot 2^{-1 / 3}}{2^{-1 / 3}-2^{-2 / 3}} \\
\kappa_{1}=-\frac{1}{\theta} \ln \left(\frac{P_{v, s a t}}{q_{0} k_{B} T}\right) \kappa_{2}=-\frac{1}{\theta \cdot 2^{2 / 3}} \ln \left[-\left(\frac{P_{v, \text { sat }}}{q_{0} k_{B} T}\right)^{2} \cdot\left(2^{\tau-1}\right) \cdot\left(q_{0} B\right)\right]
\end{gathered}
$$

\subsubsection{Chemkin-Pro Implementation}

A user may specify the keyword "NUCL" in the Chemkin-Pro input file after a reaction to designate a gas to particle transition. The particle size must be specified in the reaction line of the input file, and Arrhenius rate information must be provided to determine the rate at which particles of the designated size appear. All parameters must be known before the simulation. For nucleation, it is preferable to calculate the cluster size and nucleation flux at each time step using the gas phase species concentrations and material properties. This is intent of the "SKUPROG" user routine in Chemkin-Pro, where the "SK"

stands for "surface kinetics." By adding another keyword in the input file "USRPROG," the pre-processor knows to implement the user-routine rate of progress $(R O P)$ variable rather than use the Arrhenius rate information in the input file.

In this study, both CNT and DMT were programmed into SKUPROG so the results could be compared with published data. The data published by Viisanen et al. (1993) and Miller et al. (1983) were used to compare CNT and DMT predictions. The data of Miller et al. (1983) are valid at temperatures similar to standard conditions, and the data of Viisanen et al. (1993) are valid at lower temperatures where the supersaturation values are higher. A simple surface reaction was written in the Chemkin-Pro input file. 


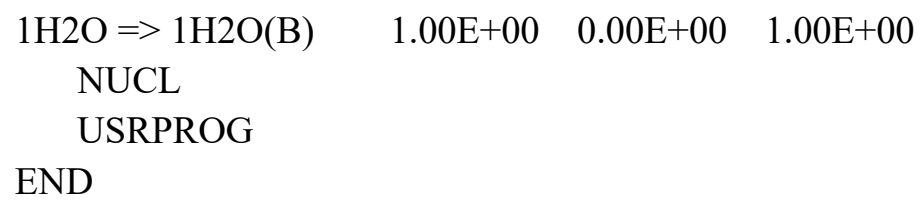

This reaction is both a nucleation reaction and a surface reaction that calls user defined functions to calculate the ROP. The values given after the reaction (Arrhenius constant, temperature exponent, and activation energy) are placeholders and were not used in simulations since USRPROG overrides the Arrhenius parameters.

For model development, the nucleation reaction was written in which a single water molecule in the gas phase transitions to a single molecule of condensed water. The condensed species is denoted "(B)" for bulk species. The SKUPROG user routine calculated the molecular flux from CNT and DMT. The molecular flux was then divided by the number of molecules in a critical cluster to give the nucleation flux (particles $\mathrm{cm}^{-3} \mathrm{~s}^{-1}$ ). In practice, the reaction index would be used to assign a non-zero nucleation flux value in the correct particle size bin associated with the critical particle size.

A MATLAB script was written to step line by line through tabulated experimental data and modify the Chemkin-Pro input file such that Chemkin-Pro started with the correct pressure, temperature, and water vapor mole fraction. Chemkin-Pro then executed a single time step such that user defined functions in SKUPROG were used to evaluate the $R O P\left(\right.$ moles $\left.\mathrm{cm}^{-3} \mathrm{~s}^{-1}\right)$. The $R O P$ values were written to a text file from SKUPROG, along with the critical cluster size (number of molecules). The particle nucleation rate (which is how experimental data are presented) was then calculated by dividing the molar nucleation rate by the number of moles per molecular cluster. CNT predictions, DMT predictions, and experimental data were plotted and shown in Figure 12 and Figure 13. Each data point is a separate Chemkin-Pro simulation with different initial conditions corresponding to those that produced experimental data for homogeneous nucleation rates of water.

Figure 12 shows theoretical predictions plotted alongside the experimental data of Viisanen et al. (1993), which are valid for higher supersaturation values (lower temperature). Aside from data taken at $239 \mathrm{~K}$, CNT was higher than experimental data by a factor of 5-10. Assumptions made in CNT and DMT may become less valid at lower temperatures.

Figure 13 shows CNT and DMT predictions plotted alongside the experimental data published by Miller et al. (1983). These data are for lower values of supersaturation and higher temperatures. CNT overpredicted experimental data by a factor of 5-10. DMT under-predicted experimental data at 286 and $297 \mathrm{~K}$ but showed good agreement at 308 and $318 \mathrm{~K}$. User routines were effectively used to incorporate homogenous nucleation into Chemkin-Pro rather than assuming a rate constant of Arrhenius form. 

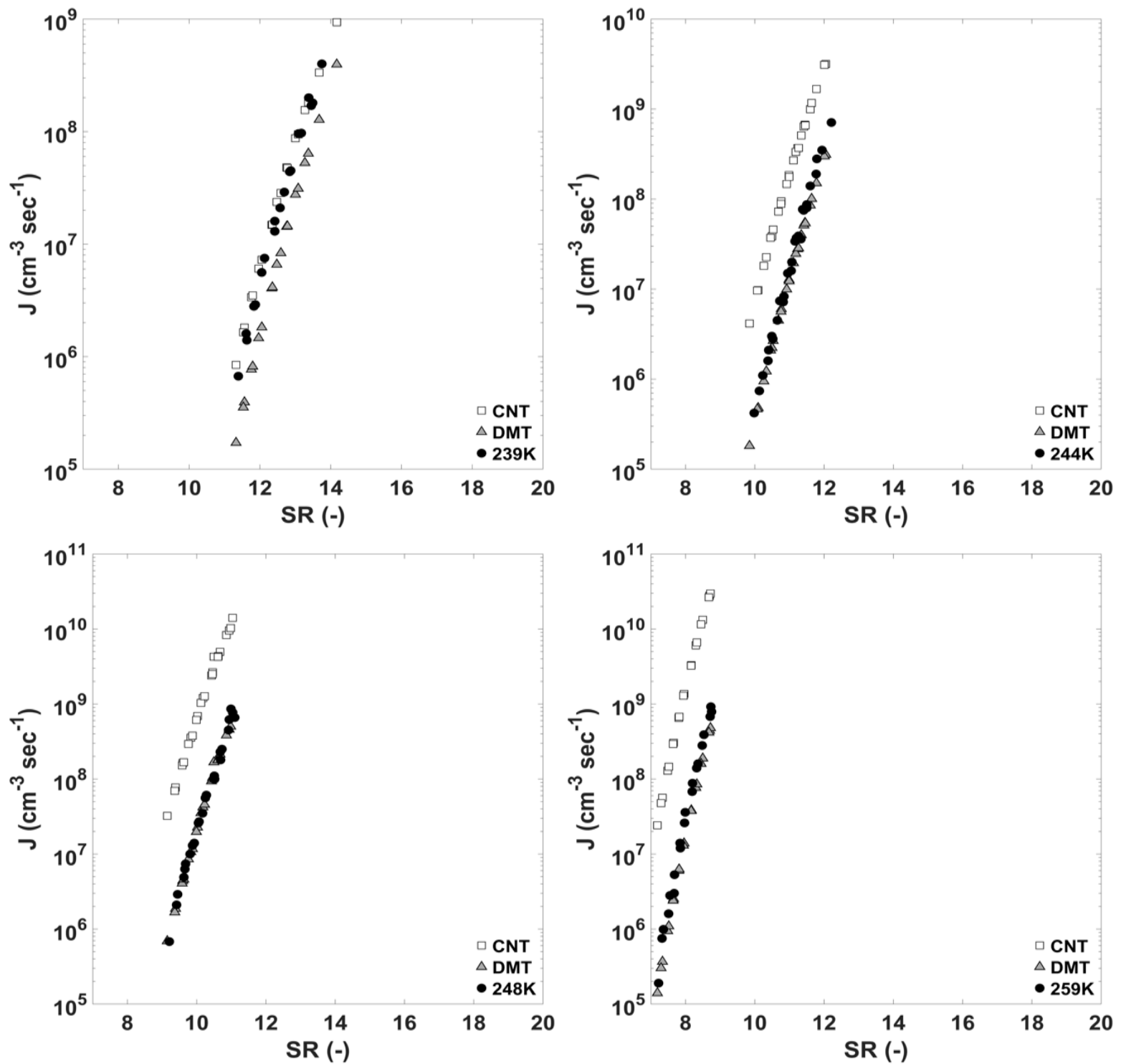

Figure 12. Homogeneous nucleation rate data for water at various gas temperatures and saturation ratios

(SRs). Data were taken from Viisanen et al. (1993). A Chemkin-Pro surface-kinetics user routine was written to calculate nucleation rates according to CNT (Wyslouzil and Wolk 2016) and the modified theory of Dillmann and Meier (1991). 

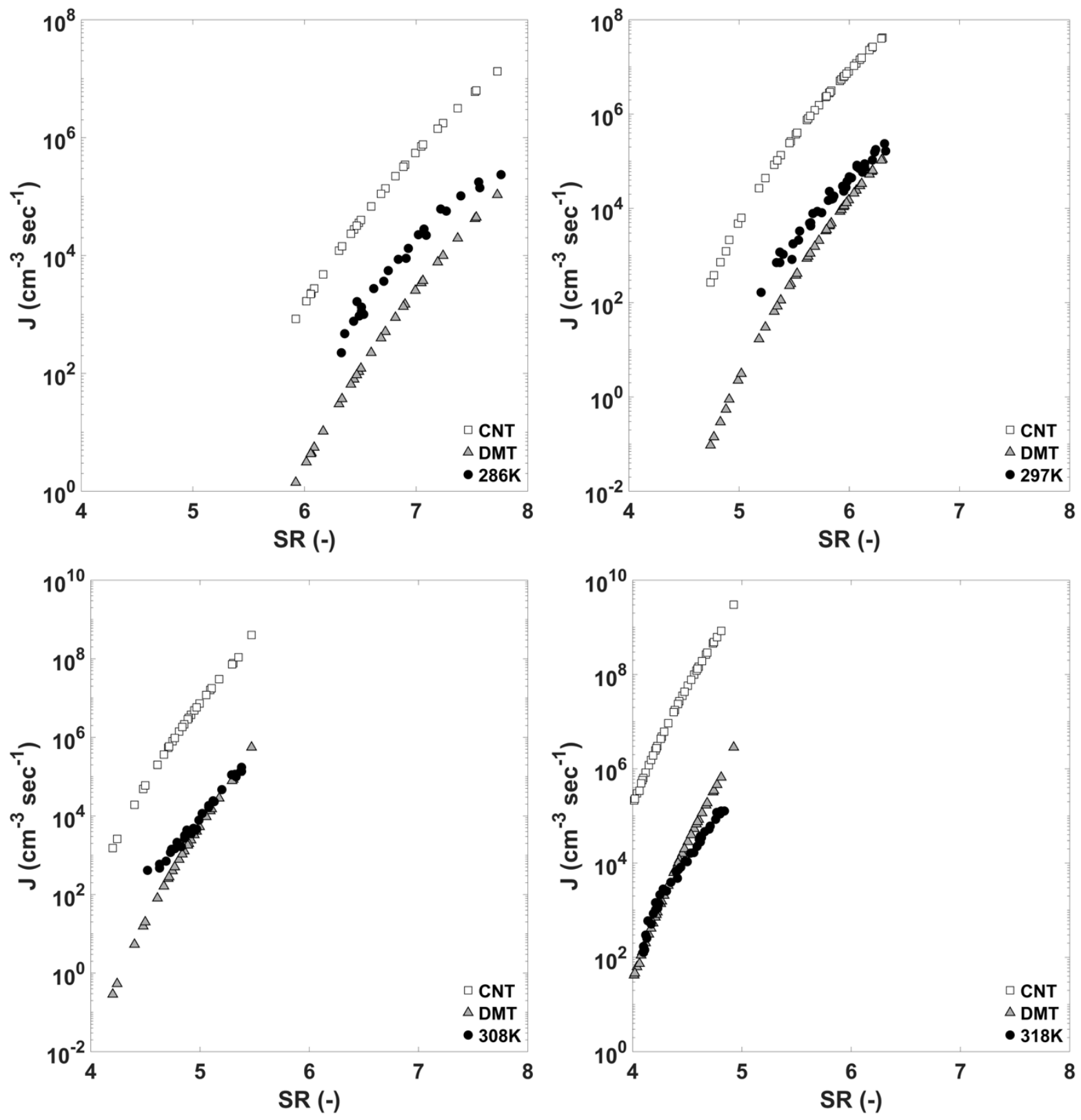

Figure 13. Homogeneous nucleation rate data for water at various gas temperatures and saturation ratios

(SRs). Data were taken from Miller et al. (1983). A Chemkin-Pro surface-kinetics user routine was written to calculate nucleation rates according to CNT (Wyslouzil and Wolk 2016) and the modified theory of Dillmann and Meier (1991). 


\subsubsection{Condensation and Evaporation}

Condensation and evaporation are common to many industrial processes such as evaporative cooling. Aerosol growth through vapor deposition is also a dominant process that affects the properties and transport of an aerosol. In this section, the objective was to implement a particle condensation and evaporation user routine in Chemkin-Pro to expand capability. This is a novel feature because particle size-dependent reaction mechanisms were only made possible by ANSYS in release 2019R1. Prior to release 2019R1, the particle size dependence could not be incorporated into condensation and evaporation rates, or any other particle surface reaction.

\subsubsection{Ordinary Differential Equation}

A conventional representation of evaporating or condensing droplets is presented by Hinds (1999). The rate of change of droplet diameter, $d_{p}$, is given by

$$
\frac{d\left(d_{p}\right)}{d t}=\frac{4 D_{v} M}{R \rho_{p} d_{p}}\left(\frac{P_{v, \infty}}{T_{\infty}}-\frac{P_{d}}{T_{d}}\right) \phi
$$

In Eq. (25), $t$ is time, $D_{v}$ is the diffusivity of vapor, $M$ is the molecular weight of the condensing or evaporating species, $\rho_{p}$ is particle density, $P_{v, \infty}$ is the free-stream vapor pressure of the condensing or evaporating species, $T_{\infty}$ is the free-stream temperature, $P_{d}$ is the vapor pressure of the condensing or evaporating species at the droplet surface, $T_{d}$ is the droplet temperature, and $\phi$ is the Fuchs correction factor. The Fuchs correction factor accounts for transport through a distance of one mean free path from the particle surface which is not appropriately characterized by a diffusive process (Hinds 1999); the growth of very small particles (less than about $1 \mu \mathrm{m}$ in physical diameter), is reduced. The Fuchs correction factor is given by

$$
\phi=\frac{2 \lambda+d_{p}}{d_{p}+5.33 \frac{\lambda^{2}}{d_{p}}+3.42 \lambda}
$$

where $\lambda$ is the mean free path of air. The mean free path of air is approximately $0.066 \mu \mathrm{m}$ at a standard temperature of $T(\mathrm{~K})$ and pressure of $P(\mathrm{kPa})$ and can be calculated at other air pressures and temperatures.

$$
\lambda=\frac{k_{B} T}{\sqrt{2} \pi d_{m}^{2} P}
$$

In Eq. (27), $d_{m}$ is the molecular diameter $(0.00037 \mu \mathrm{m}$ for air) and $P$ is the gas pressure. The Fuchs correction factor is shown in Figure 14 as a function of particle size at standard temperature and pressure $(293 \mathrm{~K}, 101,325 \mathrm{~Pa})$. 


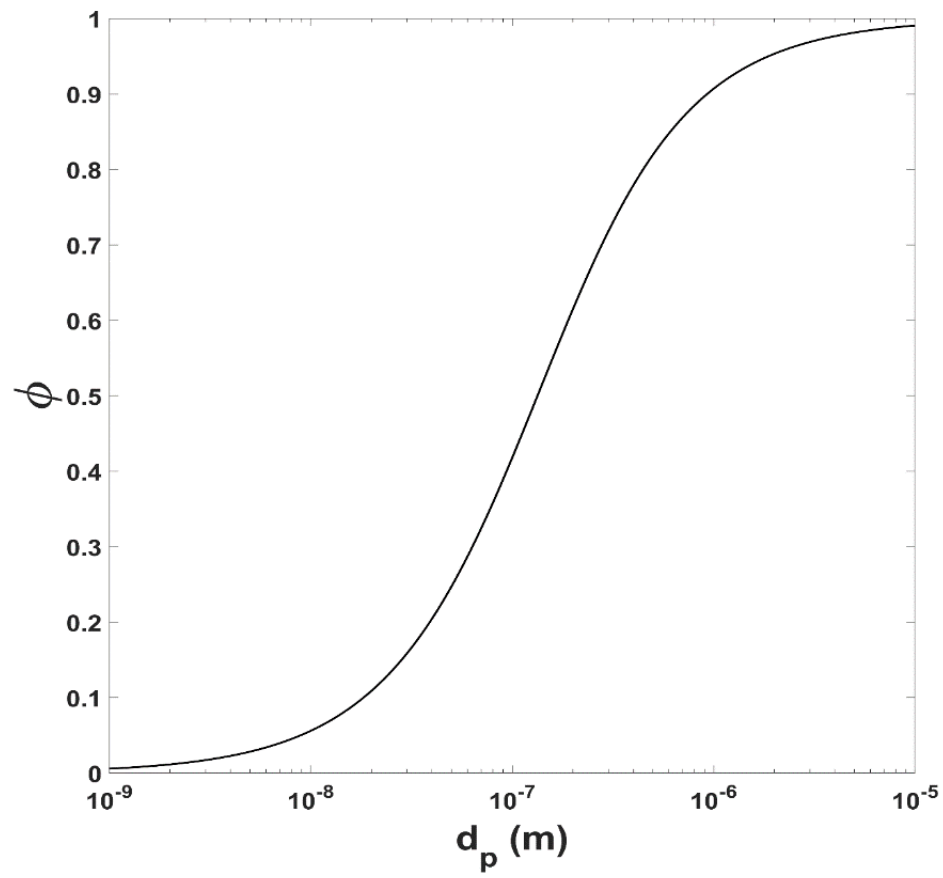

Figure 14. The Fuchs correction factor is applied to vapor mass transfer, to and from the droplet surface, to account for non-continuum effects in Eq. (20). Mass transfer is reduced for particles and droplets smaller than about $1 \mu \mathrm{m}$ in diameter.

Under most circumstances, the droplet temperature is not equal to the free-stream temperature because of the latent heat of evaporation and condensation. The conservation of energy at the droplet surface yields

$$
\dot{m} h_{f g}=h\left(T_{\infty}-T_{d}\right) \pi d_{p}^{2}
$$

This is the starting point for the derivation of the droplet temperature. In Eq. (28), $h_{f g}$ is the enthalpy of vaporization from liquid to gas, and $h$ is the convective heat transfer coefficient. The droplet Reynolds number, $R e_{d}$, is given by

$$
R e_{d}=\frac{\rho_{a} U_{a} d_{p}}{\mu_{a}}
$$

where $\rho_{a}$ is the air density, $U_{a}$ is the relative velocity of air with respect to the particle, and $\mu_{a}$ is the dynamic viscosity of air. The heat transfer parameter called the Nuesselt number is given by

$$
N u_{d}=\frac{h d_{p}}{k_{v}}
$$

where $k_{v}$ is the thermal conductivity of air. For $R e_{d} \ll 1$, which is typically the case for small aerosol particles, $N u_{d}=2$. The heat transfer coefficient is then given by

$$
h=2 \frac{k_{v}}{d_{p}}
$$

Inserting Eq. (31) into Eq. (28) along with

$$
\dot{m}=\frac{\pi}{2} \rho_{p} d_{p}{ }^{2} \frac{d\left(d_{p}\right)}{d t}
$$


gives the following relationship for the droplet temperature

$$
\frac{D_{v} M h_{f g}}{R k_{v}}\left(\frac{P_{v, \infty}}{T_{\infty}}-\frac{P_{d}}{T_{d}}\right)=T_{\infty}-T_{d}
$$

To solve Eq. (25), a MATLAB function was written to find the droplet temperature for arbitrary freestream conditions (temperature and saturation ratio). Water droplet temperatures for a variety of free stream temperatures and vapor pressures are shown in Figure 15. For under-saturated conditions, the droplet temperature is lower than the free-stream temperature. For super-saturated conditions, the droplet temperature is higher.

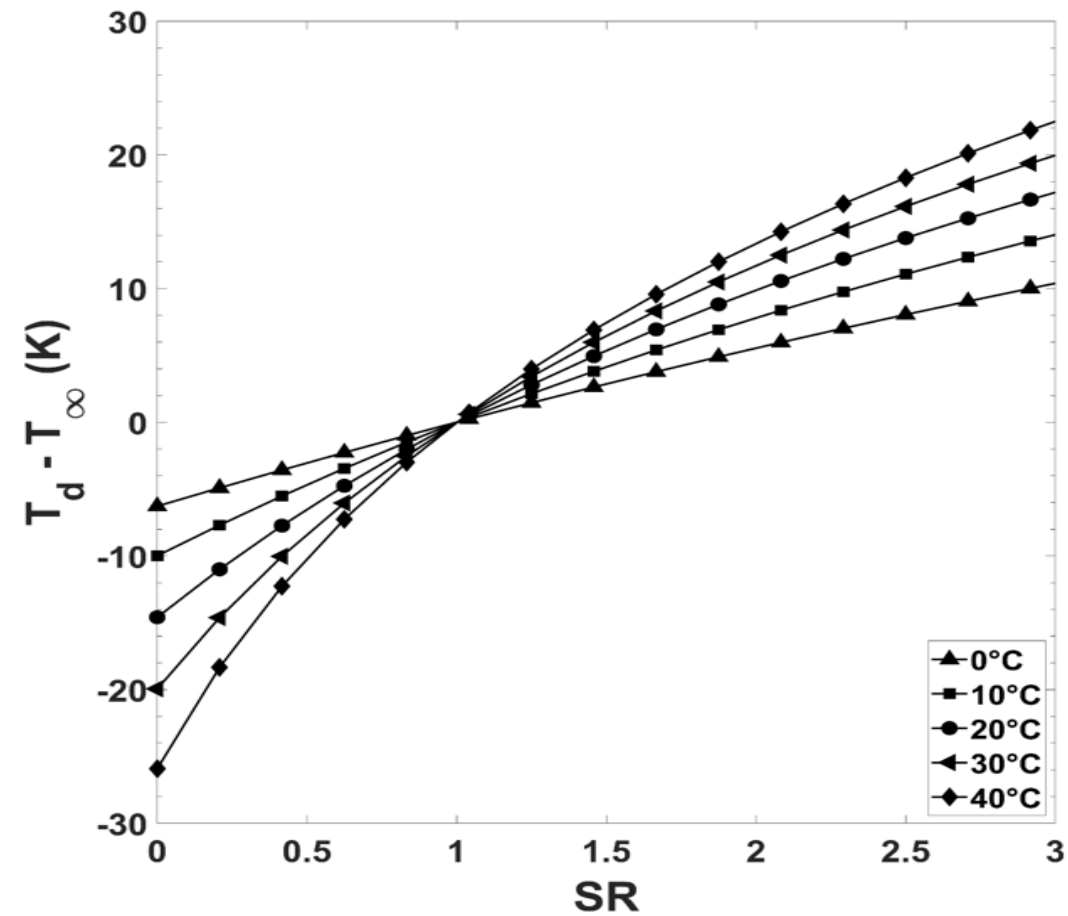

Figure 15. The difference between droplet and free-stream temperature at various free-stream temperatures (legend) and saturation ratios (SRs). For sub-saturated environments, the droplet temperature is always below the free-stream temperature.

\subsubsection{Chemkin-Pro Implementation}

To implement condensation in Chemkin-Pro, a step back from Eq. (25) is taken where the net arrival of molecules or atoms to the particle surface, $n_{z}$ (atoms/s), is given by

$$
n_{z}=\frac{2 \pi d_{p} D_{v}}{k_{B}}\left(\frac{P_{v, \infty}}{T_{\infty}}-\frac{P_{d}}{T_{d}}\right) \phi
$$

Equation (34) is appropriate when the growth rate depends on the rate of diffusion to the droplet surface rather than the rate at which molecules randomly collide (Hinds 1999). The Fuchs correction factor is again needed to account for the growth of small particles.

In Chemkin-Pro, the user-routine $R O P\left(\right.$ moles $\left.\mathrm{m}^{-2} \mathrm{~s}^{-1}\right)$ is given by

$$
R O P=\frac{n_{z}}{s_{p} N_{A v}}=R P R O G \cdot R O P_{\text {enhance }}
$$


where $s_{p}$ is the particle surface area, and $N_{a v}$ is Avogadro's number. $R P R O G$ is the size-independent $R O P$ defined in the SKUPROG (surface-kinetics) user routine.

$$
R P R O G=\frac{2 D_{v}}{k_{B}}\left(\frac{P_{v, \infty}}{T_{\infty}}-\frac{P_{d}}{T_{d}}\right)
$$

In ANSYS releases prior to 2019R1, the particle size dependence could not be included in the ROP. To facilitate size-dependent surface reaction rates, ANSYS provided the $R O P_{\text {enhance }}$ function. $R O P_{\text {enhance }}$ is calculated in a separate Chemkin-Pro user routine called "particle-user-routines." $R O P_{\text {enhance }}$ was formulated from Eq. (35) by separating out the size-dependent parameters.

$$
R O P_{\text {enhance }}=\frac{\phi}{d_{p}}
$$

$R P R O G$ and $R O P_{\text {enhance }}$ functions were both implemented in Chemkin-Pro user routines. The $R O P_{\text {enhance }}$ multiplication factor is applied at runtime to augment $R P R O G$.

\subsubsection{Verification}

To verify the performance of the Chemkin-Pro condensation surface-kinetics routine, simulations were performed in Chemkin-Pro and compared with the results of Eq. (25). The following Chemkin-Pro initial conditions and solver parameters were used: initial gas phase temperature of $293.15 \mathrm{~K}$, RH of $200 \%$, initial water droplet diameter of $50 \mathrm{~nm}$, minimum droplet diameter of $0.385 \mathrm{~nm}$ (correlating to 1 molecule), maximum droplet size of $5 \mu \mathrm{m}$, default relative and absolute tolerances (solver settings), and a simulation time of $2 \mathrm{E}-3 \mathrm{~s}$ or $2 \mathrm{~ms}$.

Figure 16 shows the initial monodisperse particle distribution at $0.385 \mathrm{~nm}$ and $1.0 \mathrm{E} 12 \mathrm{\#} / \mathrm{cm}^{3}$ denoted $t_{0}$. The ordinary differential equation (ODE) solution follows a single droplet through time as it grows. Thus, the ODE solution at the end simulation time, $2 \mathrm{~ms}$, is a single data point at $1.0 \mathrm{E} 12 \mathrm{\#} / \mathrm{cm}^{3}$ and $1,230 \mathrm{~nm}$. The number concentration is constant for Eq. (25). Chemkin-Pro redistributes particle volume amongst adjacent bins when particles grow or shrink, which is why the initially monodisperse distribution becomes polydisperse in time. This is an artifact of the discrete size structure used in Chemkin-Pro and can be considered numerical diffusion. Chemkin-Pro conserves particle volume. When particles are split amongst bins, the peak number concentration decreases from $1 \mathrm{E} 12$ to $6 \mathrm{E} 10$ over $2 \mathrm{~ms}$ of the simulation time. 


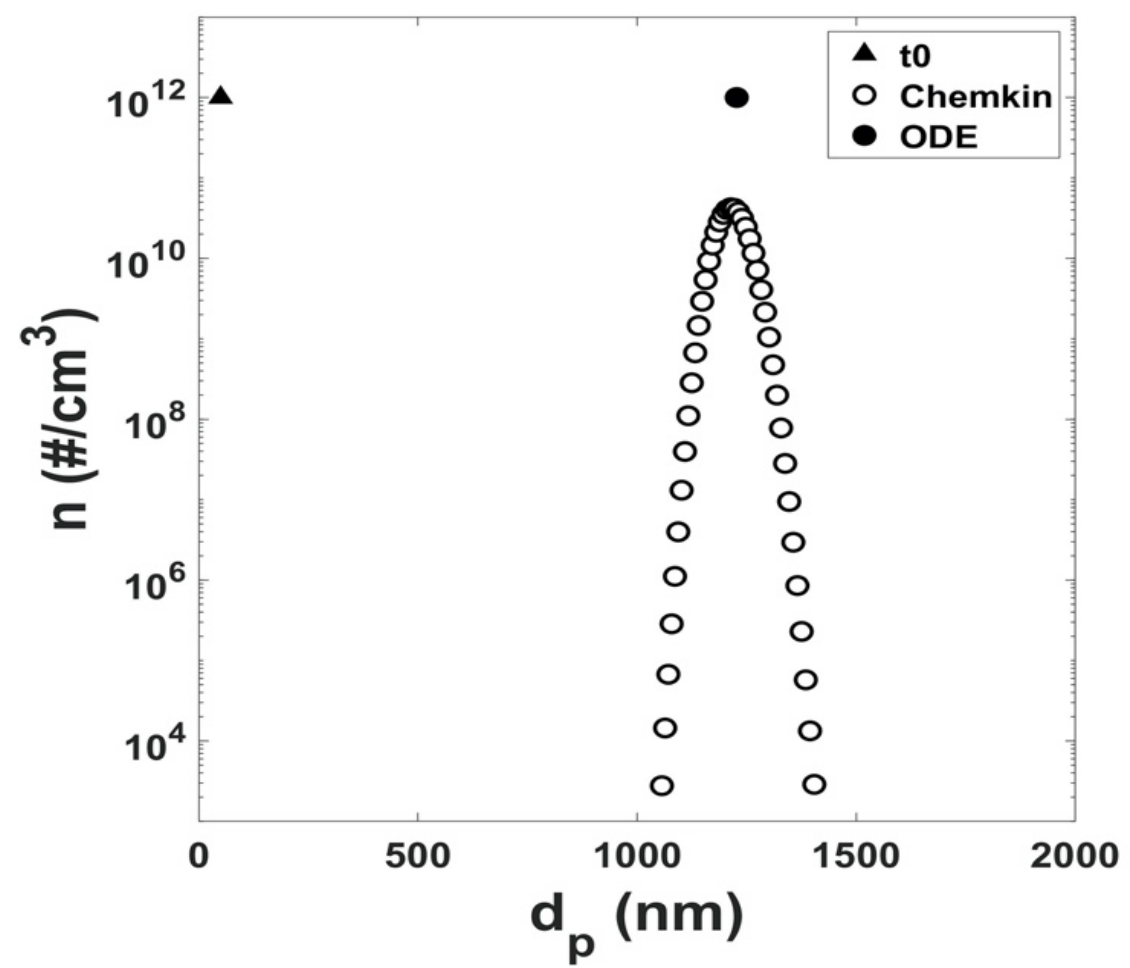

Figure 16. The number concentration, $n$, as a function of particle diameter, $d_{p}$, at $2 \mathrm{E}-3 \mathrm{~s}$ for water vapor condensation. Numerical results were calculated with Chemkin-Pro and Eq. (25) (denoted ODE). The Chemkin-Pro solutions shows numerical diffusion across the size distribution as a result of bin discretization.

Figure 17 shows the average particle diameter as a function of time. For the ODE solution, the average particle diameter is the only data point. For the Chemkin-Pro solution, the average particle diameter is calculated by weighting the individual particle sizes by the number concentration in that size bin. Good agreement was observed between Chemkin-Pro and the ODE solution.

Error in the Chemkin-Pro $d_{p, a v g}$ was calculated and is shown in Figure 18. The percent error was calculated by taking the difference between the Chemkin-Pro $d_{p, a v g}$ and the $d_{p}$ from Eq. (25), and normalizing the difference by the $d_{p}$ from Eq. (25). Percent error is shown for varying levels of bin discretization $(128,256,512,1,024,2,048$, and 4,096) bins. The size range remained constant $(0.385$ to $5,000 \mathrm{~nm}$ ), but the bin spacing decreased. Error decreased with smaller bins because of particle volume redistribution in the discretized bin structure. Increased bin resolution came at the cost of computation time.

The computer simulation times $\left(t_{\text {compute }}\right)$ for each level of bin discretization are shown in Figure 19. With 4,096 bins, the total computer simulation time was approximately $17 \mathrm{~min}$ on an Intel Core i7-8650 U processor (1.9 GHz, $32 \mathrm{~GB}$ RAM). At 2,048 bins, the computation time was closer to $3 \mathrm{~min}$.

Simulations were also performed for the case of evaporating liquid droplets. Similar results were obtained: good agreement was observed between the Chemkin-Pro surface-kinetics user routine and the ODE solution; numerical diffusion and relative error depended on the level of bin discretization; and computation times increased with increasing particle size bin resolution. These comparisons were used to verify the performance of the surface-kinetics user routine as well as ANSYS' newly implemented particle user routine, which allows for the user to implement particle size dependent surface rates of reaction. For aerosol physics and chemistry, this new Chemkin-Pro feature enables substantial improvements. 


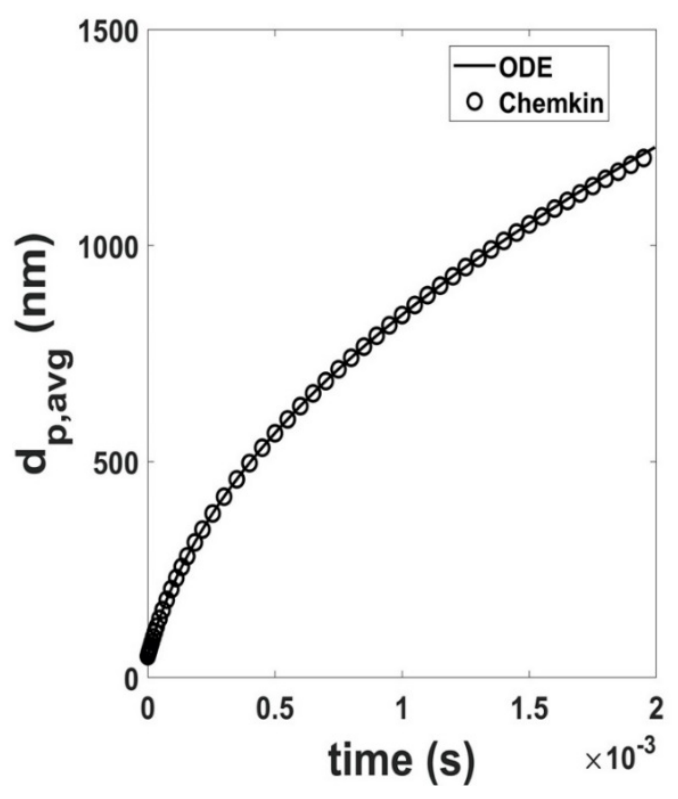

Figure 17. The average particle diameters for Eq. (25) and Chemkin-Pro as a function of time for water vapor condensation.

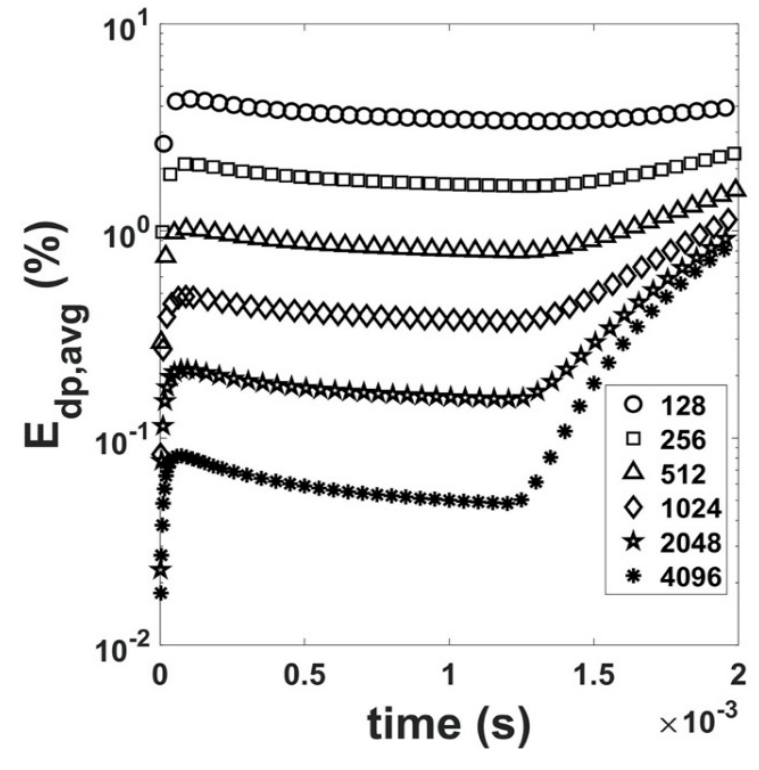

Figure 18. The errors in average particle size, $E_{d p, a v g}$, as a function simulation time for different levels of particle size distribution discretization (number of particle size bins).

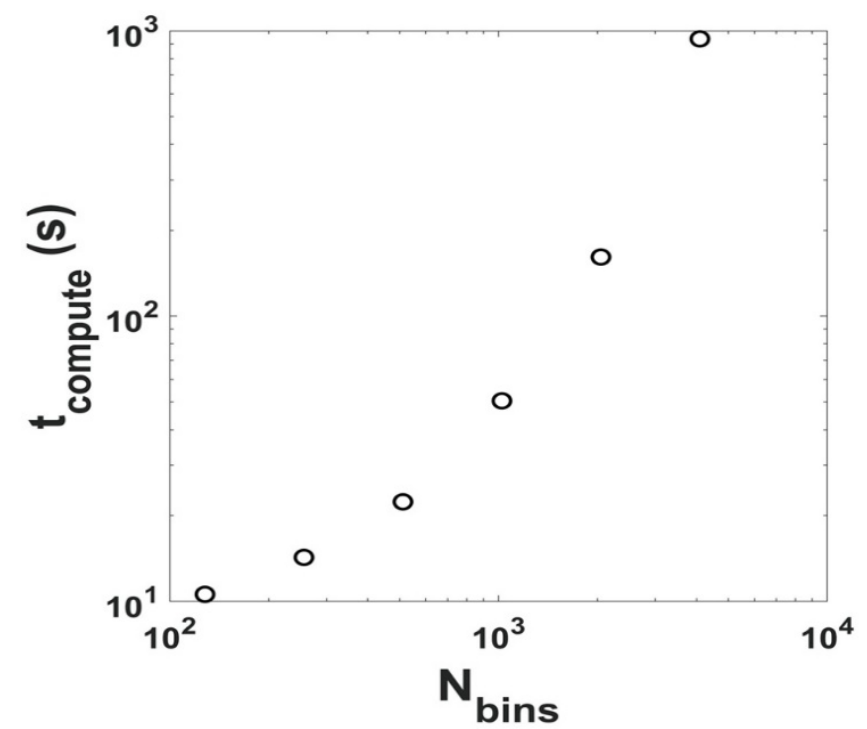

Figure 19. Computer processing times, $t_{\text {compute, }}$ for different levels of particle size discretization ranging from 128 to 4,096 bins. 


\section{Coagulation}

\subsubsection{Semi-Implicit Method}

Coagulation is the change in particle size due to two particles colliding and the formation of a volume equivalent sphere. Assuming the formation of a volume equivalent sphere is called "coalescence." A new particle of volume $V_{i, j}$ is formed from the addition of particles of volume $v_{i}$ and $v_{j}$.

$$
V_{i, j}=v_{i}+v_{j}
$$

This process is depicted in Figure 20 along with the particle bin discretization scheme developed by Jacobson and Turco (1995), which will be discussed shortly. They present a semi-implicit, volume- and volume concentration-conserving, noniterative method for calculating the volume concentration at any time $t$, in any particle size bin $m, v_{m, t}$.

$$
v_{m, t}=\frac{v_{m, t-h}+h \sum_{j=1}^{m}\left(\sum_{i=1}^{m-1} f_{i, j, m} \beta_{i, j} v_{i, t} n_{j, t-h}\right)}{1+h \sum_{j=1}^{N}\left(1-f_{m, j, m}\right) \beta_{m, j} n_{j, t-h}}
$$
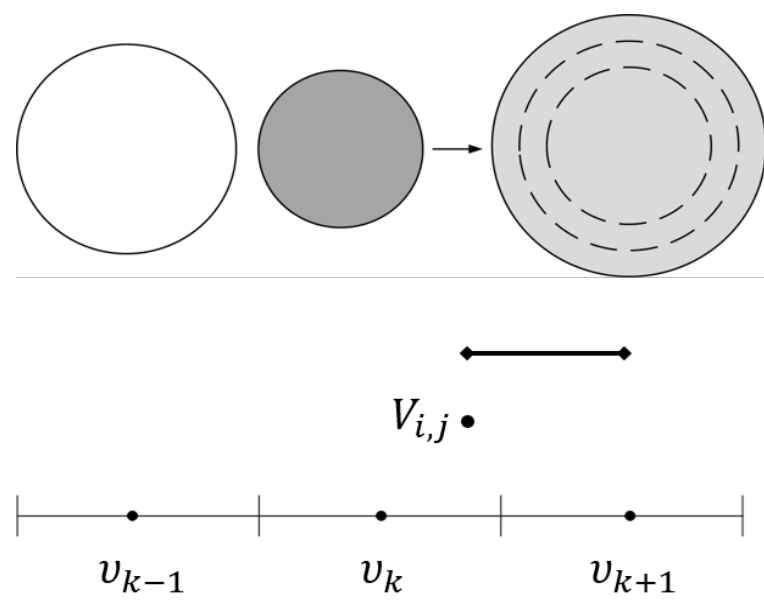

Figure 20. During coagulation and coalescence, two particles of different sizes merge to form a single particle of equivalent volume. The volume of the resultant particle must be split amongst size bins in the discrete method. Jacobson (2005) devised a numerical technique for splitting particle volume.

The solution depends on the volume concentration and number concentration at the previous time step, $v_{m, t-h}$ and $n_{j, t-h}$, respectively, and the volume concentration at the current time step for a particle size bin, which has been calculated previously, $v_{i, t}$. The coagulation kernel $\beta_{12}$ determines, along with the particle number concentrations of both species, the rate at which particles coagulate:

$$
\beta_{12}=2 \pi\left(D_{1}+D_{2}\right)\left(d_{p 1}+d_{p 2}\right)\left[\frac{d_{p 1}+d_{p 2}}{d_{p 1}+d_{p 2}+2\left(g_{1}{ }^{2}+g_{2}{ }^{2}\right)^{1 / 2}}+\frac{8\left(D_{1}+D_{2}\right)}{\left(\bar{c}_{1}{ }^{2}+\bar{c}_{2}\right)^{1 / 2}\left(d_{p 1}+d_{p 2}\right)}\right]^{-1}
$$

Equation (40) is given by Seinfeld and Pandis (2006) for the transition regime that covers free-molecular kinetics, continuum kinetics, and the region in between. $D_{1}$ and $D_{2}$ are the diffusivities of particles 1 and 2. The thermal velocity of particles are denoted $\bar{c}_{1}$ and $\bar{c}_{2} \bar{c}_{2}$. 


$$
\bar{c}_{i}=\left(\frac{8 k_{b} T}{\pi m_{i}}\right)^{1 / 2}
$$

In Eq. (41), $k_{b}$ is the Boltzmann constant, $T$ is the gas temperature, and $m$ is the mass of one molecule. The mean free path, $\ell$, is given by

$$
\ell_{i}=\frac{8 D_{i}}{\pi \bar{c}_{i}}
$$

The factor $g$ is given by

$$
g_{i}=\frac{\sqrt{2}}{3 d_{p i} \ell_{i}}\left[\left(d_{p i}+\ell_{i}\right)^{3}-\left(d_{p i}^{2}+\ell_{i}^{2}\right)^{3 / 2}\right]-d_{p i}
$$

Finally, particle diffusivity is given by

$$
D_{i}=\frac{k_{B} T C_{c}}{3 \pi \mu d_{p i}}
$$

The transition coagulation kernel, $\beta_{12}$, is shown in Figure 21.

$$
f_{i, j, m}=\left\{\begin{array}{ccc}
\left(\frac{v_{m+1}-V_{i, j}}{v_{m+1}-v_{m}}\right) \frac{v_{m}}{V_{i, j}} & v_{m} \leq V_{i, j}<v_{m+1} & m<N_{B} \\
1-f_{i, j, m-1} & v_{m-1}<V_{i, j}<v_{m} & m>1 \\
1 & V_{i, j} \geq v_{m} & m=N_{B} \\
0 & \text { all other cases } &
\end{array}\right.
$$

Figure 20 provides an illustration. $V_{i, j}$ falls between $v_{m}$ and $v_{m+1}$. If $V_{i, j}=\left(v_{m}+v_{m+1}\right) / 2$ and $v_{m+1}=$ $2 v_{m}, 2 / 3$ of the particle volume will fall into the $m$ size bin and $1 / 3$ will fall into the $m+1$ size bin. If $V_{i, j}=v_{m}$, all particle volume will fall into the $m$ size bin as expected.

One distinguishing feature of the semi-implicit method is that it has a multi-component particle formulation that would enable simulation of internally mixed aerosol dynamics (Jacobson 2005). Chemkin-Pro currently supports only a single species in the bulk of the particle, which makes it appropriate for externally mixed aerosol species. Thus, to simulate inter-aerosol coagulation and mixing, the semi-implicit method is needed. 


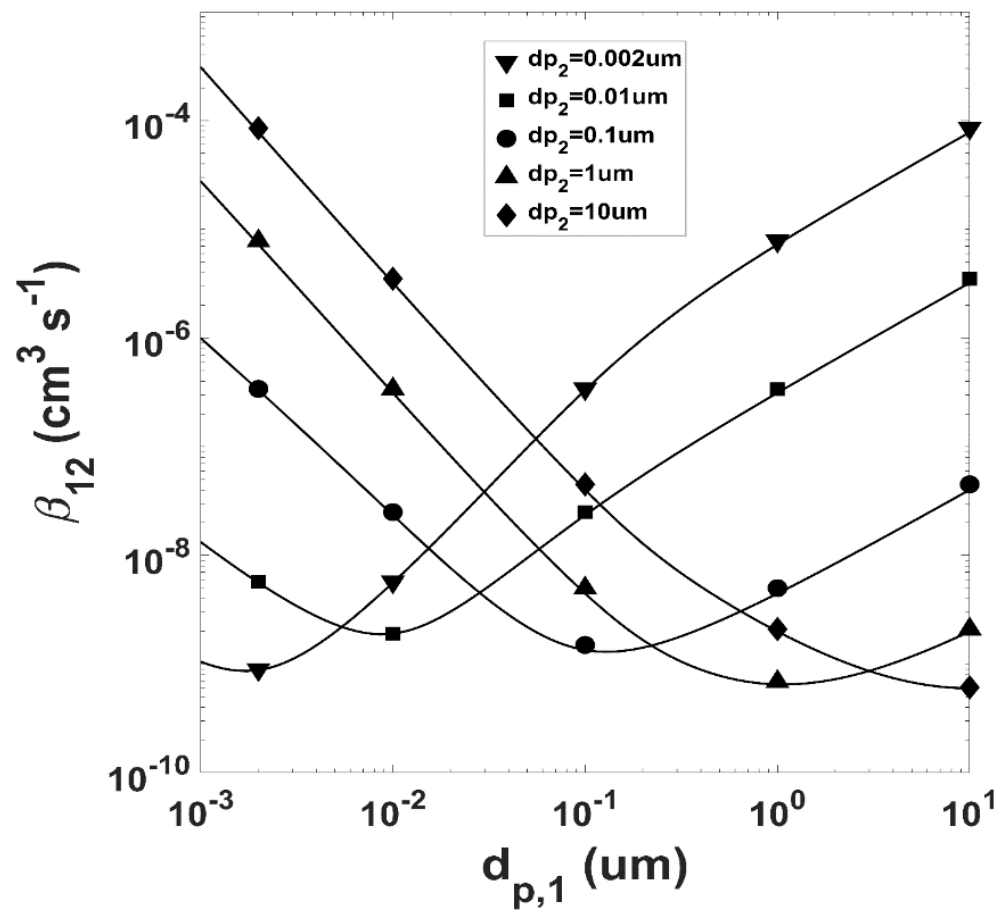

Figure 21. Brownian coagulation coefficients between particles 1 and $2, \beta_{12}$, were calculated in MATLAB and plotted alongside tabulated data (symbols) from Seinfeld and Pandis (1998).

\subsubsection{Verification}

The semi-implicit method of Jacobson and Turco (1995) was coded in MATLAB and verified against an analytical solution to the self-preserving size distribution, which has an initial form of

$$
n_{i}(t)=n_{T}(0) \frac{\Delta v_{i}}{v_{p}} \exp \left(-\frac{v_{i}}{v_{p}}\right)
$$

In Eq. (46), $n_{i}$ is the number concentration in size bin $i, n_{T}$ is the total number concentration, $\Delta v_{i}$ is the volume bin width of section $i, v_{p}$ is the particle volume at which the peak concentration occurs at time zero, and $v_{i}$ is the volume of size bin $i$. The solution to Eq. (46) is given by the following:

$$
n_{i}(t)=\frac{n_{T}(0)\left(\Delta v_{i} / v_{p}\right)}{\left[1+0.5 t \beta_{c} n_{T}(0)\right]^{2}} \exp \left(\frac{-\left(v_{i} / v_{p}\right)}{1+0.5 t \beta_{c} n_{T}(0)}\right)
$$

For this comparison, the constant coagulation kernel, $\beta_{c}$, is required for the analytical solution to be made possible:

$$
\beta_{c}=\frac{8 k_{B} T}{3 \mu}
$$

The results for Eq. (46) - (48) are plotted in Figure 22 for a total simulation time of $12 \mathrm{~h}$, with an initial peak concentration of $1.0 \mathrm{E}+6 \mathrm{~cm}^{-3}$ at a temperature of $298 \mathrm{~K}$. A constant time step of $100 \mathrm{~s}$ was used over the 12-h simulation time, for a total number of 433 time steps. A non-integer spacing factor was used to discretize the particle size distribution. The minimum and maximum particle sizes were model inputs $(0.1 \mathrm{~nm}$ and $1,000 \mathrm{~nm})$ and the particle volume ratio between adjacent bins was calculated based on the number of size bins (also an input). At 64, 128, 256, and 512 size bins, the volume ratios were 1.55, 1.24, 1.11 , and 1.06 , respectively. 
At 64 size bins, simulated aerosol number concentration differed from the analytical solution by one to two orders of magnitude at the large tail of the distribution $(\sim 70 \mathrm{~nm})$. Good agreement was observed and improved with an increasing number of particle size bins. For 128, 256, and 512 particle size bins, the computation times were 9.1, 21.4, and $131.9 \mathrm{~s}$, respectively. All showed acceptable agreement over the distribution when the particle concentration was greater than about 1 particle $\mathrm{cm}^{-3}$. This comparison was used to verify the performance of the MATLAB semi-implicit solution method for solving the coagulation equation.

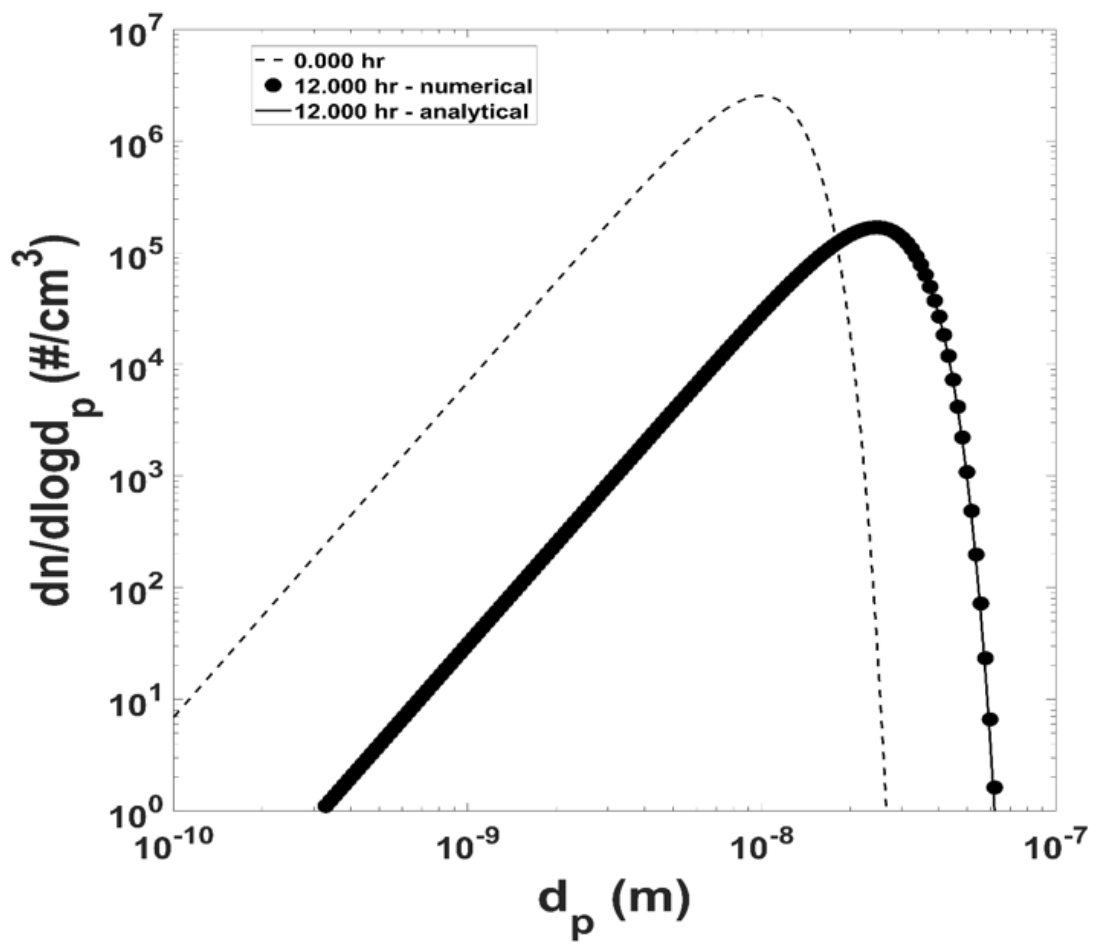

Figure 22. An analytical solution to the coagulation equation was used to verify that the MATLAB implementation of the semi-implicit method of Jacobson (2005) was correct. The initial size distribution is shown, along with the numerical solution (semi-implicit method of Jacobson) and analytical solution at $12 \mathrm{~h}$ simulation time. 


\section{RESULTS AND DISCUSSION}

\subsection{OMEGA EXPERIMENTS}

Omega $\omega$ refers to the molar ratio of $\left[\mathrm{H}_{2} \mathrm{O}\right] /\left[\mathrm{UF}_{6}\right]$ (i.e., $\omega=$ molar ratio of $\left[\mathrm{H}_{2} \mathrm{O}\right] /\left[\mathrm{UF}_{6}\right]$ ). The brackets indicate the concentrations in $\mathrm{mol}^{*} \mathrm{~L}^{-1}$ of water and uranium hexafluoride, respectively. The observed size distributions of the $\mathrm{UO}_{2} \mathrm{~F}_{2}$ particles were produced in experiments controlled by changing the $\omega$ values.

The size distributions observed by the SMPS are averaged and displayed in Figures 23 and 24. The SMPS consists of a TSI Model 3082 electrical classifier equipped with a nano-DMA (TSI Model 3085A), a soft X-ray charge neutralizer (TSI Model 3088), and a Model 3788 nanowater-based CPC. The instrument sheath flow rate was set at 15 LPM while the aerosol sampling flow rate was 1.5 LPM throughout all experiments. Each curve is an average of 27-28 measurements for a given condition. The coefficient of variation (mean over standard deviation) for each curve varied between $\pm 1 \%$ and $20 \%$ depending on the particle size. The total scanning time for each curve was $60 \mathrm{~s}$, which included the up- and down-scan times.

Figure 23 shows the particle size distributions observed for $\omega$ values of 16 and 264, water-rich conditions, which are approximately $5 \%$ and $84 \% \mathrm{RH}$, respectively, at $1 \mathrm{~atm}$ and room temperature. Figure 24 shows

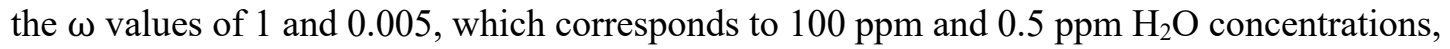
respectively. Figure 24 contrasts results obtained from water-deprived conditions to those in the waterrich ones in Figure 23.

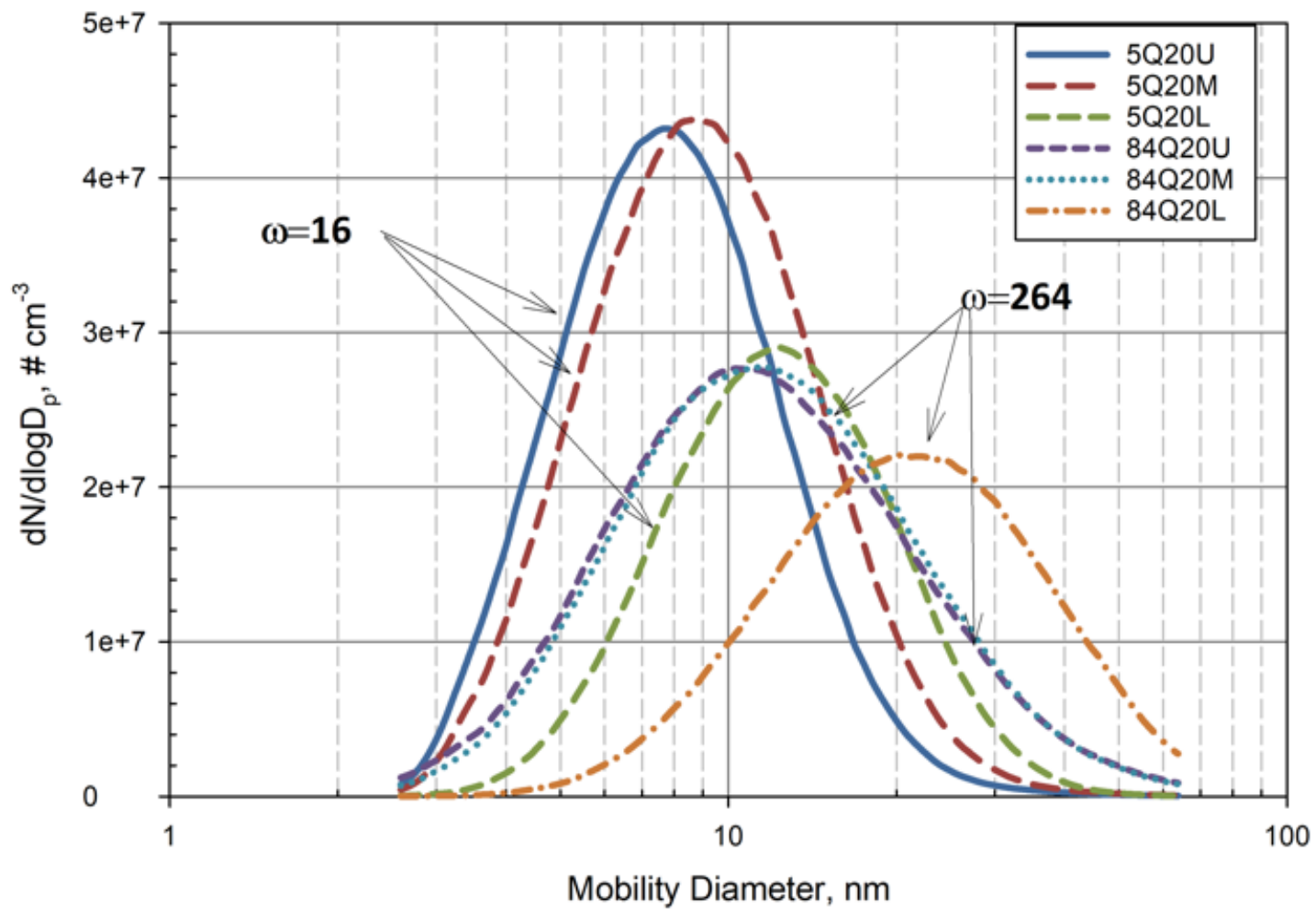

Figure 23. Particle mobility size distributions for large $\boldsymbol{\omega}$ values. The legend $\mathrm{U}, \mathrm{M}$, and $\mathrm{L}$ shows the sampling location where $\mathrm{U}$ is the upper sampling port most close to the point where $\mathrm{UF}_{6}$ and $\mathrm{H}_{2} \mathrm{O}$ were mixed, $\mathrm{M}$ is the middle port, and $\mathrm{L}$ is the port that is farther away from the mixing point. 


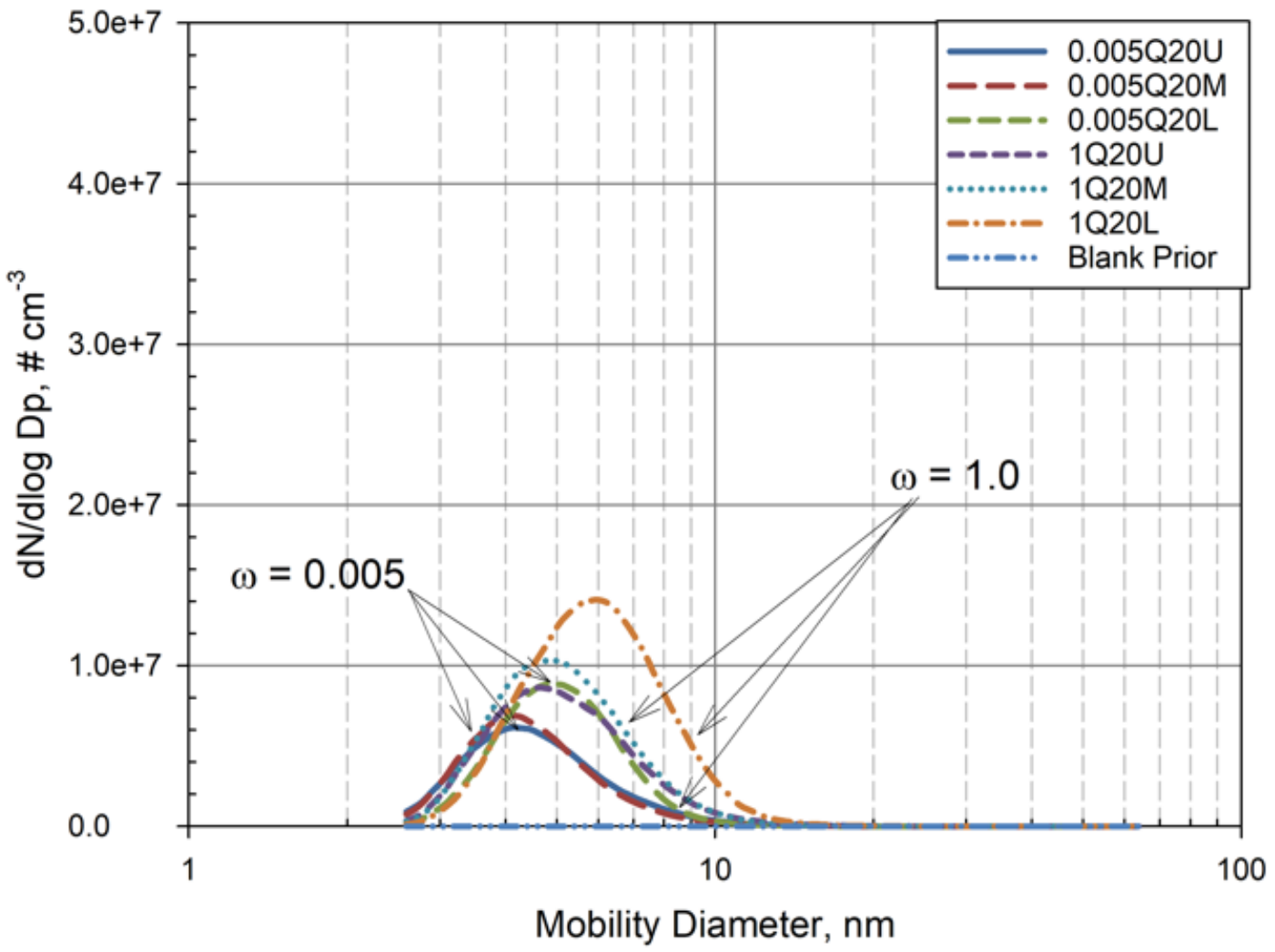

Figure 24. Particle mobility size distribution for small $\omega$ values. Legend "Blank Prior" indicates the blank concentration or background aerosol concentration in the reactor prior to the start of an experiment. The highest value on the $y$-axis is approximately $3 \times$ smaller than that in Figure 23.

As displayed in Figure 23, the $\mathrm{UO}_{2} \mathrm{~F}_{2}$ particles exhibit broad size distributions with the aerosol mobility diameter spanning from 2.5 to $90 \mathrm{~nm}$. The higher the humidity, the larger the size of the particles. For example, a water vapor concentration of $774.410 \mathrm{ppm}$ at $298 \mathrm{~K}$ and $1,013.5 \mathrm{mbar}$ (or $5 \% \mathrm{RH}$ at the given temperature and pressure) has a $\omega$ of value of 16. As shown in Figure 23, the peak size for $\omega=264$ was approximately $12 \mathrm{~nm}$ at the sampling port $U$, whereas that for $\omega=16$ was $8 \mathrm{~nm}$ observed at the same port. The results indicate the influence of water molecules on the size distribution of aerosol produced by the hydrolysis reaction.

As the produced particles traversed down the reactor column, we believe reaction might be continuously occurring between the residual trace $\mathrm{UF}_{6}$ and abundant water molecules. The subsequent reactions possibly involved HF monomers that were produced from the hydrolysis reaction and HF oligomers from the polymerization of the HF monomers causing fog formation (Cheng 2018). These reactions involving $\mathrm{HF}$ monomers and oligomers could occur on the surfaces of formed $\mathrm{UO}_{2} \mathrm{~F}_{2}$ aerosol particles complicating the chemical composition and shape of aerosol particles, according to Hou et al. (2007).

As shown in Figure 23, the peak size of a population curve increased from the port $U$ to $L$ as reflected in the right-shift of the peak size of each distribution. The growth in the distribution from $12 \mathrm{~nm}$ at the sampling port $U$ to $20 \mathrm{~nm}$ at port $\mathrm{L}$ for $\omega=264$ vs. $8 \mathrm{~nm}$ at port $U$ to $12 \mathrm{~nm}$ at port $\mathrm{L}$ for $\omega=16$ was remarkable. The growth rate is discussed in Section 3.2.

One additional observation was the decrease in the peak height of the corresponding curve at the sampling port location $\mathrm{L}$ comparing with that observed at the location $\mathrm{U}$ or $\mathrm{M}$. The relative reduction in peak height from $U$ to $L$ for $\omega=16$ was about $34 \%$, and that for $\omega=264$ was $18 \%$. Also, the availability of water in 
the condition of $\omega=264$ was higher than that in $\omega$ of 16 , which could lead to a greater reduction in the number of $\mathrm{UO}_{2} \mathrm{~F}_{2}$ particles observed at all three ports due to condensation and coalescence processes, which are particle number reduction processes. These high $\omega$ conditions are environmentally relevant, but this is the first time that aerosol particle size distributions have been systematically measured and the aerosol dynamics observed experimentally.

Figure 24 displays the SMPS curves obtained for the experimental conditions where the water molecule concentrations were limited in relation to $\mathrm{UF}_{6}$ (i.e., in the region where the $\omega$ values were less than or equal to 1 ). For example, in the case of $\omega=0.005$, water availability to $\mathrm{UF}_{6}$ molecules was severely limited because the absolute concentration of water molecules in the condition was $503 \mathrm{ppb}$ in relation to $100,000 \mathrm{ppb}$ of $\mathrm{UF}_{6}$ gas molecules. These water-deprived conditions are generally rare in the environment but were studied as part of our systematic investigation.

The range of particle diameter in Figure 24 was several times smaller than that reported in Figure 23. The peak sizes of the SMPS curves in Figure 24 were all less than $10 \mathrm{~nm}$. This is a stark contrast to the curves displayed in Figure 3 where the peak diameter of the particle population grew to sizes larger than $10 \mathrm{~nm}$.

Also, the peak heights in Figure 24 are much smaller than those observed in the larger- $\omega$ conditions, clearly indicating the adverse impacts of water availability on the aerosol formation because the available $\mathrm{UF}_{6}$ concentrations in these experiments were identical.

The peak diameters of all the aerosol populations represented in Figures 23 and 24 shifted toward the larger size as observations were moved from the sampling port $U$ to $L$. This size growth is indictive of a rapid aging effect of the produced aerosol population as it travels down the reactor column from the port $\mathrm{U}$ to $\mathrm{L}$. The growth of the peak diameter for the two small $\omega$ conditions was not as significant as that found in the large $\omega$ conditions. This could be because the amount of water molecules available to coalesce and grow the formed particles was limited in the water-deprived conditions. In fact, the peak diameter growth was merely $1 \mathrm{~nm}$ ranging from 4 at the port $\mathrm{U}$ to $5 \mathrm{~nm}$ at the port $\mathrm{L}$ for $\omega=0.005$ and also about $1 \mathrm{~nm}$ from $5 \mathrm{~nm}$ at the port $\mathrm{U}$ to $6 \mathrm{~nm}$ at port $\mathrm{L}$ for $\omega=1$. Again, this level of growth of $\mathrm{UO}_{2} \mathrm{~F}_{2}$ particles in the aerosol reactor is negligible and could be directly attributed to the result of water molecule shortage in relation to $\mathrm{UF}_{6}$ in the small- $\omega$ conditions.

The population growth pattern from the sampling port $U$ to $L$ in Figure 24 is different from that observed in Figure 23. In the water-deprived region, the number of particles appears to increase as the flow traversed from the port $\mathrm{U}$ to $\mathrm{L}$, as opposed to the decreasing trend shown in Figure 23. We interpreted the decreasing trend in Figure 23 as a result of coalescence and coagulation processes.

However, in the very dry conditions, few water molecules were available for the condensational growth. Because the reaction time constant (in nanoseconds) is much smaller than that of the coalescence (in milliseconds), the number of particles formed by the reaction would conceivably increase at a higher rate than that was reduced by the coalescence in the small $\omega$ conditions. Thus, we observed a reversed trend in the growth of total number concentrations in two very different regimes of $\omega$.

Again, more particles produced in the dry conditions led to the increase of total number concentration; the number increase would also promote coagulation/aggregation processes. The number increase, though small, could contribute to the 1-nm increase in the peak diameter of the population that was detected. However, the chemical composition of the aerosol particles might be significantly distinct in the two dramatically different $\boldsymbol{\omega}$ regimes. This will remain a topic in our future study.

Summarizing the results shown in Figures 23 and 24, we conclude that the formation and growth of aerosol particle size by $\mathrm{UF}_{6}$ hydrolysis in the gas phase strongly depends on the availability of water 
molecules. Furthermore, the total number concentration (i.e., the area under a curve) of the $\mathrm{UO}_{2} \mathrm{~F}_{2}$ particulate material produced is also regulated by the availability of water vapor concentration. The higher the water vapor concentration, the higher number and larger in size of the $\mathrm{UO}_{2} \mathrm{~F}_{2}$ aerosol particles. Controlling the availability of water molecule in the $\mathrm{UF}_{6}$ hydrolysis reaction could lead to the production of a nearly monodispersed aerosol particles. In other words, the coherent result suggests that one can precisely manipulate the size of $\mathrm{UO}_{2} \mathrm{~F}_{2}$ aerosol particles by controlling the water vapor availability and interaction of water molecules with $\mathrm{UF}_{6}$ in the reaction. This finding has significant implications in the engineering manufacturing of fuel powder materials as well as environmental sampling apparatuses.

\subsection{RATE OF PARTICLE FORMATION}

As discussed in Section 3.1, aerosol dynamics were clearly observed in the reactor at the three sampling ports (U, M, and L). Because the average flow transient times (the elapsed time, $\tau$ ) from the reaction center to these three ports were known (= [flow rate/cross-sectional area of the reactor] $/[$ distance between any two points along the reactor length]), we could accurately calculate the $\mathrm{UO}_{2} \mathrm{~F}_{2}$ particle growth rate based on the peak size of a SMPS curve observed (the GMD) at these ports in terms of $\tau$ between these ports. The GMD as a function of $\tau$ for various $\omega$ values are plotted in Figure 25.

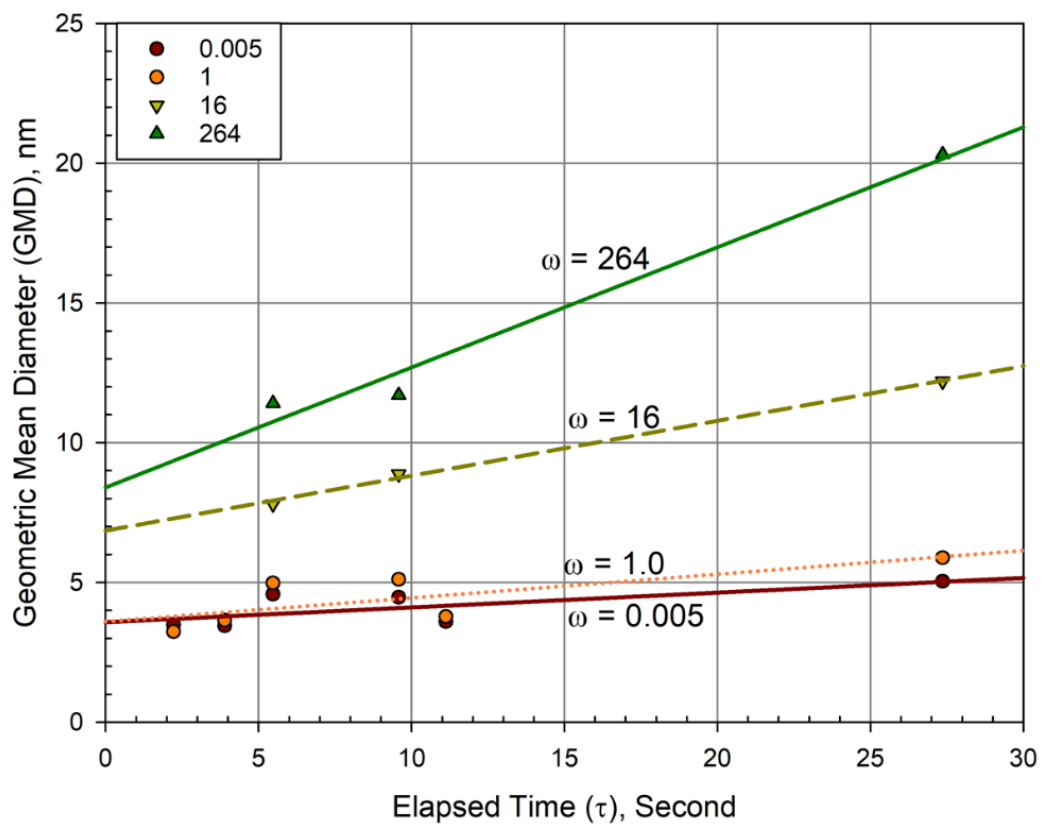

Figure 25. Particle size growth as a function of reactor elapsed time $(\tau)$ and molar ratio $(\omega)$ of a given reaction condition. The GMD of a SMPS curve is defined as the peak size of the particle size distribution curve.

As shown in Figure 25, the growth of aerosol particles in the reactor appears to follow a linear relationship with the reactor elapsed time $(\tau)$ for all $\omega$. The linear relationship holds from the time zero up to the first $30 \mathrm{~s}$ available in the aerosol reactor as shown in the $\mathrm{x}$-axis. The linear relationship appears to converge or overlapping toward the small $\omega$ values. This supports once again that the particle growth is water-limited, a finding concluded in Section 3.1.

The numeric values of derived linear regression results shown in Table 1 provide a clearer quantitative conclusion than that displayed in Figure 25. The relationship between the GMD and $\tau$ for a given $\omega$ is statistically robust as measured by the figure of merit $\mathrm{R}^{2}$ value. Furthermore, the slope of each linear 
regression line represents the particle size growth rate $(\mathrm{nm} / \mathrm{s})$ and the intercept represents the initial size of particles or size of primary particles (nm).

Table 1. Linear regression results of the curves shown in Figure 25.

\begin{tabular}{|c|c|c|c|}
\hline Molar ratio $(\omega)$ & Intercept (nm) & Slope $(\mathbf{n m} / \mathbf{s})$ & $\mathbf{R}^{\mathbf{2}}$ \\
\hline 0.005 & $3.58 \pm 0.34$ & $0.05 \pm 0.03$ & 0.71 \\
\hline 1.0 & $3.60 \pm 0.48$ & $0.08 \pm 0.04$ & 0.76 \\
\hline 16 & $6.85 \pm 0.20$ & $0.20 \pm 0.01$ & 0.99 \\
\hline 264 & $8.40 \pm 1.10$ & $0.43 \pm 0.07$ & 0.99 \\
\hline
\end{tabular}

Note: $\mathrm{R}^{2}$ shows the figure of merit of the linear regression model. The $\mathrm{R}^{2}$ values indicate the linear model fits data reasonably well.

The slope of the regression line increases as the $\omega$ value increased as shown in Table 1. In other words, the particle growth rate is increased when more water molecules are available to accelerate the aerosol dynamics. More interestingly, the growth rates (slopes) appear to approach a single number in the range of $0.05 \pm 0.03-0.08 \pm 0.04 \mathrm{~nm} / \mathrm{s}$, statistically, as the molar ratio becomes small (e.g., $\omega=1$ and 0.005 ). Thus, there is likely a condition in which the particle growth would flatten in the reactor irrespective of the molar ratio. We thus performed an interpolation calculation of the logarithmic data of the molar ratio and found that this condition is likely to be at a $\omega$ of about 1 below which the particle growth rate is strongly restricted to approximately $0.1 \mathrm{~nm} / \mathrm{s}$.

\subsection{SIZE OF PRIMARY PARTICLE}

Previous microscopic studies of $\mathrm{UO}_{2} \mathrm{~F}_{2}$ formation produced many micrographs (Bostick et al. 1983, 1984, Kips et al. 2007, 2009, Pickrell 1982, 1984, 1985). As the $\mathrm{UO}_{2} \mathrm{~F}_{2}$ particles were produced, they were likely to be in a spherical shape at the beginning. Also, as a population, these primary particles are likely to be monodispersed at the time of production. Depending on the reaction condition, availability of water molecules, number of primary particles produced, and other factors (e.g., presence of foreign nuclei and or organic gas species), these primary particles would interact with each other and the additional factors, leading to a branched structure similar to the example shown in Figure 26. Figure 26 is adapted from Bostick et al. (1984) from the $\mathrm{UF}_{6}$ hydrolysis reaction at $2 \% \mathrm{RH}$ condition. We do not know what the condition was in relation to the $\boldsymbol{\omega}$ index value defined by Bostick et al. for comparison.

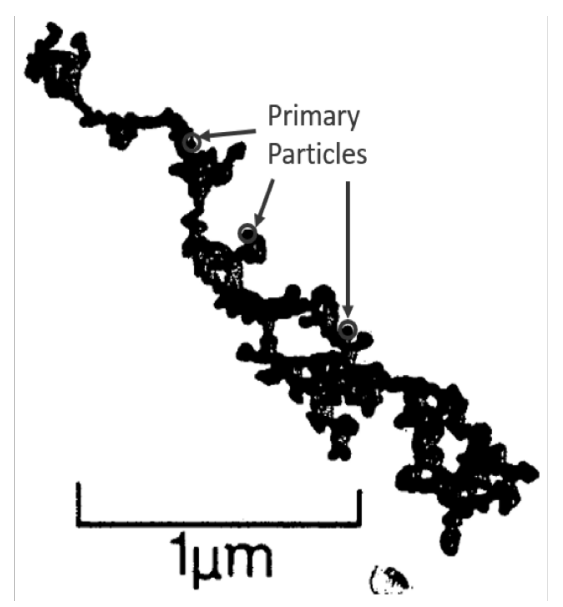

Figure 26. $\mathrm{UO}_{2} \mathrm{~F}_{2}$ particle produced at less than $2 \%$ humidity (adapted from Bostic et al. 1984). 
We used the data reported in the previous sections to estimate the size of primary $\mathrm{UO}_{2} \mathrm{~F}_{2}$ particles by using the linear regression-fit curves shown in Figure 25. If we assigned the elapsed time $\tau$ of $1 \mathrm{~ns}$ (that is, $10^{-9} \mathrm{~s}$ after the hydrolysis reaction started), the data in the Intercept column in Table 1 show the plausible size of the primary particles produced by the hydrolysis reaction. The assumption made here was that the primary particles would form in $1 \mathrm{~ns}$ after the reaction started. This is a weak assumption in our numerical exercise because increasing the $\tau$ value by $1,000,000$-fold to $1 \mathrm{~ms}$ would not change the numerical values of the intercepts shown in Table 1 in any significant extent.

The linear regression model results show that the plausible size of primary particles appears to depend on the molar ratio $\omega$; the higher the molar ratio, the larger the size of primary particles when the $\omega$ is beyond 1.7. At the lower end of the molar ratio when the water availability is limited, the size of primary particles appears to monotonically approach a number of $3.6 \pm 0.4 \mathrm{~nm}$. At the other end of the molar ratio spectrum, as more water molecules become available for aerosol dynamics through coalescence and coagulation processes, the primary particles become larger.

\subsection{MODEL PRIMARY PARTICLES}

Koch and Friedlander (1990) described the coalescence process as a volume diffusion driven reduction in surface area.

$$
\frac{d a}{d t}=-\frac{\left(a-a_{s p h}\right)}{\tau_{f}}
$$

The surface area of the coalescing particle, $a$, is initially that of two equal spherical particles, $a_{0}$. The surface area is driven to that of a perfect sphere, $a_{s p h}$, of equivalent volume over time. The characteristic fusion time, $\tau_{f}$, is dictated by material properties. Lehtinen and Zachariah (2001) noted that Koch and Friedlander's approach had been successfully implemented into many models but under-predicted the primary particle size in certain cases. In the failed cases, the predicted primary particle sizes were approximately a few nanometers while the true primary particle sizes were much larger.

Zachariah et al. (1996) observed elevated particle temperatures, $T_{p}$, during the coalescence process in molecular dynamics simulations. Because coalescence is driven by volume diffusion with an Arrhenius function of temperature, they proposed a correction to the characteristic fusion time to account for the particle temperature dependence. The new definition presented by Lehtinen and Zachariah (2001) is appropriate for both solid- and liquid-state particles.

$$
\tau_{f}\left(T_{p}\right)=\frac{3 k_{B} T_{g} N}{64 \pi \sigma_{p} D\left(T_{p}\right)}
$$

In Eq. (50), $T_{g}$ is the ambient gas temperature, $N$ is the number of atoms per coalescing particle, $\sigma_{p}$ is particle surface tension or surface free energy, and $D$ is the self-diffusion coefficient. The Arrhenius form of the diffusion coefficient is

$$
D\left(T_{p}\right)=D_{o} \exp \left(-\frac{E_{a}}{R T_{p}}\right)
$$

In Eq. (51), $D_{o}$ is the pre-exponential diffusion constant, $E_{a}$ is the activation energy for volume diffusion, and $R$ is the universal gas constant. Particle temperature was calculated by Lehtinen and Zachariah (2001) by performing an energy balance on two coalescing particles. 


$$
\begin{aligned}
\frac{d T_{p}}{d t}= & \frac{\sigma}{2 c_{p} N \tau_{f}}\left(a-a_{s p h}\right) \\
& -\frac{P_{g} c_{g} a_{s p h}}{2 c_{v} N \sqrt{2 \pi m_{g} k T_{g}}}\left(T_{p}-T_{g}\right) \\
& -\frac{\varepsilon \sigma_{S B} a_{s p h}}{2 c_{p} N}\left(T_{p}^{4}-T_{g}^{4}\right)
\end{aligned}
$$

The first term on the right side of Eq. (52) accounts for the surface energy released as surface area is decreased. The second term accounts for heat loss as the particle collides with the ambient air molecules. Here, ambient pressure is denoted by $P_{g}$, and $m_{g}$ is the mass of a gas molecule. The heat capacity of the particle at constant volume is denoted $c_{p}$, and $c_{g}$ is the heat capacity of the ambient gas. The last term accounts for radiative losses to the environment, where $\varepsilon$ is the emissivity, and $\sigma_{S B}$ is the StefanBoltzmann constant $\left(5.67 \mathrm{E}-8 \mathrm{~W} \mathrm{~m}^{2} \mathrm{~K}^{-4}\right.$ ). The radiative term was introduced by Lehtinen and Zachariah (2001). Equations (49)-(52) were combined to define a set of two coupled ODEs that can be solved for transient particle size and particle temperature. Using this approach, Lehtinen and Zachariah modeled similar particle temperatures during the coalescence process as those observed in molecular dynamics simulations.

Lehtinen and Zachariah (2001) improved upon previous works by introducing a simple growth relation from Kruis et al. (1993) to calculate particle temperatures over a series of collisions instead of modeling only a single collision event. The times at which the $n^{\text {th }}$ binary collision occurs, $t_{c o l l_{n}}$, is given by

$$
t_{\text {coll }_{n}}=\frac{\frac{6}{5} 5_{0}^{\frac{5}{6}}\left(n^{\frac{5}{6}}-1\right)}{2.228 \phi} \sqrt{\frac{\rho_{p}}{6 k T}} .
$$

The initial particle volume is denoted as $v_{0}, \rho_{p}$ is the particle density, $k$ is the Boltzmann constant $\left(1.38 \mathrm{E} 23 \mathrm{~J} \mathrm{~K}^{-1}\right)$, and $\phi$ is the particle volume loading (volume of particles divided by volume of gas). All particles are assumed to undergo simultaneous binary collisions; at each collision time, the entire aerosol concentration is halved, particle volume doubles, and particle surface area doubles. The first collision event occurs at time zero. Each subsequent collision is denoted by $n$.

Particle volume is calculated from the particle molecular weight, $M W_{p}$, Avogadro's number, $N_{\text {avg }}$, particle density, and the number of molecules in a coalescing particle.

$$
v_{s p h}=\frac{N \cdot M W_{p}}{N_{\text {avg }} \cdot \rho_{p}} .
$$

Particle diameter is then calculated assuming the coalesced volume is spherical: $v_{p}=(\pi / 6) d_{p}{ }^{3}$.

For the first time step, the initial temperature of the particle, $T_{p, 0}$, was calculated to be that prior to the collision plus the contribution from the energy released due to surface area reduction.

$$
T_{p, 0}=T_{g}+\frac{\sigma\left(a_{0}-a_{s p h}\right)}{2 N c_{v}}
$$

The initial particle surface area was taken as twice the surface area of a monomer, $N=1$ in Eq. (54). The coupled ODEs were then solved in MATLAB between $t_{c o l l, 1}$ and $t_{c o l l, 2}$. Equation (49) shows that the change in surface area is driven by the difference between the actual surface area and the surface area of an equivalent sphere. If the time between collisions is long relative to the characteristic fusion time, the 
surface area will asymptotically approach $a_{0}$. Thus, the normalized excess surface area is used as a convergence criterion to determine if the coagulation event resulted in coalescence.

$$
a^{*}=\frac{a-a_{s p h}}{a_{0}-a_{s p h}}
$$

If $a^{*}<0.05$, the collision was said to have resulted in complete coalescence.

A graphical example of this is shown in Figure 27. First, we provide the material property data used in simulations for $\mathrm{UO}_{2} \mathrm{~F}_{2}$. Where possible, literature values for $\mathrm{UO}_{2} \mathrm{~F}_{2}$ were used. Where no specific $\mathrm{UO}_{2} \mathrm{~F}_{2}$ material property data were available, data for $\mathrm{UO}_{2}$ were used. Material property data and literature references are provided in Table 2.

Table 2. Gas and particle properties used to simulate the evolution of particle size and particle temperature of coagulating and coalescing $\mathrm{UO}_{2} \mathrm{~F}_{2}$ particles.

\begin{tabular}{|c|c|c|}
\hline Model parameter & Symbol & Assumed value \\
\hline Gas pressure & $P_{g}$ & $101,325 \mathrm{~Pa}$ \\
\hline Gas temperature & $T_{g} T_{g}$ & $293.15 \mathrm{~K}$ \\
\hline Gas heat capacity & $c_{g}$ & 4.14E-23 J K ${ }^{-1}$ \\
\hline Particle emissivity & $\varepsilon$ & 1 \\
\hline Gas molecular mass & $\boldsymbol{m}_{g}$ & $4.81 \mathrm{E}-23 \mathrm{~kg}$ \\
\hline Particle surface tension & $\sigma_{p}$ & $1.4 \mathrm{~J} \mathrm{~m}^{-2}$ (Leclaire and Evo 2007) \\
\hline Particle density & $\rho_{p}$ & $6,370 \mathrm{~kg} \mathrm{~m}^{-3}$ (Leclaire and Evo 2007) \\
\hline Particle self-diffusion pre-exponential coefficient & $D_{0}$ & 4.3E-8 $\mathrm{m}^{2} \mathrm{~s}$ (Auskern and Belle 1961) \\
\hline Particle self-diffusion activation energy & $E_{a}$ & $4.86 \mathrm{E}+4 \mathrm{~J} \mathrm{~mol}^{-1}(*)$ \\
\hline Particle heat capacity & $c_{p} c_{p}$ & 4.14E-23 (Mapother et al. 1950) \\
\hline Particle molecular weight & $M W_{p}$ & 0.30802 \\
\hline
\end{tabular}

*The value of $4.86 \mathrm{E}+4$ was determined in this study as described below.

The simulated particle diameter, $d_{p}$, is shown as a function of time in Figure 27. These simulated data were generated from solutions of Eqs. (49)-(55). At approximately 4.0E-6 s, two monomers were assumed to coalesce. The coupled ODEs were then solved for particle size and temperature until the time of the second collision. Each time step was solved separately, in succession, and particle size at the end of the time step was used to determine if particle coalescence had ceased or would continue. A circular symbol is shown in Figure 27 to show the final particle size. 


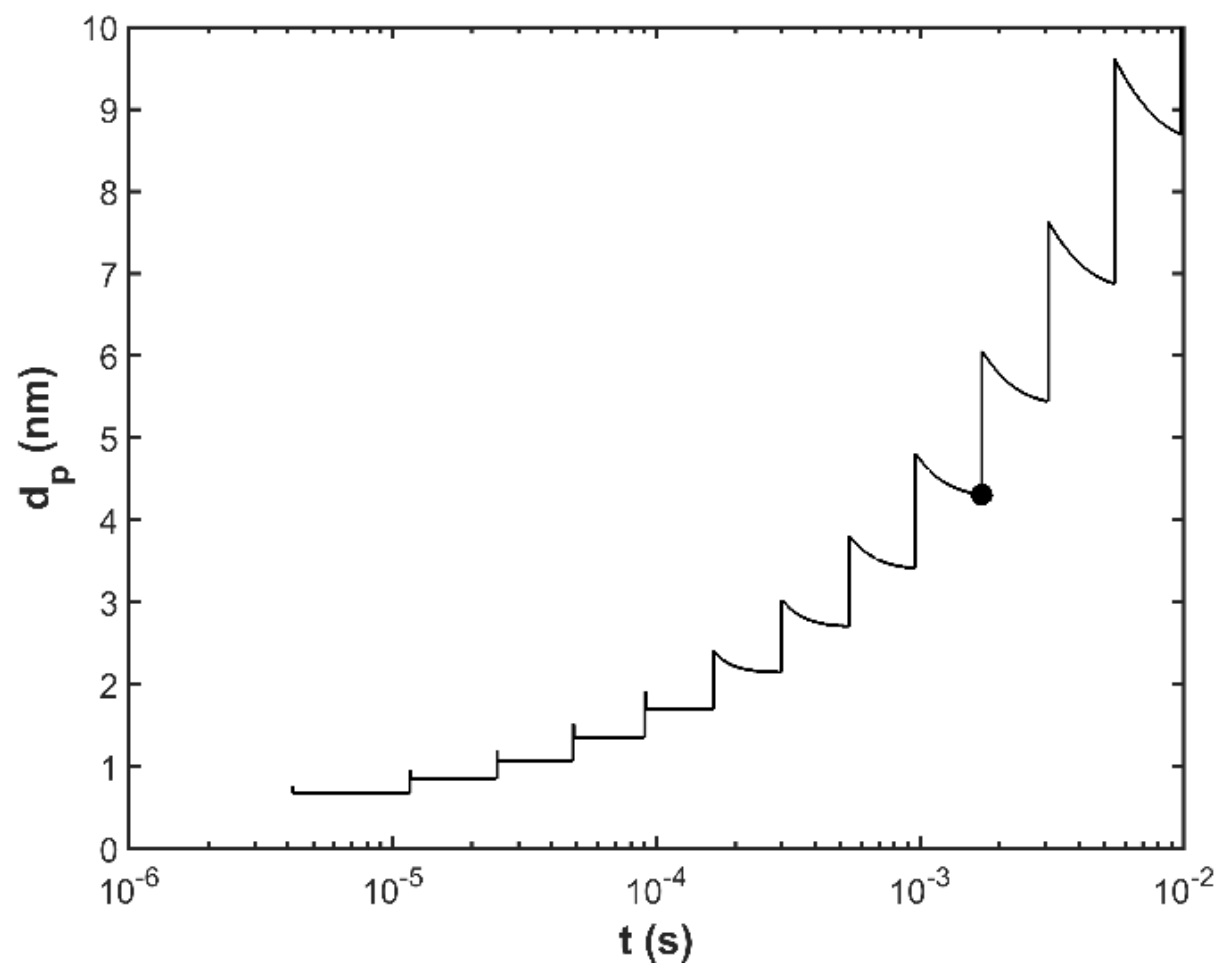

Figure 27. Simulated particle diameter $\left(d_{p}\right)$ as a function of time $(t)$ for coagulation and coalescence at 293.15 K, $1 \mathrm{~atm}$, and $2 E-7 \mathrm{~m}^{3} / \mathrm{m}^{3}$ volume loading. Discontontinuities occur at each collision time under the binary collision approximation; at $t_{\text {coll }}$, the surface area doubles instantaneously as two particles of equal surface area collide. These jumps are seen as vertical lines in the graph. The cessation of particle coalescence is marked with a circular symbol. This is the point at which the normalized excess surface area is less than $95 \%$.

Figure 28 illustrates the process being simulated. The surface area at the end of the last time step is denoted $a_{\text {old }}$. At the time of collision, two particles collide, and the surface area jumps to $2 \times a_{\text {old }}=a_{0}$. This is seen as a vertical jump in the data at the collision time: $9.6 \times 10^{-4} \mathrm{~s}$. The area $a_{0}$ is the initial condition for the ODE solve for surface area as a function of time $a(t)$. The surface area at the end of the time step is denoted $a_{\text {new }}$. The surface area for a completely coalesced particle can be shown to be $a_{s p h}=$ $a_{0} /\left(2^{1 / 3}\right)$. The perfectly coalesced particle surface area, $a_{s p h}$, is also shown. The particle is assumed to be coalesced if the difference between $a_{n e w}$ and $a_{s p h}$ is small relative to the difference between $a_{0}$ and $a_{s p h}$. Here, $a^{*}<0.05$ was taken as coalesced. 


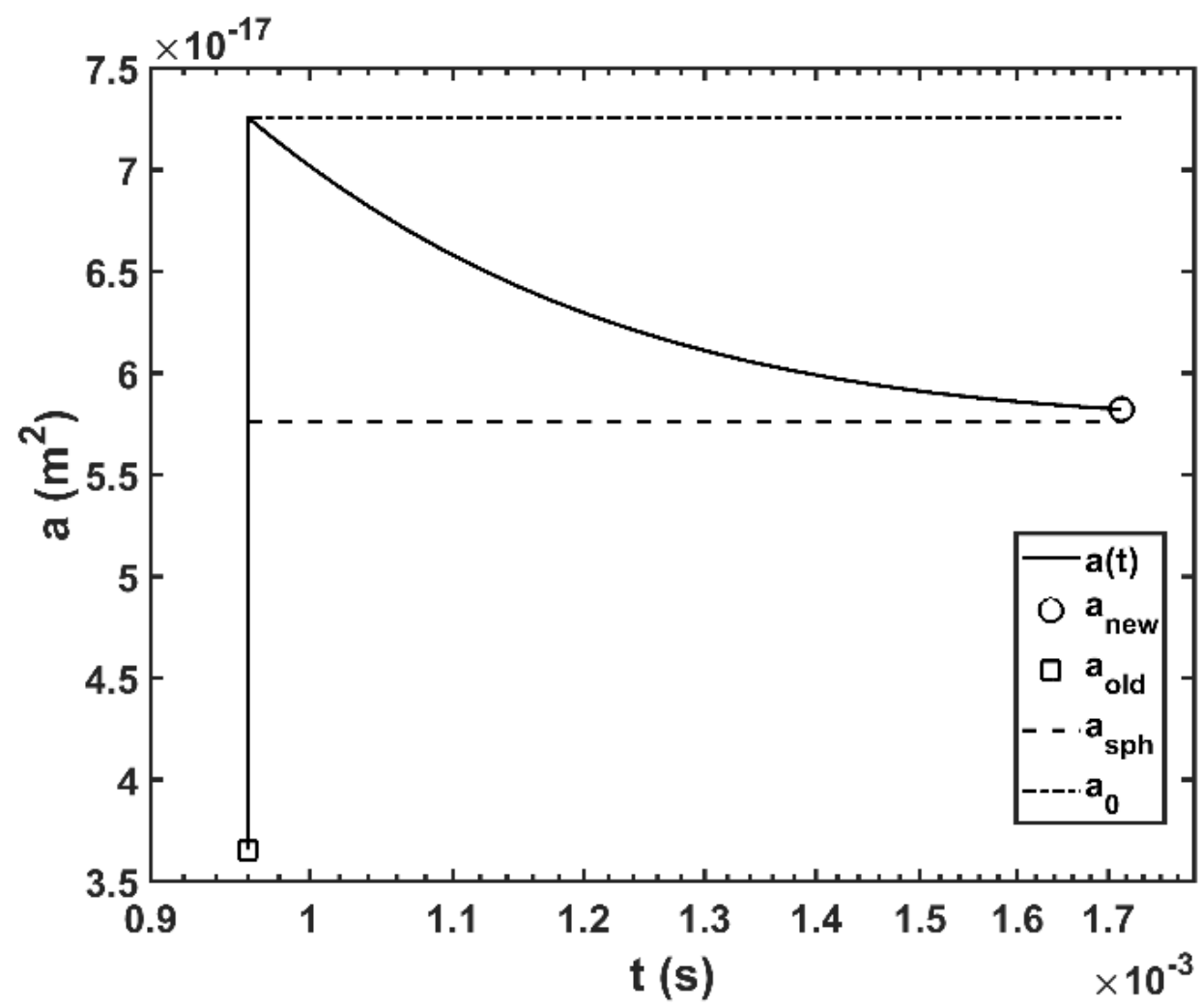

Figure 28. Process description of particle surface area in time: at the end of the previous time step the area is denoted $\boldsymbol{a}_{\text {old }}$. A discontinuous jump in particle surface area occurs at approximately $0.96 \times 10^{-3} \mathrm{~s}$ when two particles of size $\sim 3.6 \times 10^{-17} \mathrm{~m}^{2}$ collide and form a new particle with double the surface area.

Simulated particle temperatures are shown in Figure 29. The temperature spikes are the result of energy added to the particle bulk from the reduction in surface area and associated energy. The temperature quickly drops because of radiative losses and energy losses due to collisions with gas molecules. The effect of the rising temperature enhances coalescence as the self-diffusion coefficient increases with temperature. An expanded view of the second temperature spike is shown in the upper right corner of the figure. 


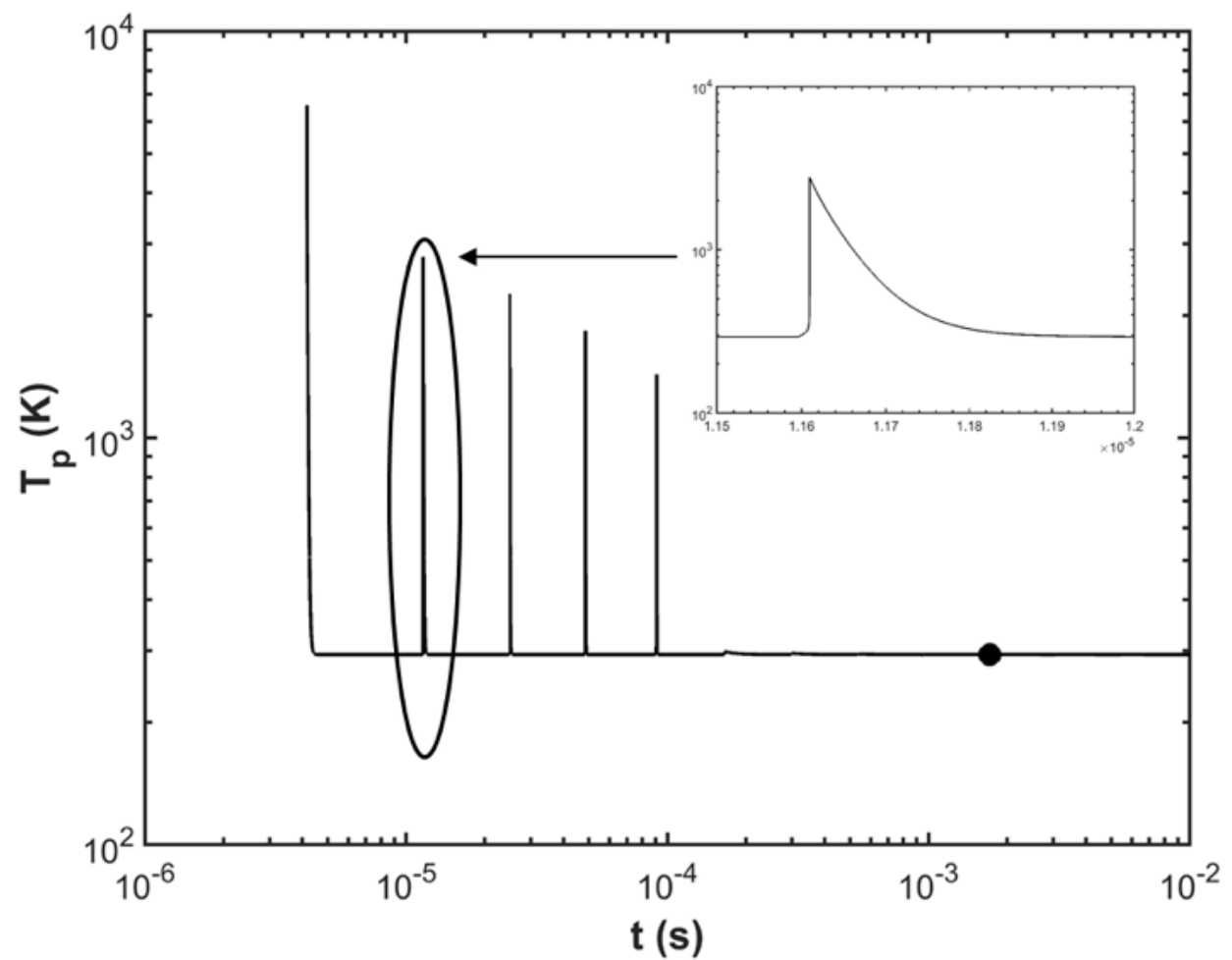

Figure 29. Simulated particle temperature $\left(T_{p}\right)$ vs. time $(t)$ for coagulation and coalescence at $293.15 \mathrm{~K}, 1 \mathrm{~atm}$, and $2 \mathrm{E}-7 \mathrm{~m}^{3} / \mathbf{m}^{3}$ volume loading. The temperature spike near $10^{-5} \mathrm{~s}$ is expanded in the upper right corner of the figure. The cessation of particle coalescence is marked with a circular symbol. This is the point at which the normalized excess surface area is less than $95 \%$.

The primary technical challenge to this modeling effort is the lack of data, and uncertainty in available data, for parameters such as $D_{0}, E_{a}$, and $\sigma$. Initially, $E_{a}$ was taken from Auskern and Belle (1961) as $8.8 \mathrm{E}-4 \mathrm{~J} \mathrm{~mol}^{-1}$. Because of the low volume loading $\left(2 \mathrm{E}-7 \mathrm{~m}^{3} / \mathrm{m}^{3}\right)$, low gas temperature, and high activation energy, no coalescence was observed. At ambient temperature, higher volume loading (on the order of $10^{-3}$ ) would result in coalescence. Because our volume loading and gas temperature were well known, $E_{a}$ was allowed to vary to see if reasonable values would result in primary particle size predictions which agreed with experiments. A plot of primary particle size vs. $E_{a} / R$ is shown in Figure 30. For large $E_{a} / R$, primary particles consist mostly of monomers and dimers. No coalescence was observed since self-diffusion must overcome a high energy barrier. At low $E_{a} / R$, all particles begin to coalesce similar to liquids. This analysis shows that $5,800<E_{a} / R<5,900 \mathrm{~K}$ gives good agreement with experimental data $\left(d_{\text {primary }}=3.6 \mathrm{~nm}\right)$. 


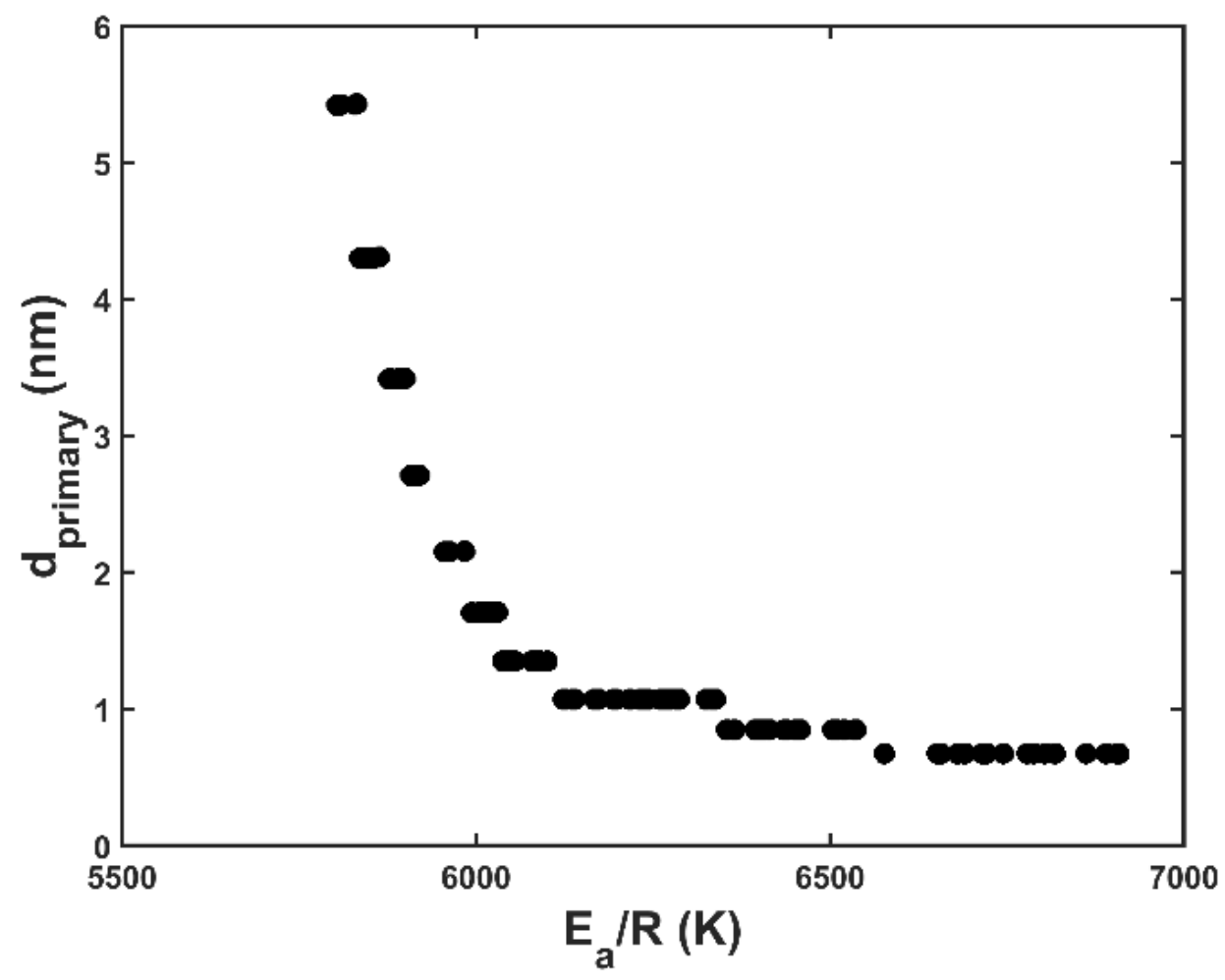

Figure 30. Primary particle size ( $d_{\text {primary }}$ ) plotted agaist the ratio of the self-diffusion activation energy to the ideal gas constant $\left(\boldsymbol{E}_{a} / \boldsymbol{R}\right)$. A value of $5,800<E_{a} / R<5,900 \mathrm{~K}$ results in a simulated primary particle size of approximately 3.4 to $4.3 \mathrm{~nm}$.

The self-diffusion coefficient was calculated at a temperature of $1,273 \mathrm{~K}$ to determine if $5,850 \mathrm{~J} \mathrm{~mol}^{-1}$ (derived from Figure 29) resulted in reasonable values. The choice of 1,273 K was somewhat arbitrary but consistent with other works (Auskern and Belle 1961, Mapother et al. 1950). Results are shown in Figure 31 . A self-diffusion coefficient of approximately $4 \mathrm{E}-10 \mathrm{~m}^{2} / \mathrm{s}$ gives a predicted primary particle diameter in the 3 to $4 \mathrm{~nm}$ range. The self-diffusion constant for $\mathrm{SiO}_{2}$ is on the order of $1 \mathrm{E}-9 \mathrm{~m}^{2} / \mathrm{s}$ (Zachariah and Carrier 1999, Auskern and Belle 1961) and $1 \mathrm{E}-9 \mathrm{~m}^{2} / \mathrm{s}$ for $\mathrm{NaCl}$ (Mapother et al. 1950). The values derived from Auskern and Belle (1961) give a self-diffusion constant much lower for uranyl ion diffusion in $\mathrm{UO}_{2}\left(1 \mathrm{E}-21 \mathrm{~m}^{2} / \mathrm{s}\right)$. Values for the anion and cation often vary considerably where the lattice structure is one parameter affecting diffusivity values. Based on data for $\mathrm{NaCl}$ and $\mathrm{SiO}_{2}$, the value derived here for $\mathrm{UO}_{2} \mathrm{~F}_{2}$ aerosol particles seems reasonable. This also leaves room for model improvement (i.e., experimental determination of the self-diffusion value of the $\mathrm{UO}_{2} \mathrm{~F}_{2}$ aerosol particles as temperature and particle composition varies). 


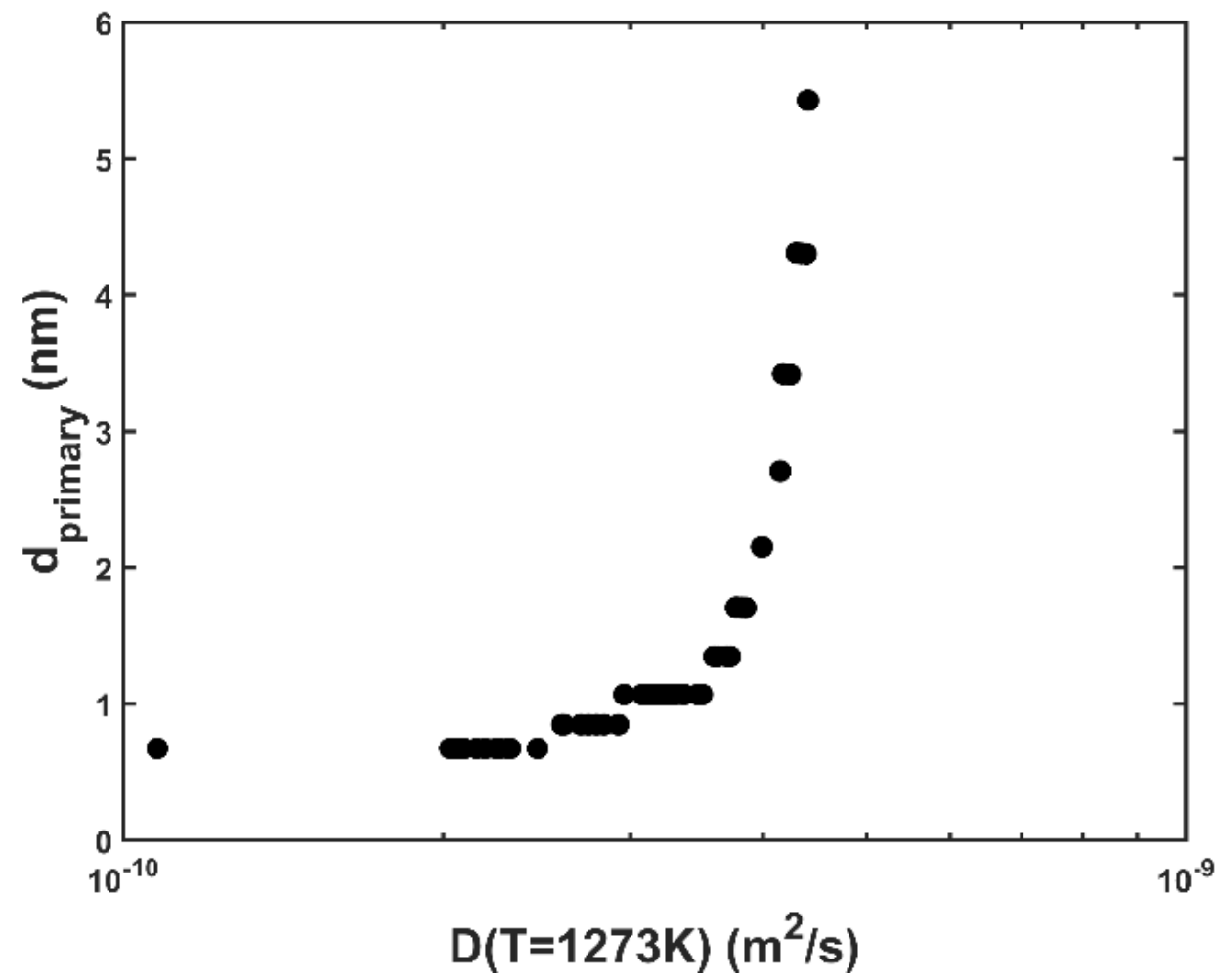

Figure 31. Primary particle size $\left(d_{\text {primary }}\right)$ plotted agaist the self-diffusion coefficient ( $D$; taken at 1,273 K). A self-diffusion coefficient around $D=4 \mathrm{E}-10 \mathrm{~m}^{2} / \mathrm{s}$ results in a primary particle size ranging from 3.4 to $4.3 \mathrm{~nm}$.

This model is based on the simplifying assumption of binary collisions: at any given point in time there exists only one particle size and all particles of that size collide with a counterpart at the exact same time. We recognize that systems of interest are polydisperse (that is, there exists a distribution of particle sizes that collide at different rates and times depending on their sizes). We also acknowledge that multi-body coalescence may occur for non-coalesced particles that contain more than two sub-particles. Any model that includes the aforementioned effects would likely be less granular than the current model. More work is needed to determine how a model that includes polydispersity and multi-body effects would differ from the model presented here.

\subsection{VERIFICATION OF AEROSOL DYNAMICS MODEL SIMULATION}

Once the semi-implicit formulation was verified against an analytical solution, the semi-implicit method was compared with results from Chemkin-Pro. Complete coalescence was assumed. When two particles come into contact, they merge and form a sphere of equivalent volume. Chemkin-Pro has the option of transitioning from coalescence to fractal aggregation. For this study, the aggregation feature was not enabled since this semi-implicit formulation does not allow for tracking particle size and volume of fractal aggregates. Initial input conditions were as follows: gas pressure of $1 \mathrm{~atm}$, gas temperature of $293 \mathrm{~K}$, reactor volume of $1 \mathrm{~cm}^{3}, 128$ particle size bins (number of sections), initial particle number density in the first size bin of 1E21 particles $\mathrm{cm}^{-3}$, section spacing factor of 1.241, particle diameter in first size bin of $0.54 \mathrm{~nm}$, and the transition coagulation regime.

Figure 32 shows the particle number concentration in particles $\mathrm{m}^{-3}$ at time zero and $1 \mathrm{E}-11,1 \mathrm{E}-10$, and $1 \mathrm{E}-9 \mathrm{~s}$. Initially, all particles were in the monomer bin (bin one). At $1 \mathrm{E}-11 \mathrm{~s}$, peaks existed at integer combinations of 2 monomers, 3 monomers, etc. However, the bin spacing was resolved beyond integer combinations. By 1E-9 s, the peak diameter was close to $3 \mathrm{~nm}$. Figure 33 shows particle number 
concentrations at later times near 1E-8, 1E-7, 1E-6, and 1E-5 s. By 1E-5 s, the peak particle diameter was close to $100 \mathrm{~nm}$. Small differences in number concentration were observed between the semi-implicit method and Chemkin-Pro. However, these differences were expected since different bin fractionation schemes are likely to distribute the volume of particles amongst adjacent bins with some variability. Overall, agreement was good. As previously stated, modeling the formation of an internally mixed aerosol would require the use of the semi-implicit method. Chemkin-Pro can currently be capable of modeling externally mixed aerosols and the transition from coalescence to fractal aggregation. Thus, both methods were shown here because they each have distinct advantages and disadvantages, and they verify the performance of the other.
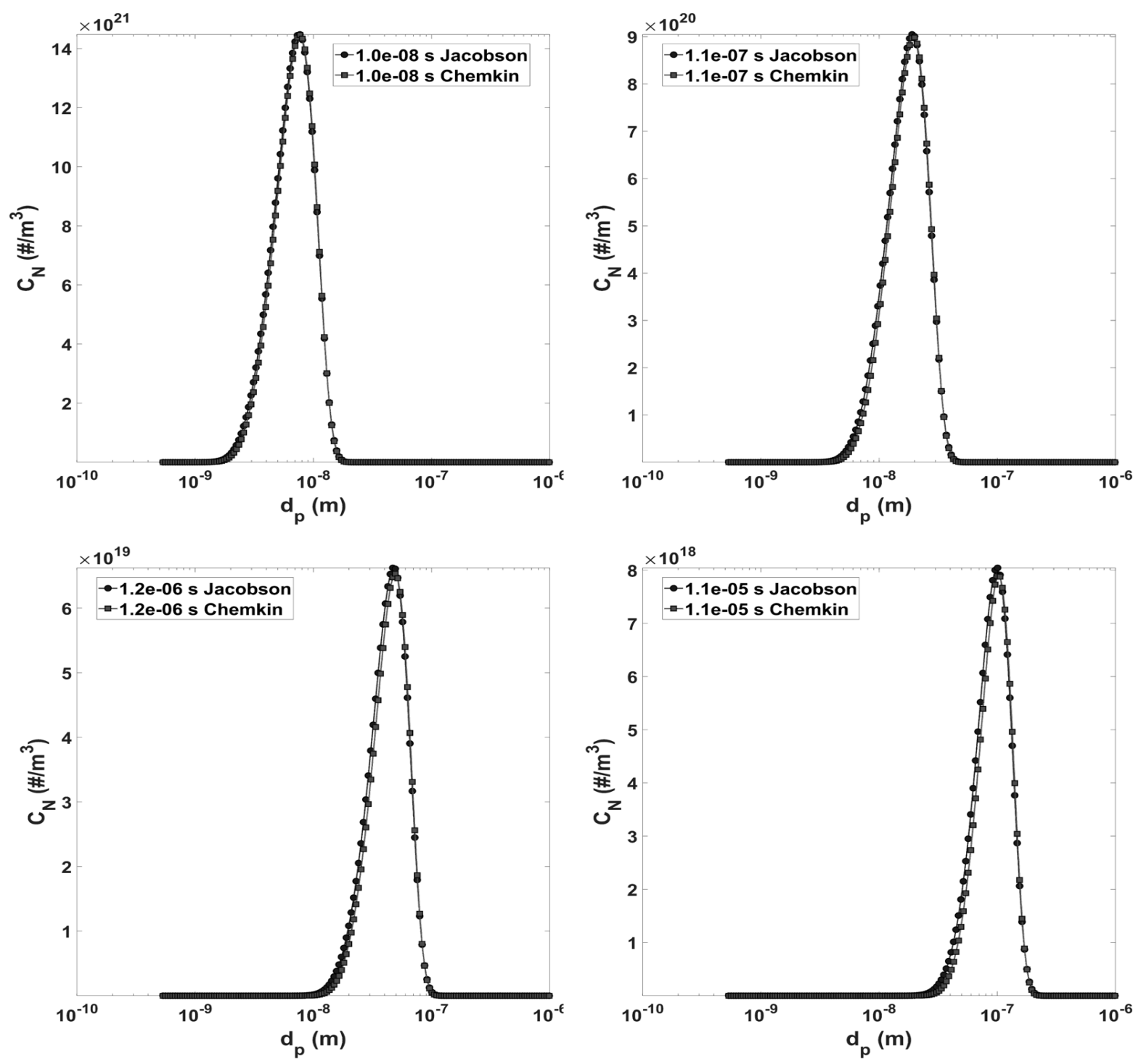

Figure 32. Particle number concentration plotted at various time steps showing the evolution of particle size. The initial distribution had all particles in the first size bin (i.e., monomers). Chemkin-Pro was used to solve for coagulation and coalescence with the transition kernel. The methods outlined by Jacobson were coded in MATLAB and compared with Chemkin-Pro for model verification. 

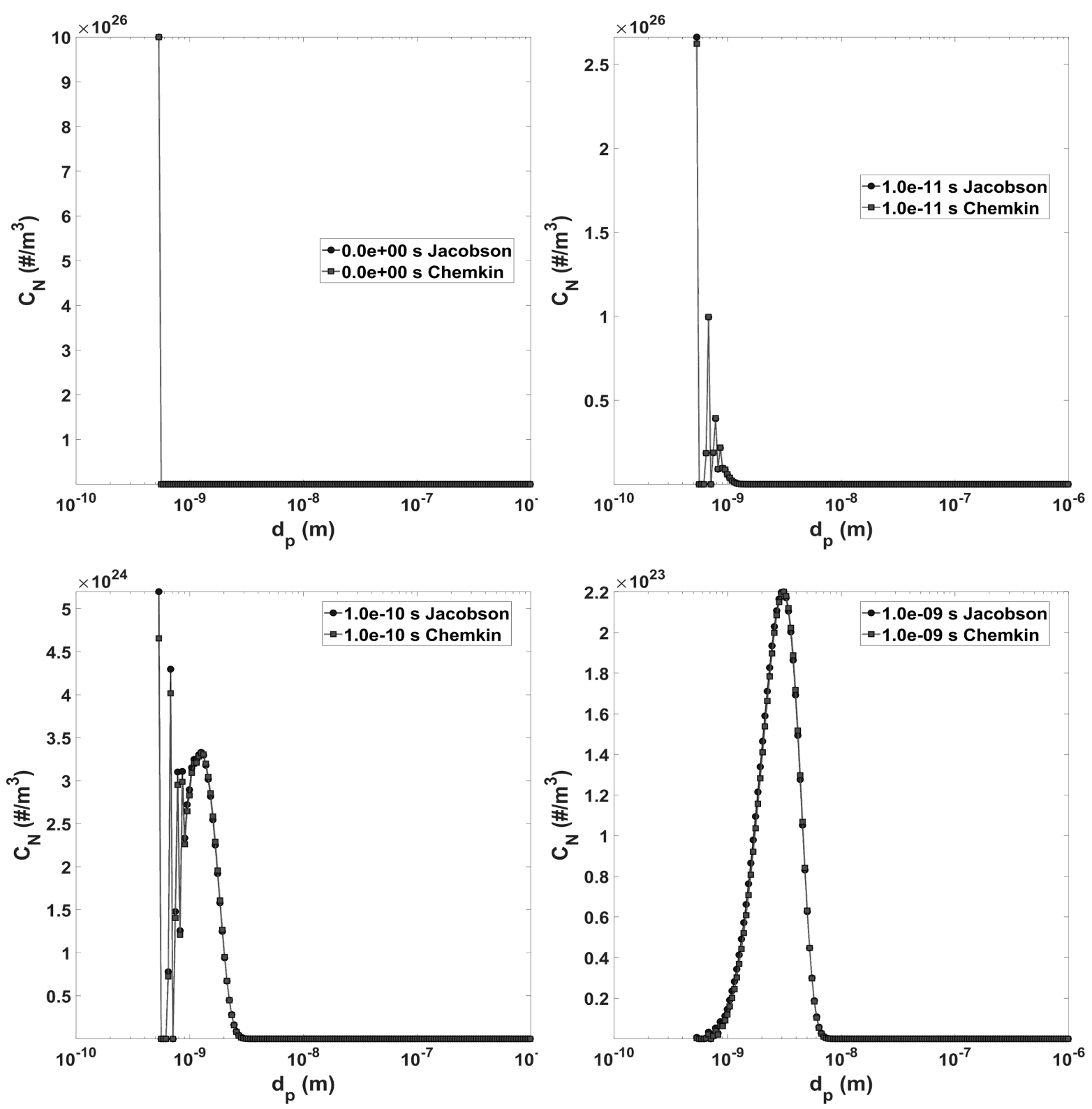

Figure 33. Particle number concentration plotted at various time steps showing the evolution of particle size. The initial distribution had all particles in the first size bin (i.e., monomers). Chemkin-Pro was used to solve for coagulation and coalescence with the transition kernel. The methods outlined by Jacobson were coded in MATLAB and compared with Chemkin-Pro for model verification. 


\section{CONCLUSIONS}

New particle formation is a grand challenge for aerosol scientists in the twenty-first century.

“.... the need to develop a viable understanding of particle nucleation and growth, spanning the transition from molecules, to clusters, to stable condensed-phase materials. This growth transition is made very complex by the fact that the physical and chemical properties of the evolving entities are changing with size. A fundamental understanding of the growth transition would be the backbone on which to support the advancement of many related applications, namely air pollution chemistry, cloud formation, species transport and diffusion, particle formation, human health related toxicology and materials synthesis. As alluded to in the paragraph above, there is a significant need at the fundamental level to develop a viable understanding of the evolution of physical and chemical properties of particles in the transition from the atomic/molecular to "bulk" particle scales. New sciences lie in this intermediate realm ...." - Sorensen et al. 2019

This research project explored the fundamental process of $\mathrm{UO}_{2} \mathrm{~F}_{2}$ particle formation in gas-phase hydrolysis reaction, a key process in nuclear fuel production and material synthesis using $\mathrm{UF}_{6}$ as the key ingredient. The project was possible because of the advances of modern aerosol science and technology and availability of high-power computing platform in the past two decades.

The aerosol physics of uranyl particle formation has been addressed successfully in this research. Based on the research works, we conclude that the formation and growth of aerosol particles by gas-phase $\mathrm{UF}_{6}$ hydrolysis is strongly dependent on the availability of water molecules in our reactor conditions. The total number concentration of the $\mathrm{UO}_{2} \mathrm{~F}_{2}$ particulate material that could be produced in the hydrolysis reaction is also regulated primarily by the availability of water molecule concentration. The higher the water molecule concentration, the higher number and larger the $\mathrm{UO}_{2} \mathrm{~F}_{2}$ aerosol particles that could be produced in the reactor. Although the aerosol reactor enabled the study of particle formation kinetics, the instrumentation was still insufficient in characterization of the chemical composition of the produced particles as well as the time-dependent evolution of the particulate species. The temporal evolution could impact the eventual fate of the particles upon release to the environment (i.e., the physio-chemical transformation, transport, and removal).

In terms of new uranyl particle formation kinetics, we found that the growth rates of aerosol particles appear to approach a single number in the range of $0.05 \pm 0.03-0.08 \pm 0.04 \mathrm{~nm} / \mathrm{s}$, statistically, as the $\omega$ value becomes smaller than 1 . The size of primary particles from the $U_{6}$ hydrolysis at a water-deprived condition was estimated to be $3.6 \pm 0.4 \mathrm{~nm}$. The higher the availability of water molecules, the larger the primary particles. The ability to precisely control the availability of water molecules in the reaction could lead to the production of nearly monodispersed aerosol particles. In other words, the result suggests that one can precisely manipulate the size of $\mathrm{UO}_{2} \mathrm{~F}_{2}$ aerosol particles by controlling the water vapor availability and interaction of water molecules with $\mathrm{UF}_{6}$ in the reaction. This finding has significant implications in the engineering manufacturing of fuel powder materials and possibly to future development and deployment of environmental sampling apparatuses.

Computational methods that we developed can be applied broadly to industrial processes such as particulate material production, as well as improve current reactive flow dynamics modeling tools. To add enhanced aerosol dynamics into Chemkin-Pro (ANSYS, Inc.), surface-kinetics user routines were implemented. MATLAB tools were developed for simulating homogeneous nucleation, condensation and evaporation, and coagulation and coalescence. Homogeneous nucleation from super-saturated vapor was implemented in the surface-kinetics user routine. CNT (Wyslouzil and Wolk 2016) and a modified theory published by Dillmann and Meier (1991) were programmed into Chemkin-Pro and compared with 
nucleation rate data published for water (Miller et al. 1983, Viisanen et al. 1993). As reported in other works, CNT differed from experimental data by one to two orders of magnitude. The modified theory of Dillmann and Meier showed good agreement with published data. Size-dependent surface reaction rates were also implemented in Chemkin-Pro. Surface condensation was implemented in the surface-kinetics user routine following the condensation rate formulation published by Hinds (1999). Separately, the same formulation was implemented in MATLAB and used to verify the performance of the Chemkin-Pro user routine for condensation and evaporation to and from water droplets. This demonstrates the newly implemented surface-kinetic rate dependence on particle size.

Finally, aerosol coagulation in Chemkin-Pro was verified against a semi-implicit coagulation formulation used in atmospheric aerosol modeling (Jacobson et al. 1994, Jacobson 1999). The semi-implicit method was programmed in MATLAB and verified using analytical solutions to simplified forms of the coagulation equation. Results from Chemkin-Pro were then compared to the semi-implicit method for the transition coagulation regime with complete coalescence where the initial distribution was composed entirely of monomers. In the current state, Chemkin-Pro is capable of modeling externally mixed aerosols, while the semi-implicit solution technique has already been extended to simulate internally mixed aerosols by Jacobson et al. (1994).

Using a reasonable value for the activation energy of self-diffusion, we also computationally verified the primary particle size and predicted a size range for the $\mathrm{UO}_{2} \mathrm{~F}_{2}$ primary particles comparable to that estimated from experiments (Cheng et al. 2020). The results strongly suggest that the volume-driven coalescence process assumption used in the derivation of the primary particle model was reasonable. Questions remain as to the chemical pathways and energetics of the nucleation process leading to the formation of the primary particles. 


\section{RECOMMENDATIONS FOR FUTURE STUDY}

We have advanced our understanding of uranyl aerosol formation physics under various conditions that included water vapor concentration range in ppb by volume to ppmv in an aerosol reactor. Given $\omega$ as the molar ratio of $\mathrm{H}_{2} \mathrm{O}$ to $\mathrm{UF}_{6}$, the high- $\omega$ conditions (e.g., water vapor content at $84 \% \mathrm{RH}$ in room temperature and $\mathrm{UF}_{6}$ of $100 \mathrm{ppmv}$ ) produced populations of $\mathrm{UO}_{2} \mathrm{~F}_{2}$ particles of broader size distributions that are associated with complicated morphologies (and larger fractal dimensions).

With advanced aerosol instrumentation available and employed in the uranium particle formation project, we probed the uranyl particle formation physics in near real time online. In the high $\omega$ conditions, we observed the formation of particles as they were produced in the gas-phase reaction and also followed the particle growth through coagulation in the flow-through aerosol reactor online in real time. These results were unachievable in the past because of a lack of suitable aerosol instruments. We analyzed data for particle growth and formation rates and found that they were proportional to $\omega$ and the aerosol reactor elapsed time $(\tau)$ (Cheng et al. 2020). The results provided a means to quantitively predict the size and size distribution of the uranyl particles at any given $\omega$ and $\tau$, which can be used to design a scale-up pilot plant to theoretically make much high-quality nuclear fuel powder. The same results can also be useful for design of a new particle sampler for a specific environmental condition at any standoff time and possibly distance.

We also discovered that the nanoscale uranyl particles produced exhibited a uniform size (called a monodispersed size distribution) when $\omega \ll 1$, which was water-deprived or in very dry conditions. The results are a distinct contrast to those obtained at the conditions, where $\omega>1$. Of course, such a dry condition was not known to be used in the past, but it can be in the future for special nuclear security applications. Our new results require further investigation and validation. However, we postulate that the ability to make a monodisperse particle size distribution could lead to a new approach in nuclear powder material production. Again, this discovery suggests that a new reactor operation that can produce precision particulate nuclear powder materials at the nanoscale and micron scale could be built in the future that can scale-up production of nuclear fuel powders of precise particle size, size distribution, and morphology.

The quantitative data obtained to date have enabled us to correlate the reaction conditions with the physical properties that produced $\mathrm{UO}_{2} \mathrm{~F}_{2}$ particles, which could provide information to enhance the tracing capability on the origin of $\mathrm{UF}_{6}$ release if used accordingly. Questions remain for future research:

1. What is the chemical composition of the produced uranyl aerosol particles at a given reaction condition?

Significance: This directly addresses the unknowns lingering for more than three decades in the scientific communities regarding how uranyl particles are formed in $\mathrm{UF}_{6}$ hydrolysis reaction.

2. How does the chemical composition vary as a function of $\omega$ and $\tau$ ?

Significance: The answer provides critical data needed to predict the quality of aerosol powder material in the gas-phase synthesis. In addition to the precision control of particle size, size distribution, and morphology, we will now have the ability to tune chemical composition to the right reaction condition and harvest at the right reactor time.

3. Is uranyl particle morphology unique to the chemical composition of particles at a given reaction condition?

Significance: The answer provides a quality confirmation to aerosol measurements and rightfully links the particulate signature to morphology data in addition to aerosol chemical composition and formation process, potentially amplifying the resolution of source identification and attribution. 


\section{REFERENCES}

Ahktar, M. K., Vemury, S., and Pratsinis, S. E., 1994, Am. Inst. Chem. Eng. J., 40(7), 1183-1192.

Ahktar, M. K., Xiong, Y., and Pratsinis, S. E., 1991, Am. Inst. Chem. Eng. J., 37(10), 1561-1570.

Anderson, J. C., Kerr, C. P., and Williams, W. R., 1994, Correlation of the Thermophysical Properties of UF6 over a Wide Range of Temperature and Pressure, ORNL/ENG/TM-51, Oak Ridge National Laboratory.

Auskern, A. B., and Belle, J., 1961, J. Nuclear Mater., 3, 311-319.

Bostick, W. D., McCulla, W. H., and Pickrell, P. W., 1984, Sampling, characterization, and remote sensing of aerosols formed in the atmospheric hydrolysis of uranium hexafluoride, K/PS-5042, Oak Ridge Gaseous Diffusion Plant.

Bostick, W. D., McCulla, W. H., Pickrell, P. W., and Branam, D. A., 1983, Sampling and characterization of aerosols formed in the atmospheric hydrolysis of UF6, K/PS-5027, Oak Ridge Gaseous Diffusion Plant.

Brock, J. R., and Oates, J., 1987, J. Aerosol Sci., 18(1), 59-64.

Chen, D.-R., Pui, D. Y. H., Mulholland, G. W., and Fernandez, M., 1999, J. Aerosol Sci., 30, 983-999.

Cheng, M. D., Ford, E. A., DePaoli, D. W., Kenik, E. A., and Angelini, P., 2007, Ind. Eng. Chem. Res., 46(19), 6269-6272.

Cheng, M. D., J Atmos. Chem., 2018, 75, 1-16.

Cheng, M. D., Richards, J. M., Omana, M. A., Hubbard, J. A., and Fugate, G. A., 2020, Reaction Chem. Engr., 5, 1708-1718.

Chou, C., Hodgson, D., Petrova, M., and Meeks, E., 2007, Proceedings of the 5th US Combustion Meeting, San Diego, CA, Mar. 25, 1-25.

Coltrin, M. E., Kee, R. J., and Rupley, F. M., 1991, Int. J. Chem. Kinet., 23(12), 1111-1128.

Coltrin, M. E., Meeks, E., Grcar, J. F., Houf, W. G., Kee, R. J., and Creighton, J. R., 1998, Mater. Res. Soc. Symp. Proc., 490 (Symposium Q - Semiconductor Process \& Device Performance Modeling), 143-154.

Creighton, J. R., Coltrin, M. E., and Figiel, J. J., 2008, Appl. Phys. Lett., 93(17), 171906.

Dillmann, A., and Meier, G. E. A., 1991, J. Chem. Phys., 94(5), 3872-3884.

Frenklach, M., and Harris, S. J., 1987, J. Colloid Interface Sci., 118(1), 252-261.

Gelbard, F., and Seinfeld, J. H., 1979, J. Colloid Interface Sci., 68(2), 363-382.

Gelbard, F., and Seinfeld, J. H., 1980, J. Colloid Interface Sci., 78(2), 485-501.

Gelbard, F., Tambour, Y., and Seinfeld, J. H., 1980, J. Colloid Interface Sci., 76(2), 541-556.

Giannissi, S. G., Venetsanos, A. G., Markatos, N., and Bartzis, J. G., 2013, J. Loss Prevention in the Process Industries, 26, 245-254.

Hanna, S. R., Strimaitis, D. G., and Chang, J. C., 1991, J. Hazardous Mater., 26, 127-158.

Hinds, W. C., 1999, Aerosol Technology: Properties, Behavior, and Measurement of Airborne Particles, Wiley, New York. 
Hou, R., Mahmud, T., Prodromidis, N., Roberts, K. J., Williams, R. A., Goddard, D. T., and Semeraz, T., 2007, Ind. Eng. Chem. Res., 46, 2020-033.

Hu, S.-W., Lin, H., Wang, X.-Y., and Chu, T.-W., 2014, J. Molecular Struct., 1062, 29-34.

Hu, S.-W., Wang, X.-Y., Chu, T.-W., and Liu, X.-Q., 2008, J. Phys. Chem., 112, 8877-8883.

Hu, S.-W., Wang, X.-Y., Chu, T.-W., and Liu, X.-Q., 2009, J. Phys. Chem., 113, 9243-9248.

Hubbard, J. A., Omana, M. A., and Cheng, M.-D., 2019, J. Thermal Sci. Engr. Appl., 12, 041007-1-14

Jacobson, M. Z., 1999, Fundamentals of Atmospheric Modeling, Cambridge University Press, New York, NY.

Jacobson, M. Z., 2005, Fundamentals of Atmospheric Modeling, Cambridge University Press, Cambridge, New York.

Jacobson, M. Z., and Turco, R. P., 1995, Aerosol Sci. Technol., 22(1), 73-92.

Jacobson, M. Z., Turco, R. P., Jensen, E. J., and Toon, O. B., 1994, Atmos. Environ., 28(7), 1327-1338.

Kangasluoma, J., Ahonen, L., Attoui, M., Vuollekoski, H., Kulmala, M. \& Petäjä, T., 2015, Aerosol Sci. Technol., 49(8), 674-681.

Kemp, R. S., 2008, Sci. Global Security, 16, 115-125.

Kemp, R. S., 2016, Ann. Rev. Earth Planet. Sci., 44, 17-35

Kessie, R. W., 1967, I\&EC Process Design Develop., 6, 105-111.

Kips, R. S., and Kristo, M. J., 2009, J. Radioanal. Nucl. Chem., 282, 1031-1035.

Kips, R. S., Leenaers, A., Tamborini, G., Betti, M., Van den Berghe, S., Wellum, R., and Taylor, P., 2007, Microsc. Microanal., 13, 156-164.

Koch, W., and Friedlander, S. K., 1990, J. Colloid Interf. Sci., 140, 419-427.

Kruis, F. E., Kusters, K. A., Pratsinis, S. E., and Scarlett, B., 1993, Aerosol Sci. Technol., 19, 514-526.

Laskin, J., Laskin, A., and Nizkorodov, S. A., 2018, Anal. Chem., 90, 166-189.

Lehtinen, K. E. J., and Zachariah, M. R., 2001, Phys. Rev. B, 63, 205402.

Lind, M. C., Garrison, S., and Becnel, J. C., 2010, J. Phys. Chem. A, 114, 4641-4646

Mapother, D., Crooks, H. N., and Maurer, R., 1950, J. Chem. Phys., 18, 1231-1236.

McClurg, R. B., and Flagan, R. C., 1998, J. Colloid Interface Sci., 201(2), 194-199.

McGraw, R., 1997, Aerosol Sci. Technol., 27(2), 255-265.

McGraw, R., and Wright, D. L., 2003, J. Aerosol Sci., 34(2), 189-209.

Messing, G. L., Zhang, S. C., and Jayanthi, G. V., 1993, J. Am. Ceram. Soc., 76(11), 2707-2726.

Miller, R. C., Anderson, R. J., Kassner, J. L., and Hagen, D. E., 1983, J. Chem. Phys., 78(6), 3204-3211.

Pickrell, P. W., 1982, Characterization of the solid, airborne materials created by the interaction of UF6 with atmospheric moisture in a contained Volume, K/PS-144, Oak Ridge Gaseous Diffusion Plant.

Pickrell, P. W., 1984, Characterization of the solid, airborne materials created by the interaction of UF6 with atmospheric moisture in a contained Volume, K/PS-915, Oak Ridge Gaseous Diffusion Plant. 
Pickrell, P. W., 1985, Characterization of the solid, airborne materials created when UF6 reacts with moist air flowing in single-pass mode, K/PS-1134, Oak Ridge Gaseous Diffusion Plant.

Pratsinis, S. E., 1998, Prog. Energy Combust. Sci., 24(3), 197-219.

Pratsinis, S. E., and Spicer, P. T., 1998, Chem. Eng. Sci., 53(10), 1861-1868.

Pratsinis, S. E., Bai, H., Frenklach, M., Mastrangelo, S. V. R., and Biswas, P., 1990, J. Am. Ceram. Soc., 73(7), 2158-2162.

Quant, F. R., Flagan, R. C., and Horton, K. D., 1993, J. Aerosol Sci., 24, Suppl. 1, S83-S84.

Rigo, M., Canu, P., Angelin, L., and Della Valle, G., 1998, Ind. Eng. Chem. Res., 37(4), 1189-1195.

Schotte, W., Ind. Eng. Chem. Res., 1987, 26, 300-306.

Seinfeld, J. H., and Pandis, S. N., 1998, Atmospheric Chemistry and Physics: From Air Pollution to Climate Change, Wiley, New York.

Seinfeld, J. H., and Pandis, S. N., 2006, Atmospheric Chemistry and Physics: From Air Pollution to Climate Change, John Wiley, Hoboken, NJ.

Smith, D. B. and Miller, J. C., 1989, J. Chem. Phys., 90, 5203-5205.

Spicer, P. T., Chaoul, O., Tsantilis, S., and Pratsinis, S. E., 2002, J. Aerosol Sci., 33(1), 17-34.

Ulrich, G. D., 1971, Combust. Sci. Technol., 4(1), 47-57.

Upadhyay, R. R., and Ezekoye, O. A., 2006, J. Aerosol Sci., 37(7), 799-819.

Vanhanen, J., Mikkilä, J., Lehtipalo, K., Sipilä, M., Manninen, H. E., Siivola, E., Petäjä, T., and Kulmala, M., 2011, Aerosol Sci. Technol., 45(4), 533-542.

Viisanen, Y., Strey, R., and Reiss, H., 1993, J. Chem. Phys., 99(6), 4680-4692.

Wang, T., Navarrete-Lopez, A. M., Li, S., Dixon, D. A., and Gole, J. L., 2010, J. Phys. Chem. A, 114(28), 7561-7570.

West, M. H., and Axler, K. M., 1995, Thermodynamic Modeling of Hydrogen Fluoride Production Relevant to Actinide Residue Treatment, LA-12909-MS, Los Alamos National Laboratory.

West, R. H., Shirley, R. A., Kraft, M., Goldsmith, C. F., and Green, W. H., 2009, Combust. Flame, 156(9), 1764-1770.

Witlox, H. W. M., Atmos. Environ., 1994a, 28, 2917-2932.

Witlox, H. W. M., Atmos. Environ., 1994b, 28, 2933-2946.

Woo, D., Seo, J., and Taesung, K., 2009, Nano, 4(2), 107-117.

Wyslouzil, B. E., and Wolk, J., 2016, J. Chem. Phys., 145(21), 211702.

Xiong, Y., and Pratsinis, S. E., 1991, J. Aerosol Sci., 22(5), 637-655.

Yook, S.-J., and Pui, D. Y. H., 2005, Estimation of Penetration Efficiencies through NASA Sampling Lines, NASA Glenn Research Center, Cleveland, OH, 44135, May 15.

Zachariah, M. R., and Carrier, M. J., 1999, J. Aerosol Sci., 30, 1139-1151.

Zachariah, M. R., Carrier, M. J., and Blaisten-Barojas, E., 1996, J. Phys. Chem., 100, 14856-14864.

Zeatoun, L. Y., and Feke, D., 2005, Part. Part. Syst. Charact., 22(4), 276-281.

Zhang, Y., Seigneur, C., Seinfeld, J. H., Jacobson, M. Z., and Binkowski, F. S., 1999, Aerosol Sci. Technol., 31(6), 487-514. 


\section{APPENDIX A. NOMENCLATURE}




\section{APPENDIX A. NOMENCLATURE}

\begin{tabular}{|l|l|}
\hline \multicolumn{1}{|c|}{ Abbreviation } & \multicolumn{1}{c|}{ Definition } \\
\hline API & application programming interface \\
\hline CNT & classical nucleation theory \\
\hline CPC & condensation particle counter \\
\hline DMA & differential mobility analyzer \\
\hline DMT & Dillmann and Meier theory \\
\hline GMD & geometric mean diameter \\
\hline HEPA & high-efficiency particulate air \\
\hline ODE & ordinary differential equation \\
\hline RH & relative humidity \\
\hline$R O P$ & rate of progress variable in Chemkin-Pro surface-kinetics user routine \\
\hline$R O P$ enhance & particle size dependent term of ROP variable \\
\hline$R P R O G$ & particle size independent term of ROP variable \\
\hline SKUPROG & Surface-Kinetics Chemkin-Pro user routine \\
\hline SMPS & scanning mobility particle sizer \\
\hline
\end{tabular}

\begin{tabular}{|l|l|}
\hline \multicolumn{2}{|c|}{ Symbols } \\
\hline$A$ & Prefactor in Arrhenius rate coefficient \\
\hline$a_{n}$ & Coefficients used to calculate surface tension of water as a function of temperature \\
\hline$\alpha$ & constant \\
\hline$\beta_{12}$ & Coagulation kernel between particles one and two - transition regime \\
\hline$\beta_{c}$ & Coagulation kernel — constant \\
\hline$B_{x}$ & number of molecules striking the droplet surface per unit area per unit time \\
\hline$C_{p k}^{o}$ & specific heat capacity \\
\hline$d_{m}$ & molecular diameter \\
\hline$d_{p}$ & particle/droplet diameter \\
\hline$D_{v}$ & diffusivity of vapor \\
\hline$E$ & Activation energy in Arrhenius rate coefficient \\
\hline$f$ & bin partitioning constant in semi-implicit coagulation method \\
\hline$\Delta G$ & Gibbs Free Energy \\
\hline$\Delta G_{c}$ & Gibbs Free Energy change at the critical cluster radius \\
\hline$g$ & variable in transition coagulation kernel \\
\hline$h$ & convective heat transfer coefficient \\
\hline$h_{f g}$ & Enthalpy of vaporization from liquid to gas \\
\hline$H_{k}^{o}$ & specific enthalpy \\
\hline$i_{c}$ & number of molecules in the critical cluster (DMT theory) \\
\hline$J$ & homogeneous nucleation rate \\
\hline
\end{tabular}




\begin{tabular}{|c|c|}
\hline \multicolumn{2}{|r|}{ Symbols } \\
\hline$K$ & Chemical rate constant \\
\hline$k$ & different species in thermodynamic input expressions in Chemkin-Pro \\
\hline$k_{B}$ & Boltzmann constant \\
\hline$k_{v}$ & thermal conductivity of air \\
\hline$\kappa$ & constant used in the Dillmann-Meier nucleation theory \\
\hline$\lambda$ & mean free path of gas \\
\hline$\ell$ & mean free path used in transition coagulation kernel \\
\hline$\mu_{a}$ & dynamic viscosity of air \\
\hline$m_{1}$ & mass of a single molecule of the nucleating species \\
\hline$M$ & molecular mass/weight of the nucleating species \\
\hline$n$ & aerosol number concentration \\
\hline$N_{x}$ & molecular concentration of nucleating species in the gas phase \\
\hline$n_{z}$ & net arrival of molecules to a particle surface per unit time \\
\hline$N_{a v}$ & Avogadro's number \\
\hline$N u_{D}$ & Nusselt number \\
\hline$P$ & gas pressure \\
\hline$\rho_{a}$ & air density \\
\hline$\rho_{c}$ & critical point density of water \\
\hline$P_{d}$ & vapor pressure of condensing or evaporating species at droplet surface \\
\hline$\rho_{p}$ & bulk density of the liquid phase (or particle) \\
\hline$P_{v, \infty}$ & free-stream vapor pressure of the condensing or evaporating species \\
\hline$P_{v, s a t}(T)$ & saturation vapor pressure at the free-stream temperature \\
\hline$\Psi$ & source term in the aerosol dynamics equation \\
\hline$\phi$ & Fuchs correction factor \\
\hline$q_{0}$ & Constant used in the Dillmann-Meier nucleation theory \\
\hline$r_{c}$ & critical cluster radius \\
\hline$r_{p}$ & particle radius \\
\hline $\mathfrak{R}$ & removal term in aerosol dynamics equation \\
\hline$R$ & universal gas constant \\
\hline$R e_{d}$ & droplet Reynolds number \\
\hline$S R$ & Saturation ratio of the nucleation species (unitless) \\
\hline$\sigma_{p}$ & liquid surface tension of bulk material \\
\hline$S_{k}^{o}$ & specific entropy \\
\hline$s_{1}$ & surface area of an individual module of the nucleating species \\
\hline$s_{p}$ & particle surface area \\
\hline$\tau$ & Constant used in the Dillmann-Meier nucleation theory \\
\hline$\theta$ & dimensionless surface tension \\
\hline$t$ & time \\
\hline
\end{tabular}




\begin{tabular}{|l|l|}
\hline \multicolumn{2}{|l|}{ Symbols } \\
\hline$T$ & free-stream temperature \\
\hline$T_{{ }^{\circ} C}$ & degrees Celsius temperature \\
\hline$T_{d}$ & droplet temperature \\
\hline$T_{\infty}$ & free-stream temperature \\
\hline$u, v$ & given particle volume (particle sizes) \\
\hline$U_{a}$ & relative velocity of air (with respect to the particle) \\
\hline$v$ & particle volume concentration \\
\hline$x$ & variable used in the Dillmann-Meier nucleation theory \\
\hline$\xi$ & temperature exponent in Arrhenius rate coefficient \\
\hline$Z_{n}$ & non-equilibrium correction factor \\
\hline
\end{tabular}


